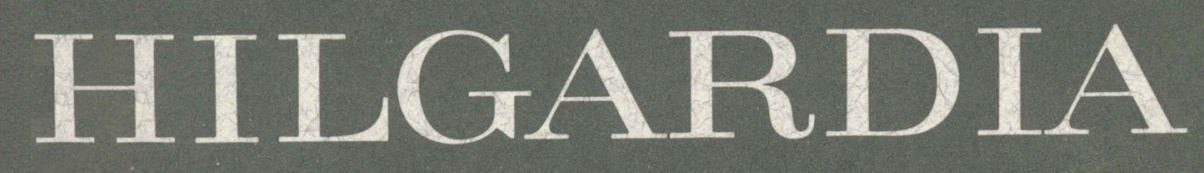

A JOURNAL OF AGRICULTURAL SCIENCE PUBLISHED BY PHE CALIFORNIA AGRICULTURAL EXPERIMENT STATION

Volume 36, Number $14 \cdot$ September, 1965

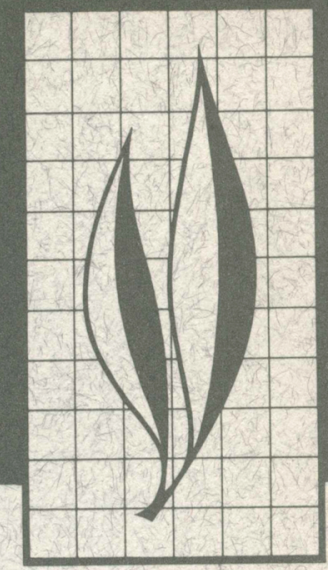

\title{
A Sunlight Phytotron Unit as a Practical Research Tool
}

F. P. Zscheile, S. M. Henderson, A. S. Leonard, L. W. Neubauer, and S. J. Sluka 


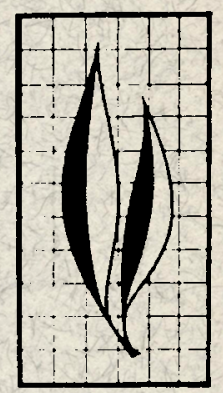

Since 1953 a Phytotron Committee at Davis has been concerned with various means of controlling the environment of plants. A glass block-roofed phytotron unit which combined the best features of the greenhouse (sunlight) and the conventional growth chamber (insulation) was built and tested as a possible research tool.

The present study reports details of the phytotron unit's construction, operation, and maintenance; energy exchanges and operating costs; efficiency of the glass blocks as a light-transmitting medium; and preliminary experiments with plants. Incandescent lighting was investigated. Other devices, including reflectors and rotation of a room to face the sun, were studied.

Some of the detailed information gathered during the course of this study has been omitted from this publication. The information is available, however, on microfilm for anyone having need for further details.

Directions for obtaining a microfilm of this supplementary material will be found on the inside back cover.

\section{THE AUTHORS:}

F. P. Zscheile is Professor of Agronomy and Biochemist in the Experiment Station, Davis.

S. M. Henderson is Professor of Agricultural Engineering and Agricultural Engineer in the Experiment Station, Davis.

A. S. Leonard is Lecturer in Engineering and Agricultural Engineer in the Experiment Station, Davis.

L. W. Neubauer is Professor of Agricultural Engineering and Agricultural Engineer in the Experiment Station, Davis.

S. J. Sluka is former Assistant Specialist in Agricultural Engineering, now Associate Specialist in Animal Physiology, Davis. 


\title{
A Sunlight Phytotron Unit
}

\author{
as a \\ Practical Research Tool $^{1}$
}

\section{INTRODUCTION}

Conventional glasshouses or greenhouses have long been used to modify environmental conditions of plants, particularly to raise the temperature in winter. Nearly all the radiant, freely admitted energy from the sun is converted by absorption processes to longer wavelength heat, to which glass is impervious. However, only very limited control of conditions is economically feasible in greenhouses; lack of insulation permits excessive solar heating in the day and makes heating at night inefficient.

A casual survey made in the greenhouses at Davis in July, at noon, showed a wide range of sunlight intensities as a result of shadows and of whitewash applied to decrease the daytime temperatures. Intensities varied from 400 foot-candles, for shade plants, to 6,200 ft-c, while outside direct sun was about 9,000 ft-c. When bright sun at bench height was 5,000 to $6,000 \mathrm{ft}-\mathrm{c}$, in a 2-inch-wide shadow, the intensity was 1,000 to 1,500 . The estimated "average" condition was 2,000 to $3,000 \mathrm{ft}$-c with temperatures in the high 90 's. At solar altitudes of 20 to 30 degrees, intensities varied threefold, depending upon the location in the greenhouse. An extensive study of sunlight intensities as a function of season and in relation to dimen- sions, orientation, and roof slopes of glasshouses in England was reported by Whittle and Lawrence (1959). ${ }^{2}$ They correlated growth of tomato seedlings with the light-time integral. Whittle and Lawrence $(1960 a, b)$ also conducted detailed studies on air temperatures prevailing in simple glasshouses, both single- and double-glazed, at different seasons, in England.

An early and successful attempt to control environment of plants on a small scale was made by Davis and Hoagland (1928). They constructed a chamber $2^{\prime} \times 5^{\prime} \times 5^{\prime}$ illuminated with incandescent light and having good temperature control (at about $70^{\circ} \mathrm{F}$ ), suitable for the growth of good wheat plants in a uniform and reproducible manner. Ulrich (1954) has also discussed the significance of controlled climate facilities for agricultural research.

Numerous modifications of greenhouses and artificially lighted rooms have been employed during the last 40 years at the Boyce Thompson Institute for Plant Research at Yonkers, New York. Some of these involved filtration of sunlight by colored glass. One largescale effort there employed forty-eight 1,000-watt incandescent bulbs with reflectors, which formed a canopy that

\footnotetext{
${ }^{1}$ Submitted for publication December 20, 1963.

'See "Literature Cited" for citations referred to in the text by author and date.
} 
was moved over the outside of the greenhouse at night on a gantry crane, for extension of the natural daylength (Thompson, 1925). From 400 to $500 \mathrm{ft}-\mathrm{c}$ intensities were obtained at plant level. Parker (1946) outlined and discussed the principal needs of a plant physiologist for controlled environment, and reviewed earlier efforts to meet those requirements.

The first large-scale phytotron was the Earhart Plant Research Laboratory, completed in 1949 at the California Institute of Technology in Pasadena (Went, 1950). In this facility, airconditioned greenhouse rooms have fixed day-night temperature differences ranging from $6^{\circ}$ to $18^{\circ} \mathrm{F}$ within an over-all range among the rooms of $50^{\circ}$ to $86^{\circ} \mathrm{F}$. Numerous smaller, interior rooms are illuminated with a fluorescent-incandescent combination of lights. In these greenhouse rooms, incandescent lamps supplement sunlight when intensity falls below $250 \mathrm{ft}$-c over a daylength of 16 hours. Rooms are maintained at constant temperatures in a range from $36^{\circ}$ to $86^{\circ} \mathrm{F}$. Plants (necessarily small) are moved twice each day from one condition to another. A constant humidity (26 per cent) and sterile conditions (against plant pathogens and insects) are maintained in all rooms and in the associated hallways and laboratories. The entire facility is under one roof. Results with these plant-growth units have been important to plant physiology in certain areas of investigation and with certain plants. A detailed description of the laboratory and results of research on numerous plants have been published by Went (1957). Many aspects of growth-room performance are discussed in Hudson (1957).

Went (1961) has described a "Climatron," a large Plexiglas dome that utilizes sunlight. It has a controlled and large gradient of temperature across the area, for producing several representative climates.

Two phytotron installations some- what resembling the Pasadena facility have been in operation for several years in the Netherlands. They were described by Braak and Smeets (1956) and Alberda (1958).

An Australian phytotron has been described in detail, including economics of operation, by Morse and Evans (1962). It employs many reach-in type cabinets of glass, each with its own air conditioning (cooling) system. Some cabinets have fluorescent-incandescent lighting. Others are inside a large greenhouse of many sections, each of which has a controlled temperature above that of the cabinets. Sunlight provides illumination.

In recent years, many research workers who have needed more complete control of environment for plants than is provided by greenhouses have used insulated rooms with artificial illumination. They have thus eliminated the continual change of conditions caused by change of the sun's position. Some of the larger rooms have been used primarily for studies of photoperiodism and associated phenomena. The Agricultural Research Service controlled-environment rooms at Beltsville, Maryland, were developed and used by H. A. Borthwick, M. W. Parker, S. B. Hendricks and associates, who have made excellent contributions to their areas of plant physiology over a period of years. The light sources have ranged from a carbon arc in the center of an illuminated area 9 feet in diameter (Parker, 1946 ) to rooms $9^{\prime} \times 16^{\prime}$ with $71 / 2$-foot ceilings covered with closely packed fluorescent light tubes and a smaller number of incandescent sources (Ditchman, 1955). High frequency was employed at times to obtain greater intensities from fluorescent lamps. A very effective, small environment cabinet (approximately $30^{\prime \prime} \times 30^{\prime \prime}$ of useful plant space) has been described in detail by Hiesey and Milner (1962). Irradiation is by fluorescent lights outside a double-pane glass box. 
During the last few years, several companies have placed prefabricated plant-growth rooms on the market. These rooms provide temperature and humidity controls and fluorescent light supplemented by incandescent sources. Many such rooms are relatively small, although some models may be assembled in various sizes. Great advances have been made in fluorescent tube design for more efficient production of light suitable for plant growth, but such facilities are very expensive, both to install and to operate. Carpenter and Moulsley (1960) have experimented extensively with the relation of lamp temperature, voltage, lamp spacing, wall reflecting surfaces, and cabinet dimensions to the lighting efficiency and performance of fluorescent lights. While such rooms do not provide intensities approaching that of sunlight, intensities of 4,500 to $5,500 \mathrm{ft}$-c are available for smaller plants. A single exception is the room at the Southern Piedmont Soil Conservation Field Station, Watkinsville, Georgia, in which incandescent sources alone provide intensities equal to sunlight. The radiation is filtered through 4 inches of water, and operational costs are almost prohibitive. This design was developed from a smaller chamber $\left(3^{\prime} \times 41 / 2^{\prime} \times 31 / 2^{\prime}\right)$ described by Platt (1957), in which thirty-six 300watt reflector spot incandescent lamps provided 8,500 to $12,000 \mathrm{ft}$-c (solar intensity magnitude). Filtration of this radiation by $10 \mathrm{~cm}$ of water over glass provided a heat level comparable with that of solar radiation.

Lack of sufficient intensity has frequently been a serious deficiency. When light intensity is a limiting factor for plant growth (photosynthesis), the proper study of other single factors becomes difficult if not impossible. The importance of higher intensities $(4,000$ ft-c and higher) in studies of stem elongation has been emphasized by Lockhart (1961).

Facilities in operation at present have certain deficiencies, at least for some types of research: (1) insufficient light intensity of wavelengths associated with effective photosynthesis; (2) insufficient range of temperature or humidity; (3) chamber too small for use of larger plants, such as small trees, full-size grapevines, castor beans, sunflowers; (4) excessive cost of installation and/or operation per sq. ft. of plant space; and (5) difficulties of maintenance, particularly in relation to constant light intensity over long periods of time. The cost of operation is frequently overlooked and often unknown, but it is a continuing expense long after the initial cost has been forgotten.

The need for improved plant-growth facilities has been studied by a Committee on Controlled Environmental Facilities for Plants, at Davis, since 1953. We have made a careful survey of present-day building materials, and have developed some new designs in which the best features of both greenhouse (sunlight) and conventional growth rooms (insulation) are combined to use sunlight to a maximum degree and to provide a wide range of experimental conditions at relatively low cost. The best quality of light is thus provided at high intensities.

Plant experimenters give various estimates of adequate light intensities for optimum plant growth, varying from 1,500 to $4,000 \mathrm{ft}-\mathrm{c}$, depending upon the plant. Many crop plants may benefit from values as high as full solar intensities. Our aim has been to remove light intensity as a limiting factor for plant growth in so far as possible and to provide a well-diffused light, coming mostly from above, at as uniform adequate intensity as possible, over the entire room during a maximum part of the day. With sunlight, this may always remain an idealized objective in so far as relatively large areas are concerned-nevertheless, great improvements over average greenhouse per- 
formance seem practically attainable.

This study presents our earlier results in some detail, since many modifications are possible to accommodate different types of problems. Several experimental models of different sizes were built to study different facets of the entire operation of phytotrons. The investigation was begun in 1957, and results with glass blocks were completed in 1962. Only preliminary transmission measurements on plastic materials are included in this report. Preliminary reports appeared in 1961 (Zscheile et al.), 1962 (Zscheile, Drever, and Houston), and 1963 (Zscheile et al.).
The following conversion factors have been used in this paper:

$1 \mathrm{cal}=0.00397 \mathrm{Btu}$.

1 cal per sq. $\mathrm{cm} . \mathrm{min} .=698$ watts per sq. meter.

1 cal per sq. $\mathrm{cm}$. day $=3.69 \mathrm{Btu}$ per sq. $\mathrm{ft}$. day.

1 cal per sq. $\mathrm{cm} . \mathrm{min} .=221 \mathrm{Btu}$ per sq. $\mathrm{ft}$. hr.

In direct energy conversion:

$1 \mathrm{Btu}=252 \mathrm{cal}$.

$1 \mathrm{kw}$-hr. $=3,415$ Btu (in heating elements and incandescent filaments)

1 h.p. $=746$ watts (in motors 1 h.p. = effectively, 1 kw.)

In refrigeration studies:

1 ton (capacity) $=12,000$ Btu per hr. (transferred)

For our ft-c meter, solar radiation factors are: With horizontal meter, 9,700 ft-c per (cal. per sq. $\mathrm{cm} . \min$.) $=44 \mathrm{ft}-\mathrm{c}$ per (Btu per sq. ft. hr.)

With meter directly facing sun, $10,400 \mathrm{ft}-\mathrm{c}$ per $($ cal per sq. cm. $\min )=.47 \mathrm{ft}-\mathrm{c}$ per (Btu per sq. ft. hr.)

Constants used or developed in this study include:

The sun delivers 325 Btu per sq. ft. hr. (maximum) perpendicular to the earth's surface at Davis, California.

Factors to convert total solar radiation per clear day (horizontal + diffuse) from cal. per sq. cm. day to ft-c hr. per day are: 130 (winter), 134 (spring), 144 (summer), and 147 (fall).

Rate of heat loss from large room with glass-block roof: 273 Btu per hr. ${ }^{\circ} \mathrm{F}$ gradient at $25^{\circ} \mathrm{F}$ (sensible + radiation).

Power needed for heating (in dark): 0.149 $\mathrm{kw}$ per ${ }^{\circ} \mathrm{F}$ above $25^{\circ} \mathrm{F}$ temperature differential (due to fan motor heat).

Power needed for cooling over 24-hr. period (with sun, and below the $25^{\circ} \mathrm{F}$ differential) depends on the fan speed: $0.0739 \mathrm{kw}$ per ${ }^{\circ} \mathrm{F}$ for $655 \mathrm{rpm}$. $0.0533 \mathrm{kw}$ per ${ }^{\circ} \mathrm{F}$ for $505 \mathrm{rpm}$. $0.0600 \mathrm{kw}$ per ${ }^{\circ} \mathrm{F}$ for $419 \mathrm{rpm}$.

\section{INTRODUCTION OF SUNLIGHT INTO PLANT-GROWTH ROOM}

Double-pane plate glass was considered undesirable as a roof material because it is expensive and it presents problems (1) of easy breakage, (2) of moisture condensation between panes under extremes of inside and outside temperature differences $\left(90^{\circ} \mathrm{F}\right)$, and (3) of light diffusion, necessary to eliminate sharply defined shadows at the plant level. In greenhouse light, abrupt changes of intensity (e.g., from 5,000 to 2,000 ft-c in the space of 6 inches) occur over portions of individual leaves, plants, and groups of plants. These changes vary with position of the sun during the day and season and with the plants' location in the greenhouse in relation to overhead supporting structures, pipes, fans, and heaters. Such variation must influence the net growth rates of plants in a significant fashion.

Glass blocks ${ }^{3}$ seemed likely to permit effective use of sunlight to give shadowless light inside the room, and good insulation. These blocks are made of clear crown glass, relatively free of iron

${ }^{\mathbf{3}}$ Toplite, Kimble Glass Company. See American Institute of Architects File No. 12-J, "Prefabricated Toplite Roof Panels," for light transmission and insulation data. Distributed by Owens-Illinois, Toledo 1, Ohio. 
oxide. They have been used commercially primarily as skylights to equalize light intensities over the school or work day, and to reject excessive solar heat. While our objectives were somewhat at variance with the commercial uses, our findings are in no case in disagreement with the manufacturer's claims. Boyd (1953 and n.d.) has presented extensive tables of brightness and transmission characteristics of early Toplite blocks from the point of view of illumination for visual purposes. His methods were described in Life (1953). In 1958 no large expanse of Toplite units was available to us for study, although Matthews $(1956 a, b)$ had described their use in a house built for their designer, R. A. Boyd, and Boyd and Reid (1954) had described their use in school design. The Hillsdale School was later built in San Mateo, California (Life, 1957). From it we obtained preliminary measurements. In schoolroom ceilings, light transmitted by $33^{\prime \prime} \times 69^{\prime \prime}$ isolated, nearly horizontal panels of $101 / 4$-inch blocks with fiberglass mats showed that intensities attained were about 1,800 ft-c at 3 inches and 740 ft-c at 3 feet below the panels, at midday in April. (Blocks were designed to be oriented $\mathrm{N} \rightarrow \mathrm{N}$; i.e., the "north" side toward the north.) Neighboring panels and white reflecting walls should enhance this value. Calculations of probable re- sults with a design better suited to our purpose gave 3,700 ft-c as a maximum value 7 feet from the ceiling with $\mathrm{N} \rightarrow \mathrm{S}$ orientation of blocks $\left(180^{\circ}\right.$ from that for designed use), and 2,100 ft-c with $\mathrm{E} \longleftrightarrow \mathrm{W}$ (one-half of the blocks $90^{\circ}$ clockwise from designed orientation and half at $90^{\circ}$ counterclockwise).

NOTE: For all figures showing lighttransmission values as a function of the time of day, data were taken as close as possible to midwinter, midsummer, and the equinoxes. When inside data were obtained within a few days of those dates (December 21, June 21, and March or September 21), a standard reference curve of outdoor values is presented as a symmetrical curve of short dashes. These reference curves represent observed sunlight intensities for Davis, California, as measured with a horizontal light meter (see Appendix for details) on the more critical days of the year. The dates of the data themselves are indicated below the curves, near the time axis. When considerable error would have resulted from comparison of data with a seasonal reference curve, due to appreciably different solar altitude or azimuth angles, a corrected reference curve is substituted, calculated for the date concerned. That date appears above the data curves, near the reference curve to which it corresponds.

\section{SINGLE BLOCK}

Early in 1958 a systematic study of the Toplite unit No. 1180, without mat, was undertaken to learn what percentage of light was transmitted by the unit when it was irradiated from different angles and oriented at different directions in relation to the light source.

A cross-section of the top plate of the block is shown in figure 1 . It is 1 foot square, with a top surface that is smooth and easily cleaned. The second surface is composed of asymmetric prisms, designed to provide a more uniformly illuminated schoolroom during the school day (9:00 a.m. to 3:00 p.m.). Maximum noontime light is reduced, and north light is effectively admitted all day. The lower plate of the glass block is covered with four-sided pyramids designed for diffusion only, and its lower outer surface is smooth. A fiberglass mat may be placed midway between the plates for additional insulation and diffusion, but it decreases transmission by about 30 per cent, and was undesirable for our purpose. 

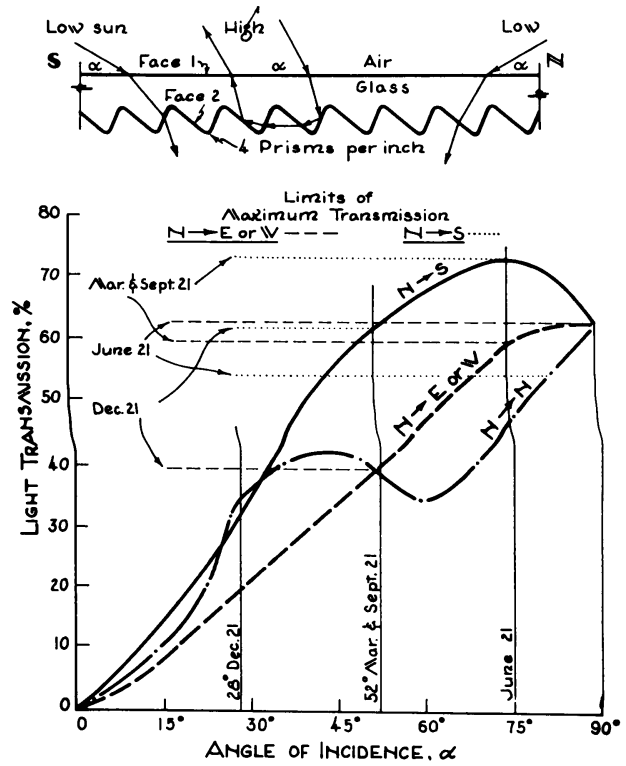

Fig. 1. Top: cross-section of top plate of glass block No. 1180, showing light-directing action of prismatic structure of face 2. Lower: light transmission of glass block No. 1180 as a function of angle of incidence or solar altitude at noon (source is perpendicular to direction of prisms on face 2). Dates indicate values that apply at midday at critical seasons. Arrows indicate orientation of "north" side of block in schoolroom application for which it was designed. Meter horizontal under center of block. Elevation of block $0^{\circ}$.

Figure 1 shows that different orientations of the block provide different transmission values as a function of solar altitude or angle of incidence for the light. Figure $1 \mathrm{~A}^{4}$ presents the annual range of solar altitude and azimuth positions at Davis, California, over the days and seasons, and indicates daylengths involved. From the data in figures 1 and $1 \mathrm{~A}$ we concluded that, for design purposes, equinox conditions represent the annual range better than do those for any other single date, even though the solar positions are changing rapidly at that time of year. The importance of winter is minimized at Davis because most of the cloudy weather occurs at that period
(43 per cent in December and January).

Figure 2 shows transmission curves for single blocks at the principal seasons, with the nominal "north" side oriented toward the principal points of the compass. The light meter was placed horizontally under the center of the block, within 1 or 2 inches of the glass, since in normal use the block would not be elevated. More asymmetrical curves are obtained if the orientation is toward diagonal compass points. With the $\mathrm{N} \rightarrow \mathrm{N}$ orientation, a remarkably uniform intensity is obtained during the middle four hours of the day, at all seasons. Even in midwinter the noon intensity is about 80 per cent of equinox or summer values. This orientation rejects the intense light from the sun at high elevations.

For obtaining maximum sunlight, however, other orientations are preferable. The $\mathrm{N} \rightarrow \mathrm{S}$ orientation appreciably increases both the ft-c hours per day and the maximum noon intensity except at midwinter, when this difference is not so great, but is still worthwhile for plant growth. For over half of the year (spring to fall), $\mathrm{N} \rightarrow \mathrm{S}$ provides about twice the total daily irradiance given by $\mathrm{N} \rightarrow \mathrm{N} . \mathrm{N} \rightarrow \mathrm{E}$ and $\mathrm{N} \rightarrow \mathrm{W}$ provide high maxima in the morning and afternoon, respectively, with minor maxima in the opposite periods, and intermediate values at noon. All three orientations give higher maximum intensities and daily irradiance values than does $\mathrm{N} \rightarrow \mathrm{N}$, except in midwinter.

The maximum for $\mathrm{N} \rightarrow \mathrm{S}$ (April 10) is 81 per cent of the outdoors value. On April 7, measurements recorded close to the block $(1 / 4$ inch) showed a curve of the same shape but with the maximum 86 per cent of the outdoors value, indicating the effectiveness of this orientation at fairly high solar altitudes.

Figure 3 shows an obvious method of getting more sunlight through the

\footnotetext{
"Figure and table numbers followed by "A" will be found in the Appendix.
} 


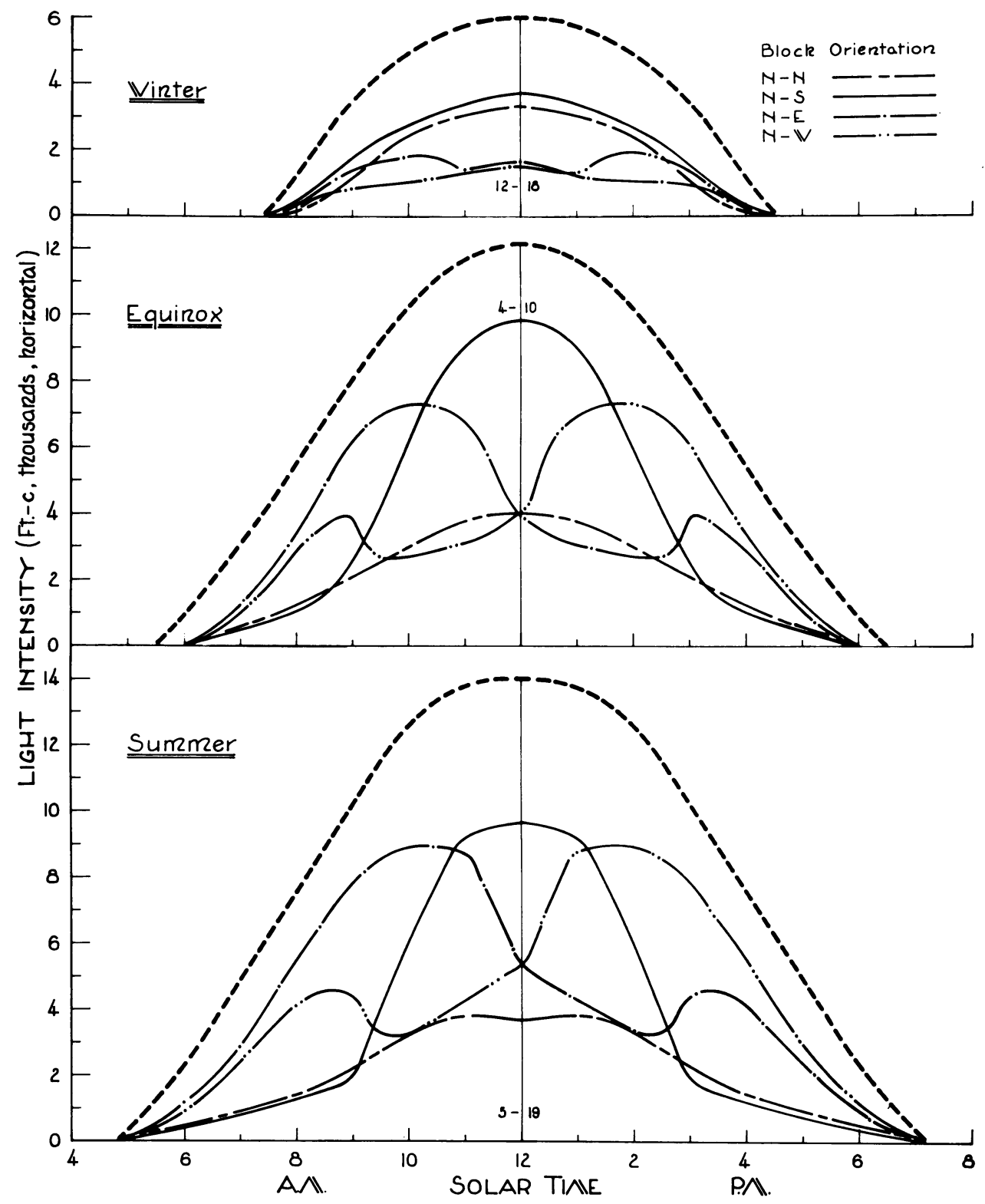

Fig. 2. Sunlight transmission by single glass block (No. 1180) oriented toward principal compass points. Curves with short dashes only, indicate outdoor values on bright days of dates noted. Elevation $0^{\circ}$.

block by inclining it toward the sun so that more light is intercepted (cosine law). Direct comparison may be made with figure 2 ; differences are better understood by reference to figure 1 . The $23^{\circ}$ inclination essentially moves the curves for figure 2 ahead one sea- son, since $23.5^{\circ}$ is the difference in solar noon altitude between seasons. Curves for June 21 proceed to the $90^{\circ}$ value, then either retrace for $\mathrm{N} \rightarrow \mathrm{E}$ or $\mathrm{N} \rightarrow \mathrm{W}$ or follow the opposite curve $8^{\circ}$ back below $90^{\circ}\left(23^{\circ}\right.$ minus $\left.15^{\circ}\right)$. Winter shows the most consistency with this 
explanation when $23^{\circ}$ elevation raises the $\mathrm{N} \rightarrow \mathrm{S}$ curve almost to outdoors values, and other curves are less drastically changed. The percentage gain is considerably greater in winter. In summer $\mathrm{N} \rightarrow \mathrm{N}$ increases considerably at noon and $\mathrm{N} \rightarrow \mathrm{S}$ decreases greatly. At equinox, conditions change less.

\section{SINGLE PANEL OF BLOCKS}

Figures 4 and 5 show similar curves or panel toward the south are prefor a 4-foot panel of 16 blocks. In all sented. Transmission values close to the cases several inclinations of the block block or panels are maximum values;

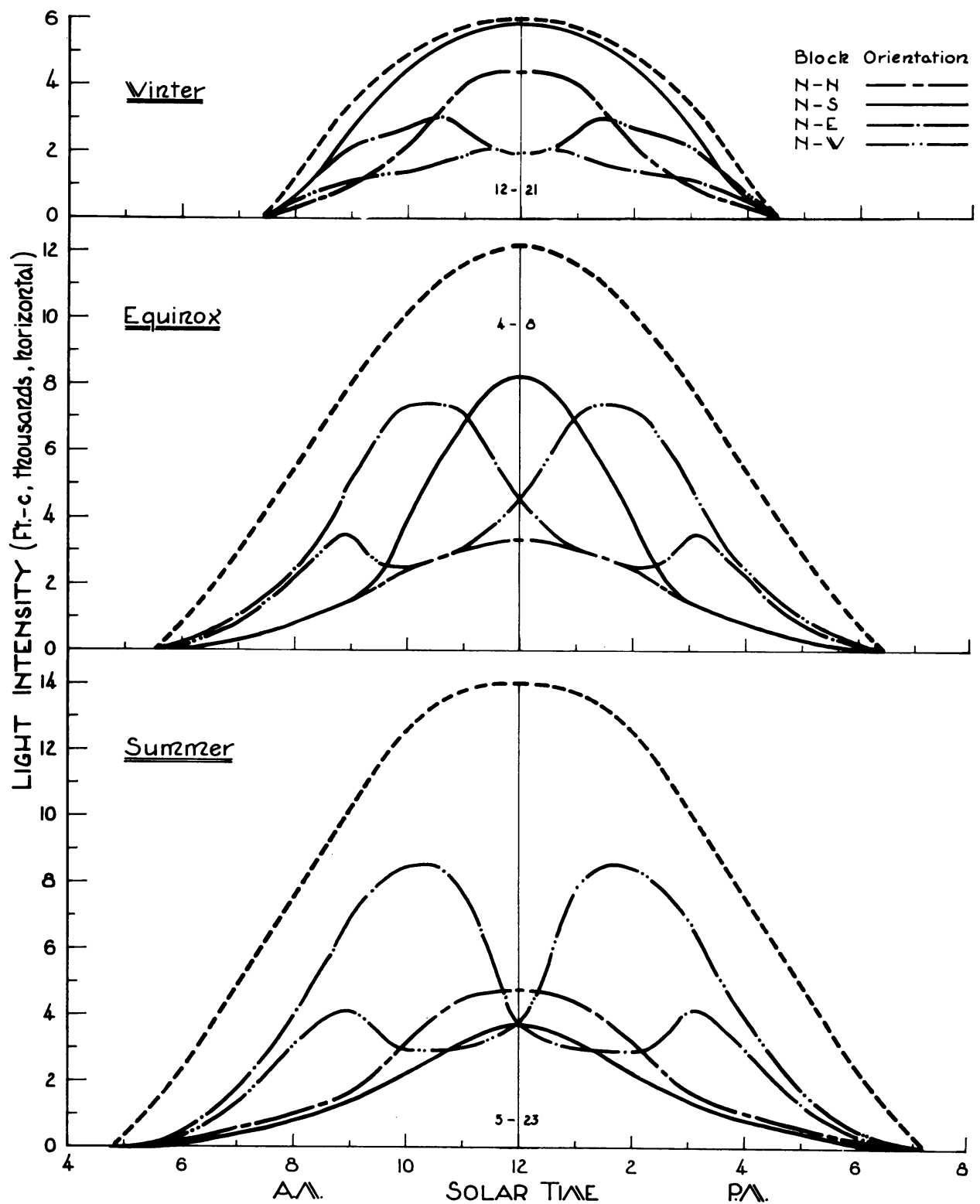

Fig. 3. Sunlight transmission by single glass block (No. 1180) oriented toward principal compass points. Meter horizontal $21 / 2$ inches below lower south edge of block. Elevation $23^{\circ}$. 
values in actual room situations will in general be less because of reflection losses on walls and the like.

A winter study of $\mathrm{N} \rightarrow \mathrm{N}$ at different elevations from $0^{\circ}$ to $40^{\circ}$ indicated that at a distance of over 2 feet from the panel, the horizontal meter provides more meaningful readings than does a meter parallel to the panel. The differences between elevation angles are greater with the horizontal reading and consistent with the $\mathrm{N} \rightarrow \mathrm{N}$ curve of figure 1 . With the meter parallel, a broad noon maximum ranged from 1,500 to $2,500 \mathrm{ft}$-c; with the meter hori- zontal, higher daily averages were recorded, with maxima from 3,300 to 4,700 ft-c.

Figure 4 compares a $\mathrm{N} \rightarrow \mathrm{S}$ panel with various elevations of $23^{\circ}$ or lessthe angle range that appears practical in a room 12 feet deep. It became apparent at this stage of our study that the $\mathrm{N} \rightarrow \mathrm{N}$ orientation would not be the most useful for our objective. The equinox curves show clearly the great decrease of intensity when distance from the panel extends down to 5 feet; the summer curves show the same effect for distances less than 23 inches. These

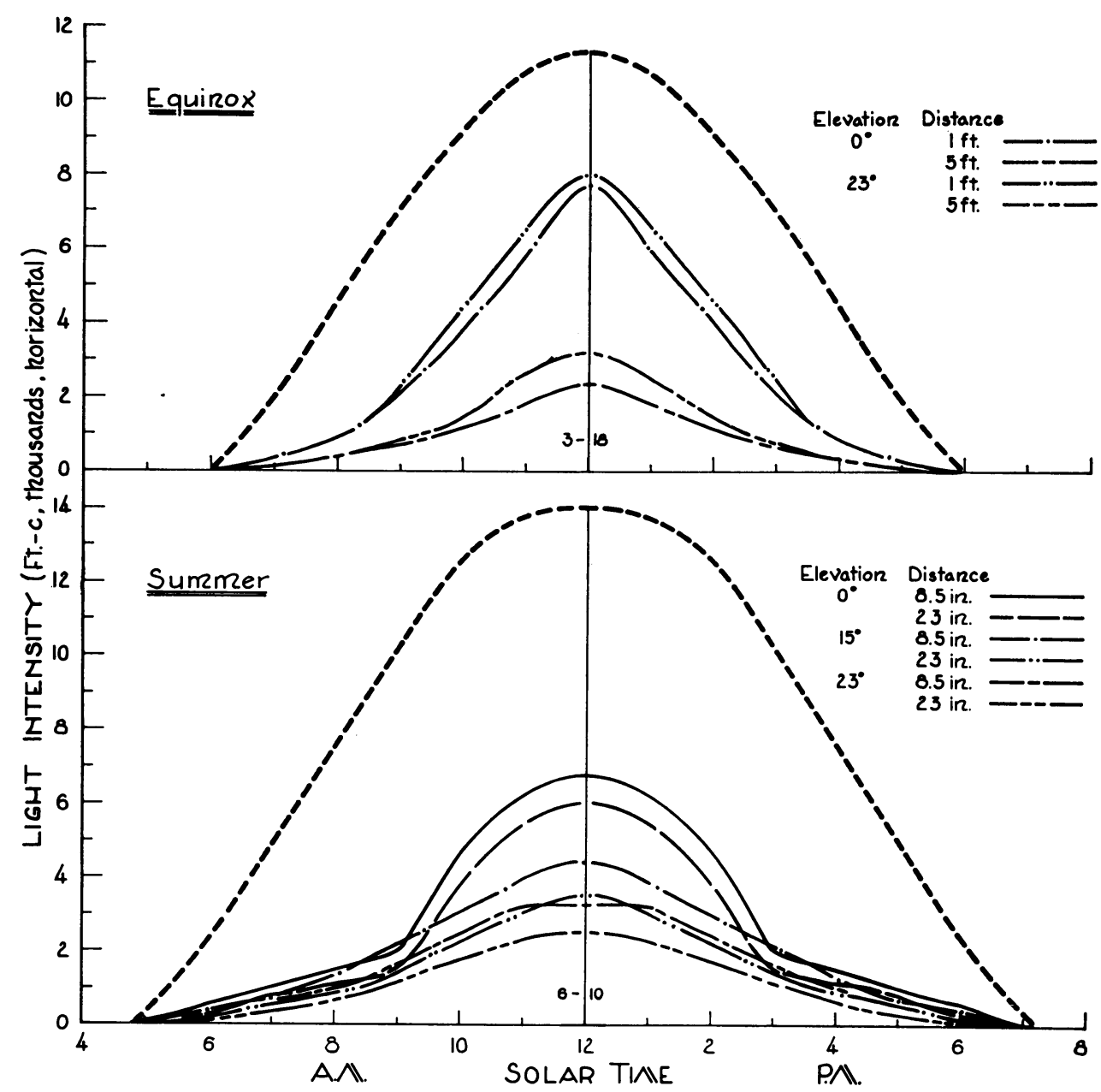

Fig. 4. Sunlight transmission by $4^{\prime} \times 4^{\prime}$ panel of glass blocks oriented $\mathrm{N} \rightarrow \mathrm{S}$. Meter horizontal at different distances below plane of south edge of panel, under center. Elevation 0 to $23^{\circ}$ to south. 


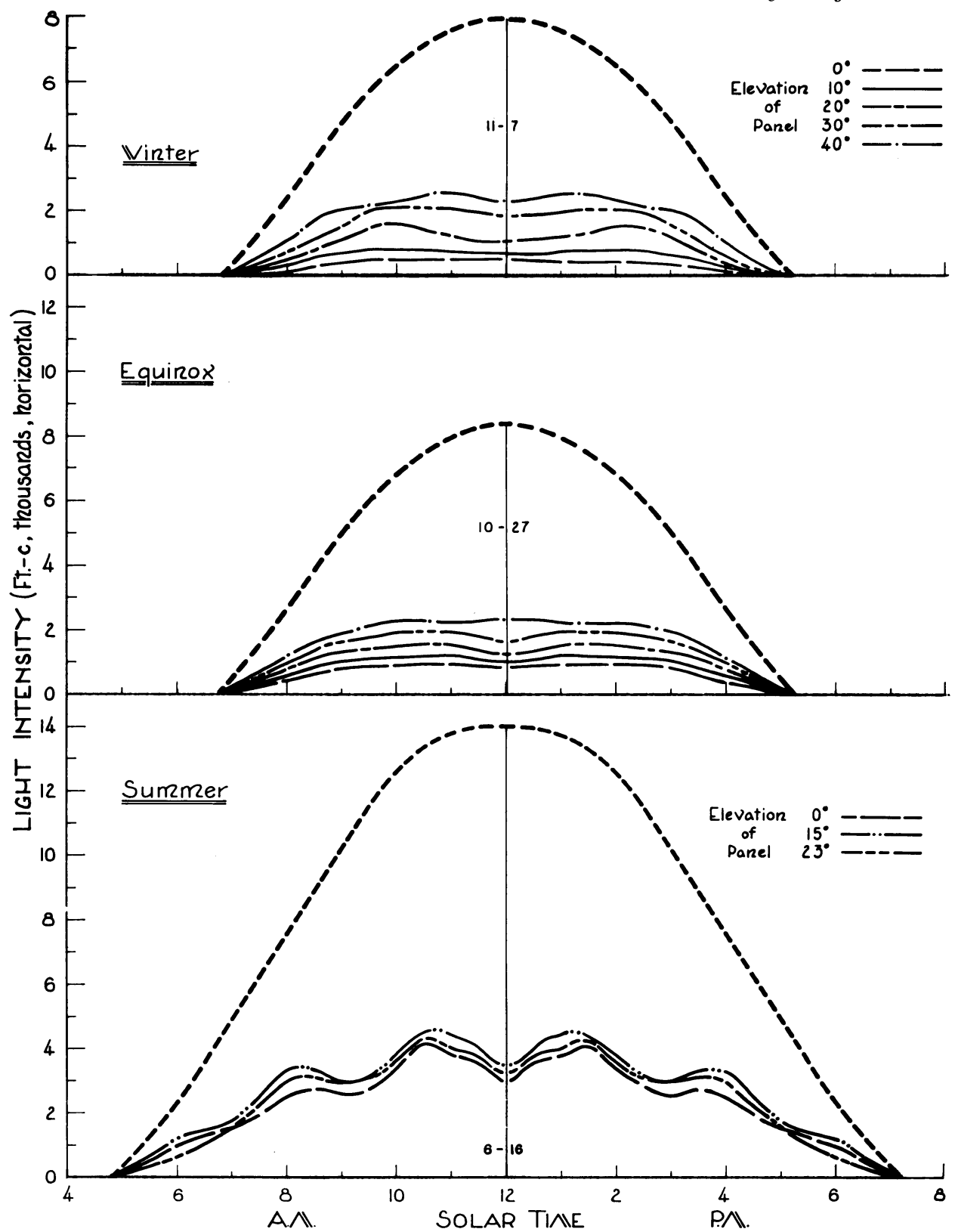

Fig. 5. Sunlight transmission by $4^{\prime} \times 4^{\prime}$ panel of glass blocks oriented $\mathrm{E} \longleftrightarrow \mathrm{W}$ at different elevations to south. Winter chart: elevation 0 to $40^{\circ}$; meter parallel to panel, 28 inches from center. Equinox chart: elevation 0 to $40^{\circ}$; meter horizontal, 26 inches below plane of south edge of panel under center. Summer chart: elevation 0 to $23^{\circ}$; meter horizontal, 23 inches below plane of south edge of panel, under center.

differences might be expected to be less under a greater expanse of many panels (see figs. 12 and $4 \mathrm{M}$ to $6 \mathrm{M}^{5}$ ). A relatively small effect of increasing eleva- tion angle from $0^{\circ}$ to $23^{\circ}$, apparent at equinox, is greater, on a percentage basis, at a distance of 5 feet than at 1 foot. The change is in the opposite

\footnotetext{
${ }^{5}$ Figures followed by "M" appear in the microfilm supplement.
} 
direction and of greater magnitude in summer. These findings agree with predictions from the $\mathrm{N} \rightarrow \mathrm{S}$ curve of figure 1.

The results in figures 2 and 3 suggested that higher intensities might be extended for more hours per day and might be more effective for total plant growth, even if not so high as the noon maximum given by the $\mathrm{N} \rightarrow \mathrm{S}$ orientation. Panels were made with blocks alternately oriented $\mathrm{N} \rightarrow \mathrm{E}$ and $\mathrm{N} \rightarrow \mathrm{W}$, in a checkerboard pattern. Winter and equinox data in figure 5 are for dates intermediate between equinox and winter. These data are parallel in relation to elevation angle, and slightly favor the earlier date, although the horizontal position of the meter is probably a more important factor. Increasing noon intensities with angle concur with the $\mathrm{N} \rightarrow \mathrm{E}$ or $\rightarrow$ W curve in figure 1. The summer data change less with increasing angle, and show the reversion

\section{STATIONARY ROOM WITH FLAT GLASS-BLOCK ROOF}

This insulated and air-conditioned pilot room was $12^{\prime} 6^{\prime \prime} \times 16^{\prime} 9^{\prime \prime} \times 13^{\prime}$ inside. To it were added high-pressure and low-pressure chambers, an instrument room, a compressor shed, and a storage area, bringing the over-all size to $25^{\prime} 10^{\prime \prime} \times 26^{\prime} 5^{\prime \prime} \times(\max$. $) 13^{\prime}$. These additions provided for control of temperature, humidity, and ventilation. The basic floor plan is shown in figure 6 .

A general view of the stationary room is shown in figure 7 . The building is of sturdy but simple wood-frame construction. Modern materials, functional needs, and initial and operating costs were considered. A 4-inch concrete subfloor was placed on firm soil. The insulation, composed of 2-inch styrofoam bricks, was laid in place, with a 4-inch concrete finish floor over it. This was sloped at $1 / 4$ inch per foot toward the drain at the center of the controlled chamber. Floor construction may be seen in the vertical section shown in figure 8 . predicted from figure 1. Figure 5 demonstrates the longer, more uniform day under this orientation.

On June 26, with a reflector box having white-painted sides, light was recorded 30 inches under the center of an $\mathrm{E} \longleftrightarrow \mathrm{W}$ panel at $0^{\circ}$ elevation. A broad fluctuating maximum, characteristic of this orientation, was recorded, with eight hours above 3,000 ft-c, including seven hours of intensity 3,500 to $5,000 \mathrm{ft}$-c. The white walls resulted in a considerably higher curve than that shown in figure 5 for summer.

From these measurements it is obvious that, for effective work in winter, or for other situations requiring longer daylength, we must provide adequate artificial light to supplement the sun. Thus, the wintertime performance, although significant on bright sunny days, is not of major importance in designing for this locality.

The principal exterior walls were insulated with 6 inches of styrofoam between the $2^{\prime \prime} \times 6^{\prime \prime}$ studs, which were placed 16 inches on center. Vapor seals of sheet polyethylene and aluminum were placed on both sides of the studding, which was finished with $1 / 2$-inch exterior-type Douglas fir plywood and two coats of white paint. Interior walls, partitions, and shed walls were not insulated. Studs in these areas were $2^{\prime \prime} \times 4^{\prime \prime}$ lumber.

The main roof of glass blocks was built nearly flat, sloping (south) only 1 inch in 24 to provide positive drainage for rain and wash water. The special glass prisms had been designed to serve best on a zero angle or slope. The shed roof over other areas was sloped 3 inches in 12 for stronger drainage and simpler standard construction.

\section{Ventilation}

Figure 9 shows other structural details and certain ventilating features. 


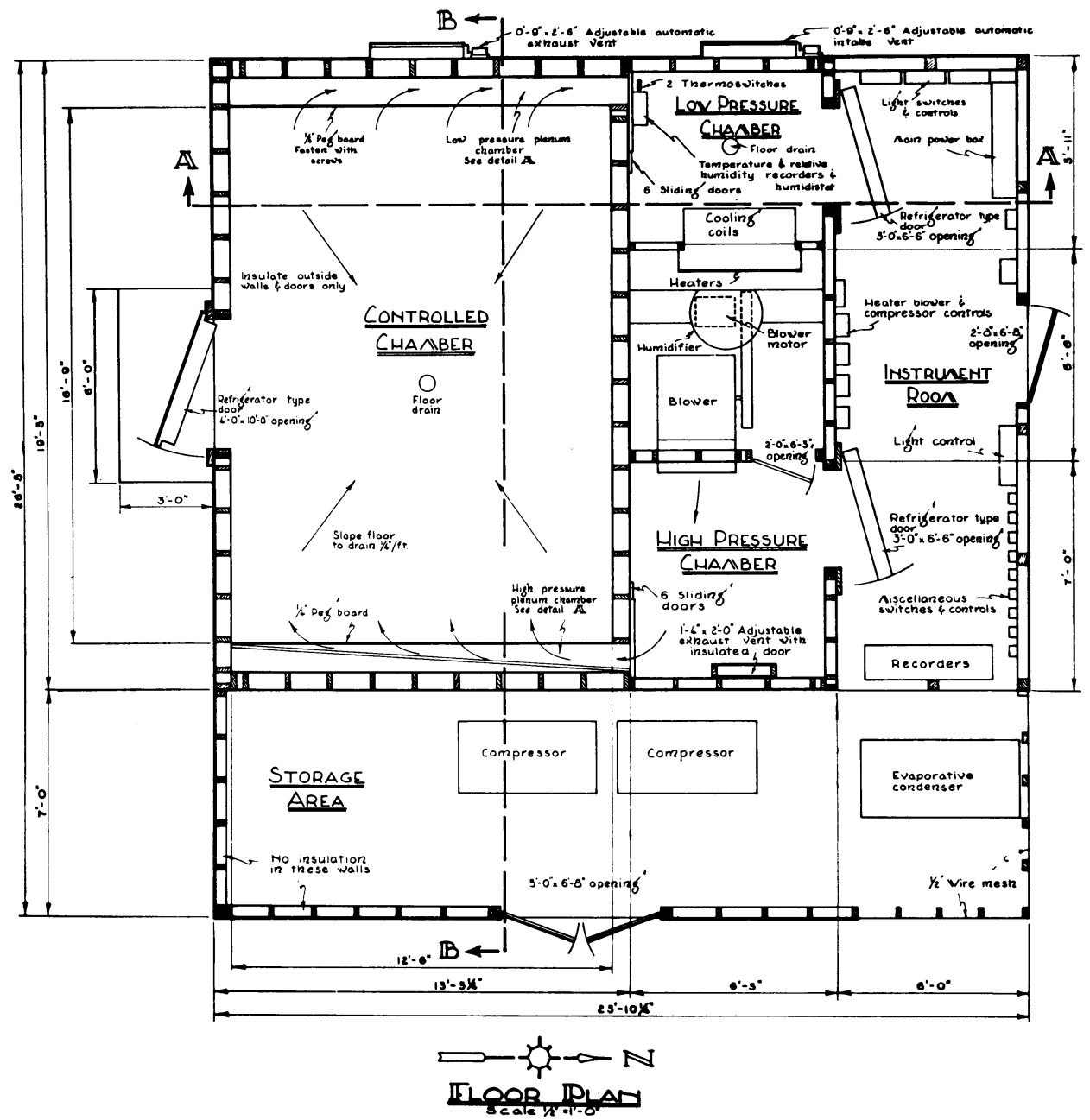

Fig. 6. Floor plan of large controlled room and associated plenum chamber, instrument room, and equipment. Curved arrows indicate direction of air movement.

The path of air movement is shown in figure 10. An air-conditioning system with essentially horizontal air flow, in a conventional greenhouse, has been described by Bottländer (1959).

The seven low-pressure exhaust ducts (fig. 9), numbered from bottom, are not tapered like the high-pressure ducts. It was observed that air tended to move out from the east wall toward the northwest corner of the room or the north ends of the exhaust ducts, rather than uniformly across the room. To remedy this, some of the peg-board holes toward the north were blocked off with strips of tape, forcing an equal volume of air to exhaust through the holes all along the ducts, to the south end. As a result of studies with the adjustable exhaust vent for discarding hot air from the incandescent bulb surfaces, we divided the original uppermost exhaust duct (symmetrical with No. 6 on high-pressure side) into two equal ducts, Nos. 6 and 7, approximately 20 inches high (figs. 8 and 9).

The horizontal plenum ducts were formed by flat, horizontal $2^{\prime \prime} \times 10^{\prime \prime}$ planks, 24 inches on center.

The aluminum-framed panels of 16 


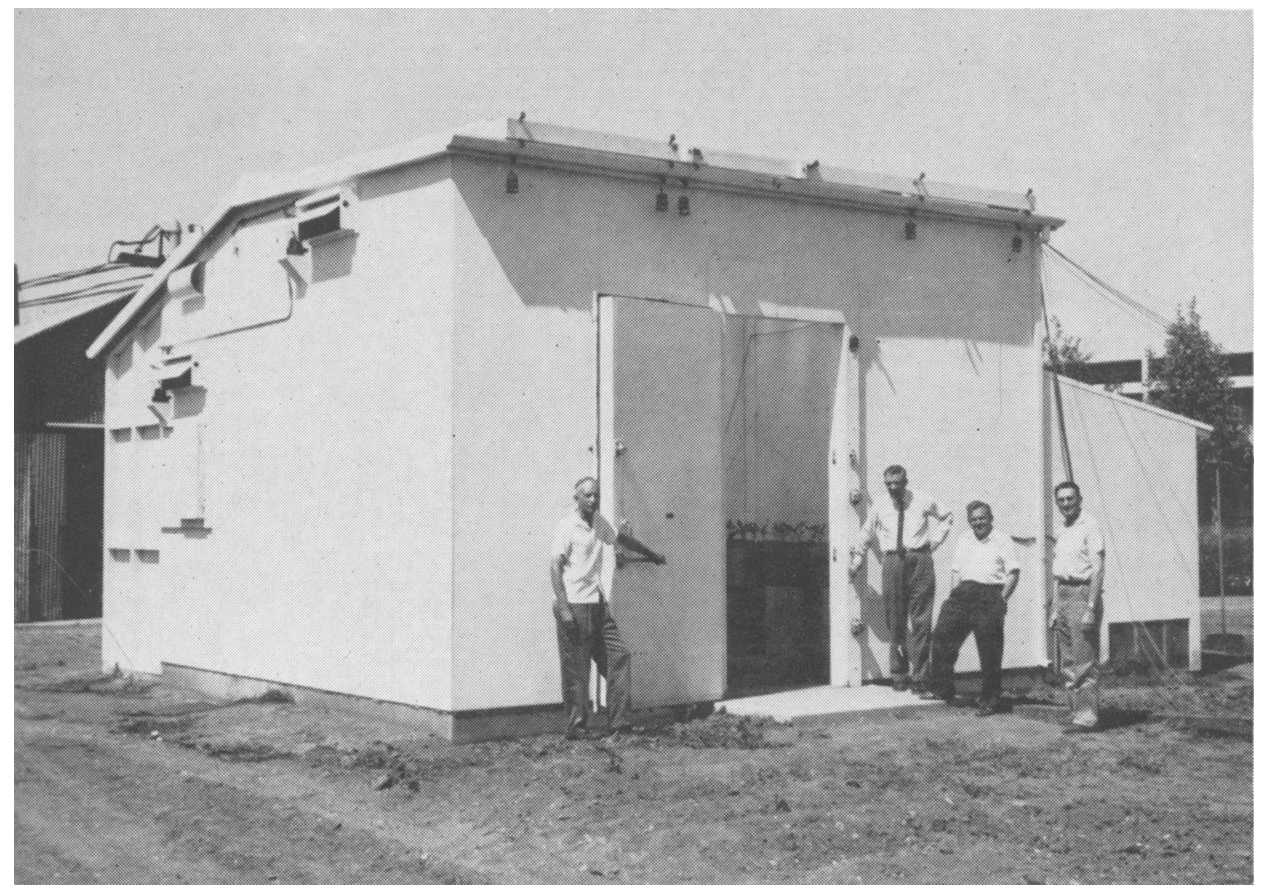

Fig. 7. Large room viewed from southwest, looking into south door toward east wall and plants on benches. Open vents are in west wall, outlet high on right, inlet lower on left; differential thermoregulator is above the latter. Weights for dark curtain are suspended near top of south wall.

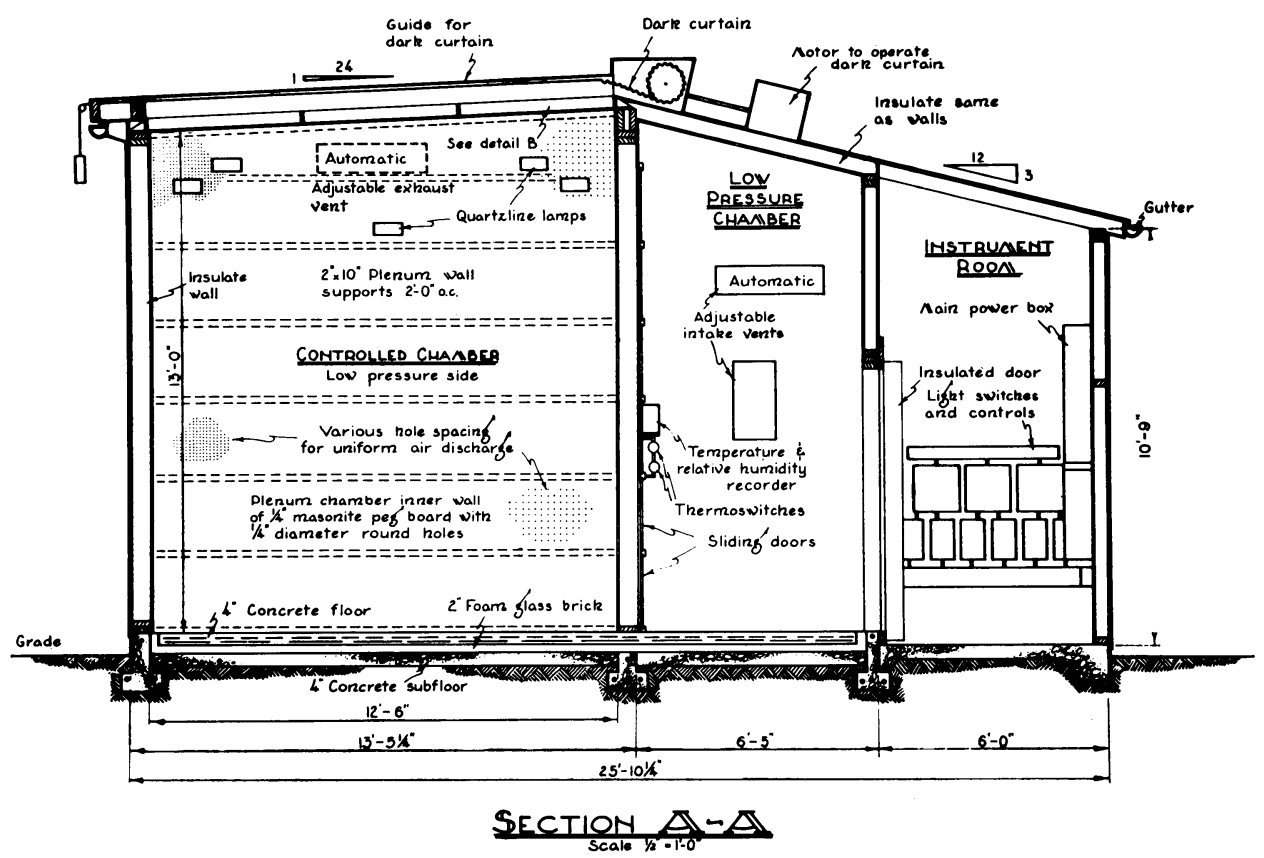

Fig. 8. Vertical section A-A, looking west, of large controlled room and associated plenum chamber and instrument room. 


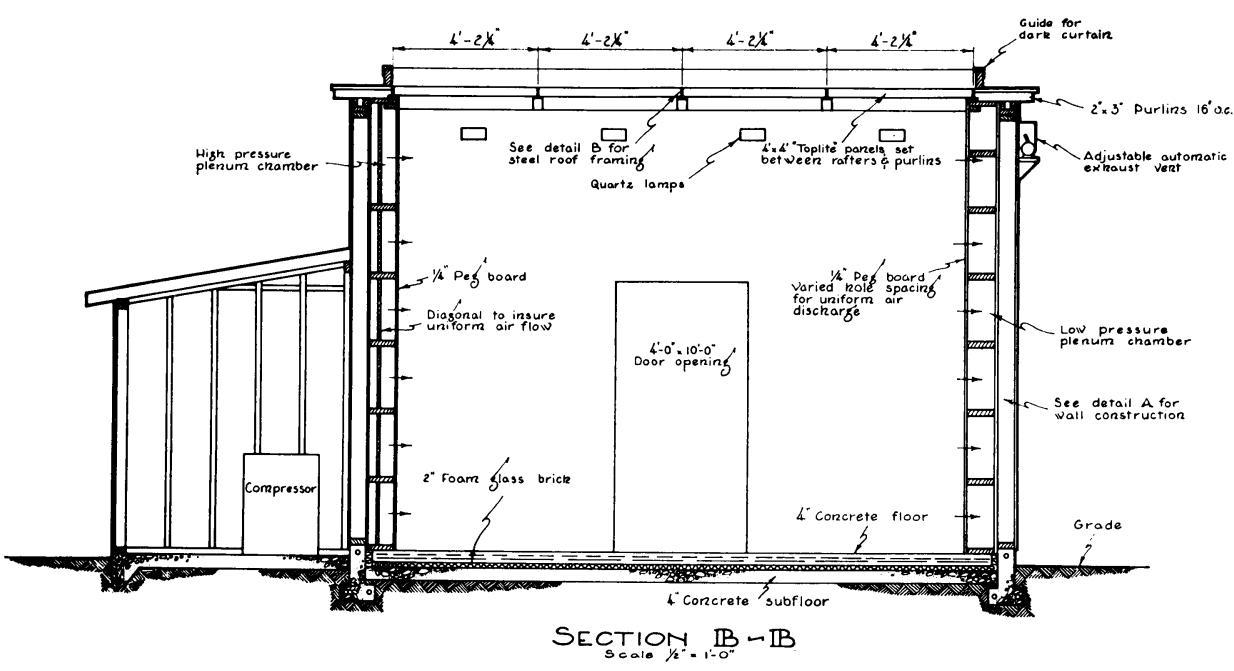

Fig. 9. Vertical section B-B, looking south, of large controlled room and equipment-storage space. At left (east), high-pressure plenum chamber tapered from 10 inches to zero, to provide uniform air flow from blower fan. Each of six ducts, numbered from bottom, is about 2 feet high, carrying "high" pressure air along until it escapes through 1/4" pegboard into experimental room. It then moves across room, escaping through pegboard again into "low" pressure horizontal ducts or plenum chamber on right (west) side. From there, air passes through cooling coils, heaters, and humidifier (if operating) back to blower.

glass blocks, $12^{\prime \prime} \times 12^{\prime \prime}$ each, were prefabricated by the Kimble Glass Co. (n.d.). The roof structure is shown in figure 11 .

The roof panels of this room could be raised either by derrick or manually with a quadrupod device of steel tubing, revolved $90^{\circ}$ or $180^{\circ}$ to a different angle of presentation toward the sun, and dropped back in place. Observations were made, both by recording light meters and the Eppley pyrheliometer, and, at intervals, with the hand-held light meter. Observations were taken throughout the day, in different locations in the room, at different elevations from the floor, and at different seasons of the year. Results are presented in figures 12 and 13. Figure 12 shows seasonal results on the customary $\mathrm{N} \rightarrow \mathrm{N}$ and $\mathrm{N} \rightarrow \mathrm{S}$ orientations. The $\mathrm{E} \longleftrightarrow \mathrm{W}$ is the checkerboard combination mentioned above.

After these combinations had been studied, it was suggested that a fourth combination (of panels) might be more effective over the entire year. In this arrangement, the northern and central rows (east-west) were of panels with all blocks in the checkerboard design, and the southernmost row was of blocks oriented $\mathrm{N} \rightarrow \mathrm{S}$. These measurements in the center of the room and only 3 feet below the roof do not permit full participation of all the blocks but only of those near the center. With these reservations, the $\mathrm{N} \rightarrow \mathrm{S}$ orientation appears best for winter and equinox, but in terms of ft-c hours per day, the $\mathrm{E} \longleftrightarrow \mathrm{W}$ appears best, with the mixed arrangement intermediate. Summation of ft-c hours from simultaneous recordings on July 17 for positions 3 feet below the center of panels of the mixed arrangement indicated that the $\mathrm{E} \longleftrightarrow \mathrm{W}$ panel transmitted 21 per cent more light $(34,700$ ft-c hours) over the day than did the $\mathrm{N} \rightarrow \mathrm{S}$ panel $(28,490$ ft-c hours).

Figure 13 shows the intensity curves for the entire room at six positions for summer, at a working distance for medium-sized plants. 


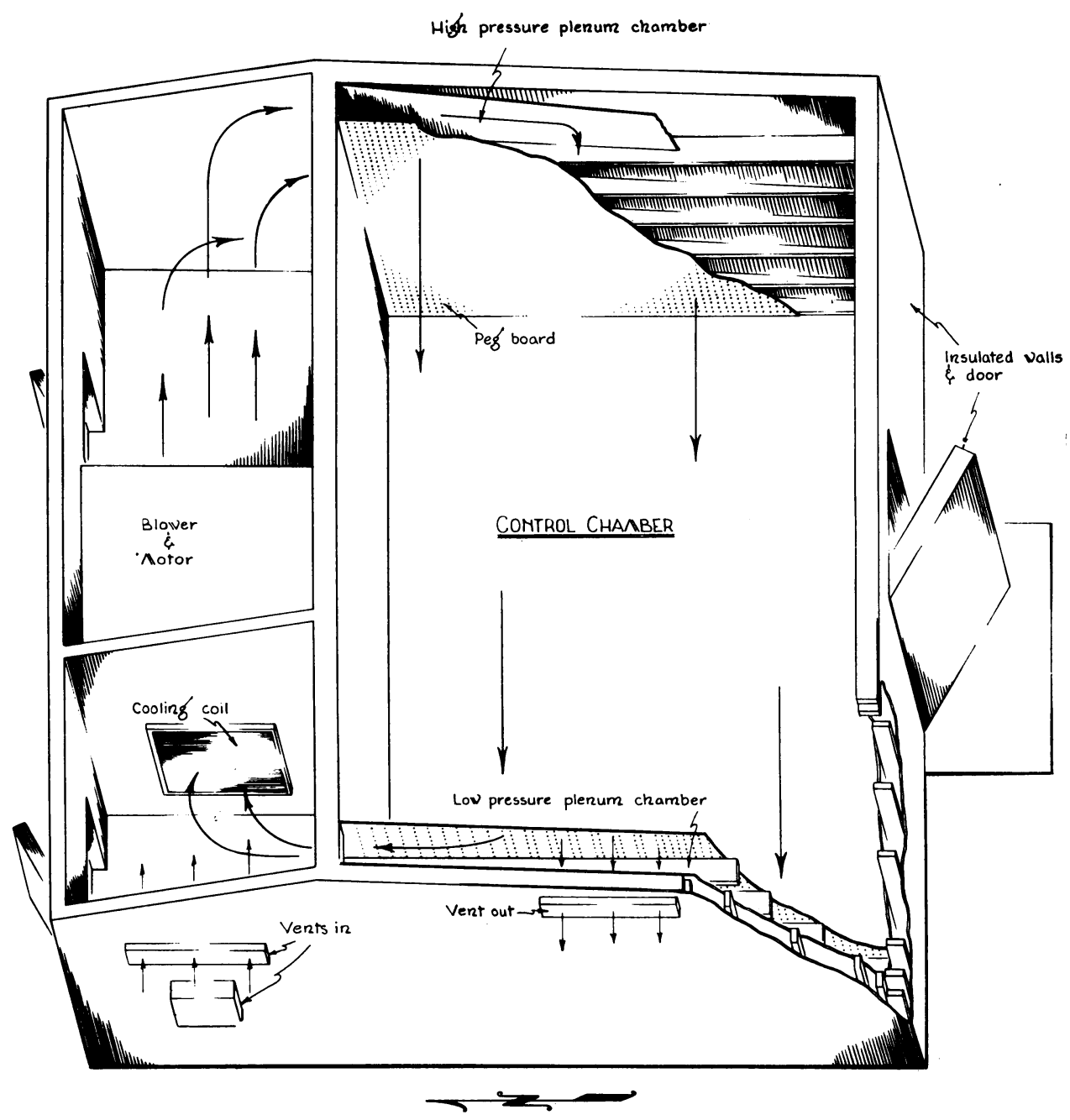

Fig. 10. Air-flow diagram viewed from above. Figure is seen from west.

\section{Effects of Room Size on Light Distribution}

Table 1A presents the approximate percentages of sunlight admitted to the large room at two distances from the roof, both as maximum intensities (not necessarily at noontime) and as total ft-c hours. The 3 -foot distance represents a room with a 7 - or 8 -foot roof, suitable for smaller plants, while the 8 -foot distance would apply to smaller plants in a room 13 feet high that would be better adapted to young trees.

Results indicate that the $\mathrm{N} \rightarrow \mathrm{N}$ ori- entation is inadequate for plant growth. The $\mathrm{N} \rightarrow \mathrm{S}$ orientation produces a very high maximum intensity at midday, but it is of comparatively short duration. The $\mathrm{E} \longleftrightarrow \mathrm{W}$ alternate-block orientation is most suitable, producing a relatively long day of moderate intensity. The mixed orientation provides higher intensities near the south wall at 8 feet from the roof than does the $\mathrm{E} \leftarrow \mathrm{W}$ or $\mathrm{N} \rightarrow \mathrm{N}$, and on the yearround basis, this combination gives the best performance, so far as uniformity of room illumination is concerned. 


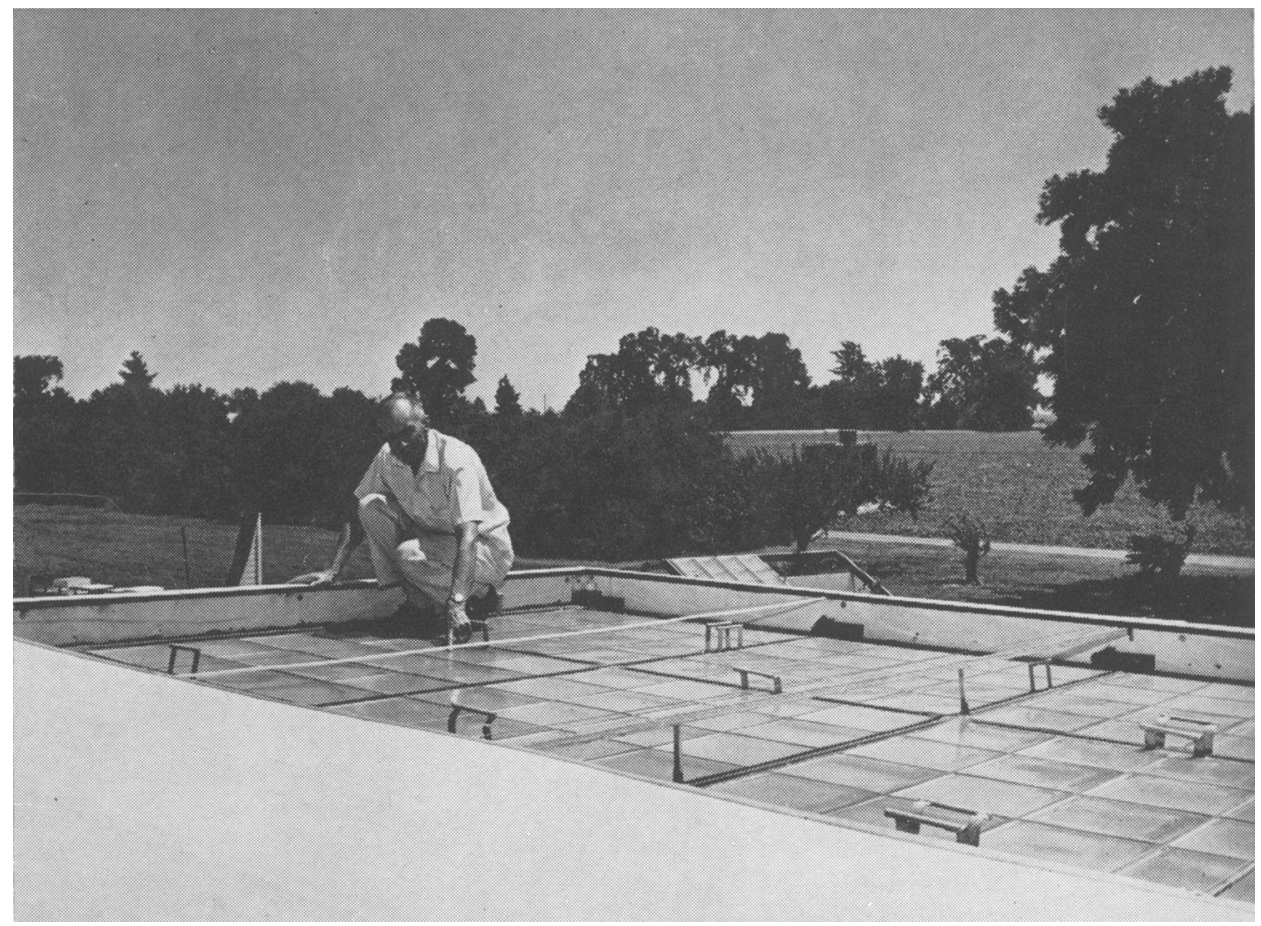

Fig. 11 Roof of large room viewed from northwest. Handles for panels are visible. Two cables supporting dark curtain stretch from north to south. Grooves for dark curtain are visible around edge of roof.

\section{USE OF A REFLECTOR}

A reflector intercepts sunlight for reflection downward into a room. With a glass-block roof, $\mathrm{N} \rightarrow \mathrm{N}$ orientation would admit the most light from the reflector.

A small plywood cubicle $46^{\prime \prime} \times 46^{\prime \prime}$ $\times 48^{\prime \prime}$ was built to study the possible advantages of a reflecting surface above the north side of the room. The reflector was 50 inches high and 8 feet wide and extended upward from the north edge of the roof. Several surfaces and several angles of inclination were tried.

Although the principle is a simple one, improvement in uniformity of irradiation within the room was not attained. This method of intensifying light, although inexpensive, was considered impractical for a large room because of problems of angle control and wind resistance.

\section{A HELIOSTAT ROTATING MIRROR SYSTEM}

This system, often called a heliostat, seemed most capable of developing the highest intensity of light and heat of any natural solar-radiant methods.

By proper rotation of parabolic mirrors, the sun's rays are reflected always toward one spot, the small mirror appearing above the adjustable mirrors which comprise an approximate paraboloid of revolution. The small mirror reflects all light and heat rays directly downward through the glass roof of the small test chamber.

Figure 14 shows the construction and the reflections of the solar rays to the plant environment test room at noon 


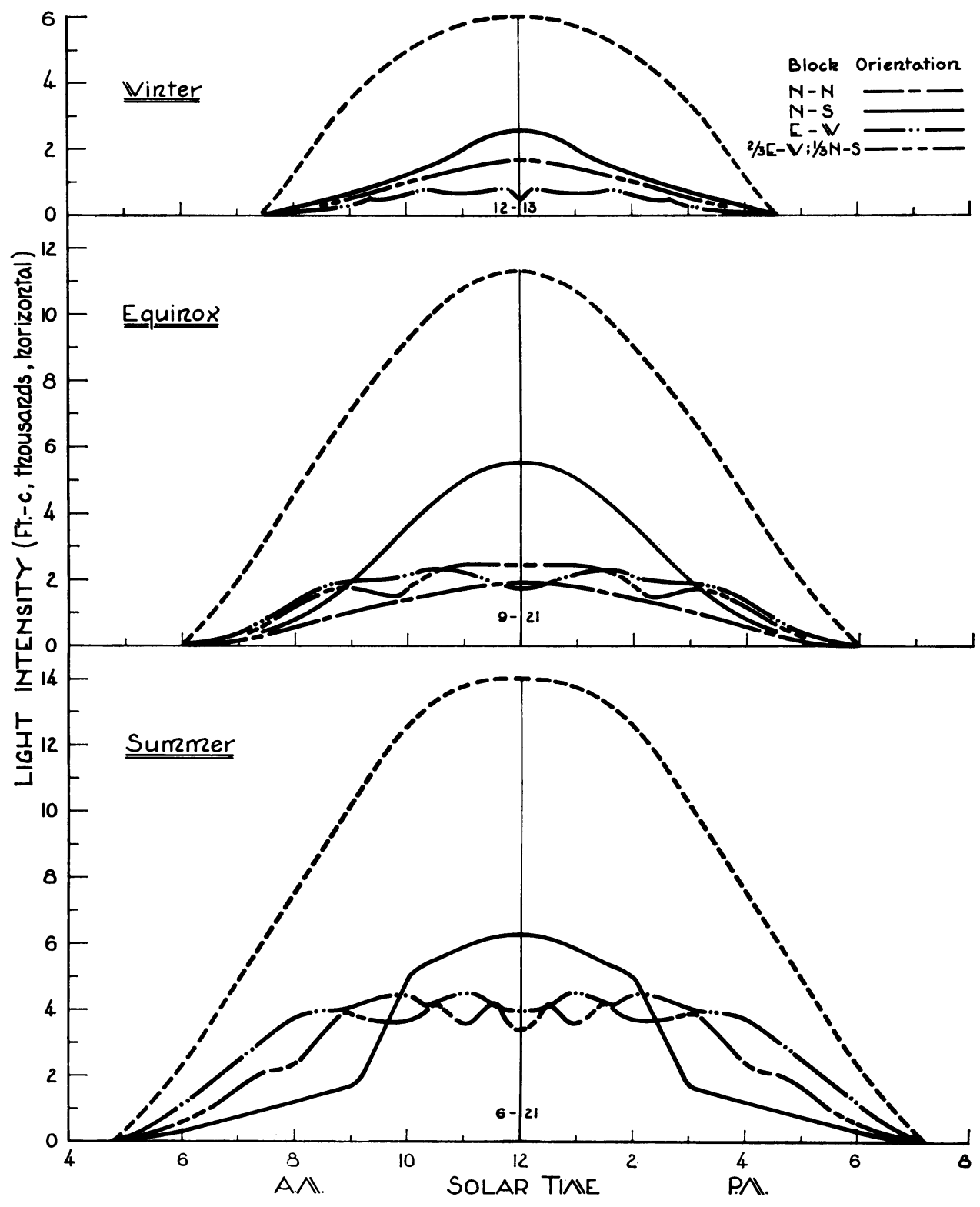

Fig. 12. Sunlight intensities in large room with glass-block roof, measured 3 feet below roof in center of room. Glass block orientation varied. Elevation $0^{\circ}$.

during the winter. The latitude angle of $38.5^{\circ}$ must be made to correspond to the actual location of the heliostat: the number of degrees north of the equator.

Figure $3 \mathrm{~A}$ shows that intensities of reasonably high values $(2,000$ to 4,000 ft-c) may be obtained throughout the year, of course with different day- lengths. The curves in general lie closer together (greater uniformity over the cubicle) than for most other systems presented thus far. With greater ease in mirror adjustment and a more nearly accurate rotational system, the winter curves could agree as well as those for other seasons. We did not at- 


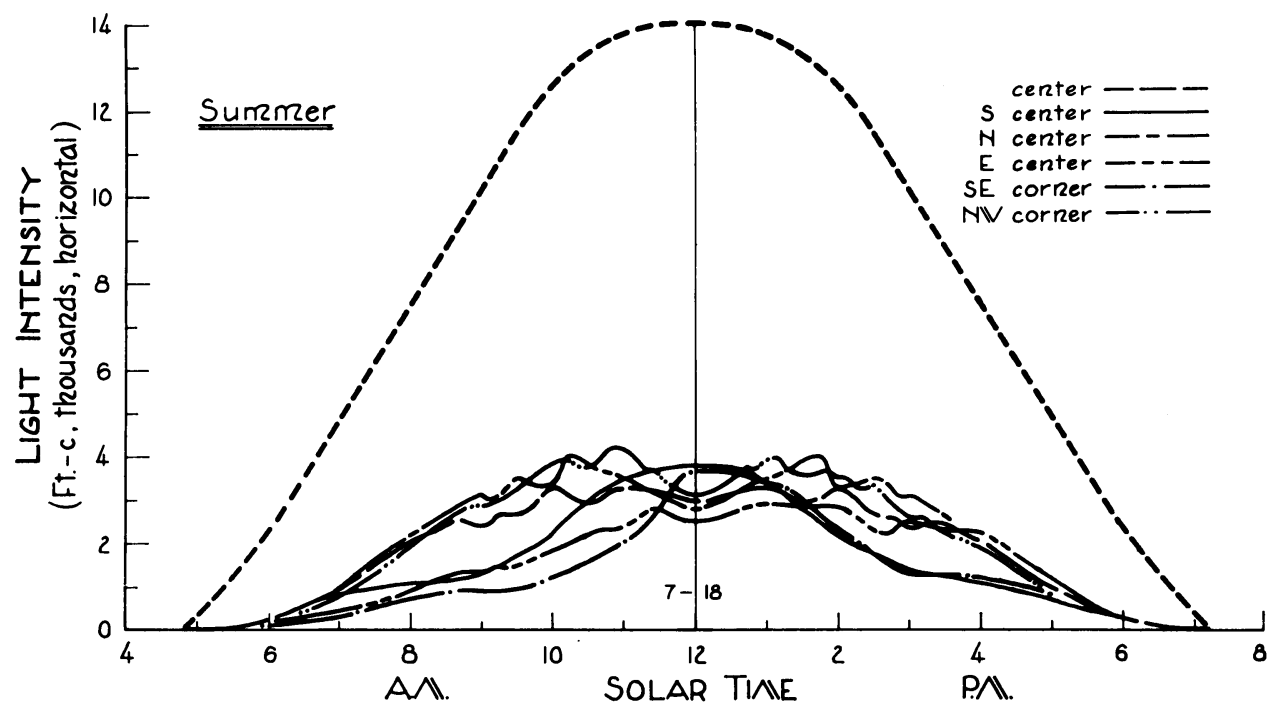

Fig. 13. Sunlight intensities in large room with glass-block roof. Block orientation $2 / 3$ $\mathrm{E} \longleftrightarrow \mathrm{W}, 1 / 3 \mathrm{~N} \rightarrow \mathrm{S}$, meter 7 feet 3 inches below roof, 2 feet from wall except for center curve. Elevation $0^{\circ}$.

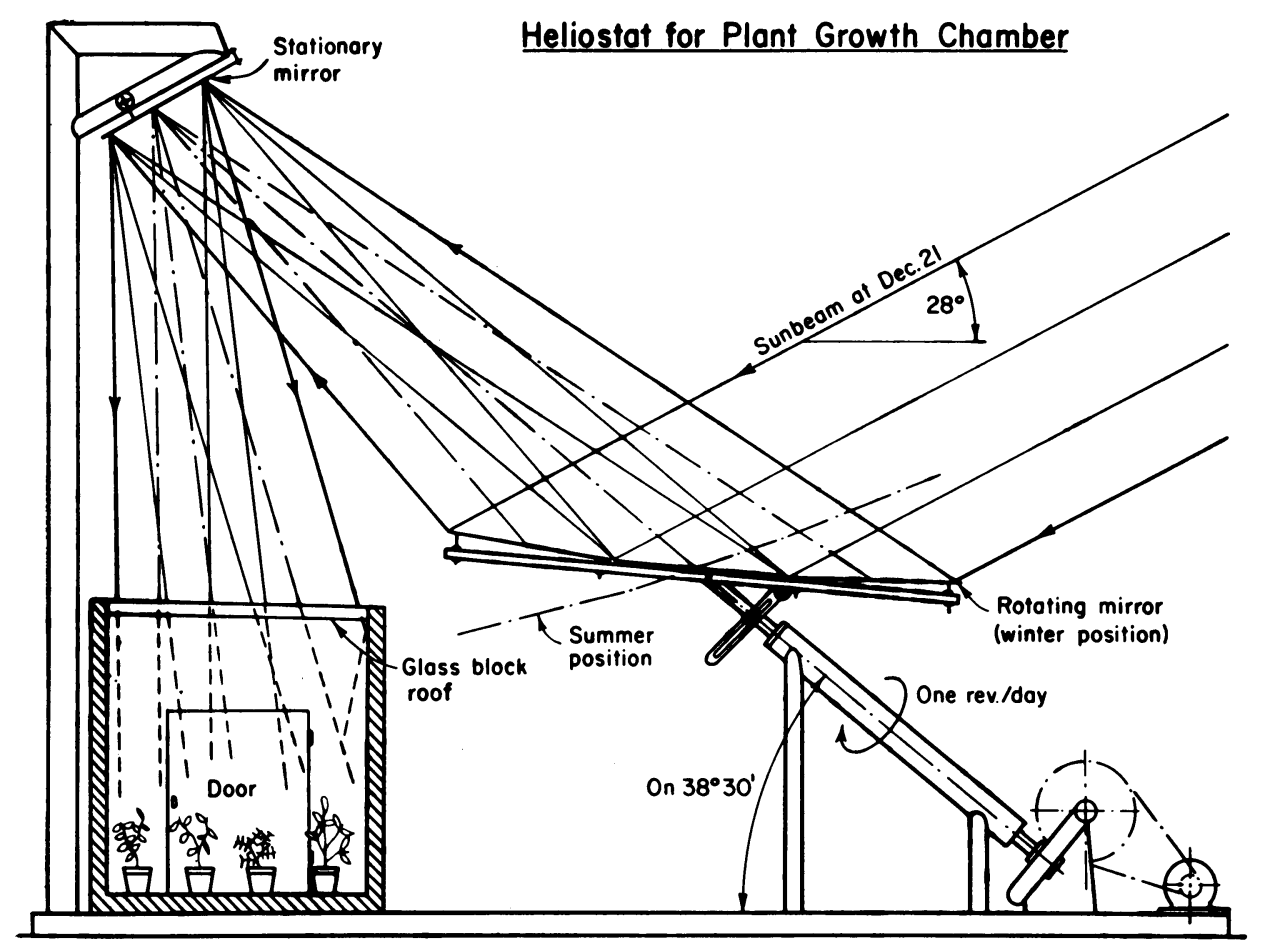

Fig. 14. Light paths and mirror positions at noon in winter and summer. 
tempt to achieve the best possible uniformity here.

This system has distinct possibilities for use on a small scale, for example, in a cubicle about $4^{\prime} \times 4^{\prime}$. By increasing the rotating mirror area, very high sunlight intensities, even higher than those outdoors, might be attained within the growth chamber. However, maintaining correct focus of the individual mirrors of the rotating section with changing seasons, cleaning of the reflecting surfaces, and wind resistance are serious problems when large sizes are contemplated. This method is not so promising for our large-room applications as is the rotating room.

\section{THE ROTATING ROOM}

The rotating room seems most promising for improvement of both distribution and intensity within fairly large rooms, say $12^{\prime} \times 16^{\prime}$. A $6^{\prime} \times 8^{\prime}$ model with adjustable roof and walls was constructed for the study of light problems alone (fig. 15).

This small building, or phytorotor was rotated once every 24 hours, but being on a horizontal plane, it did not follow the sun accurately. Adjustments were necessary for the horizontal solar projection, as well as for the astronomical equation of time. A future unit will include automatic controls for these features, and will follow the sun by means of light-sensitive solar cells or electric eyes.

When the room was rotated, the sun shone to best advantage through the sloping glass roof as well as through the glass blocks in the front wall. Constructed on a solid frame, the three glass walls were interchangeable, and

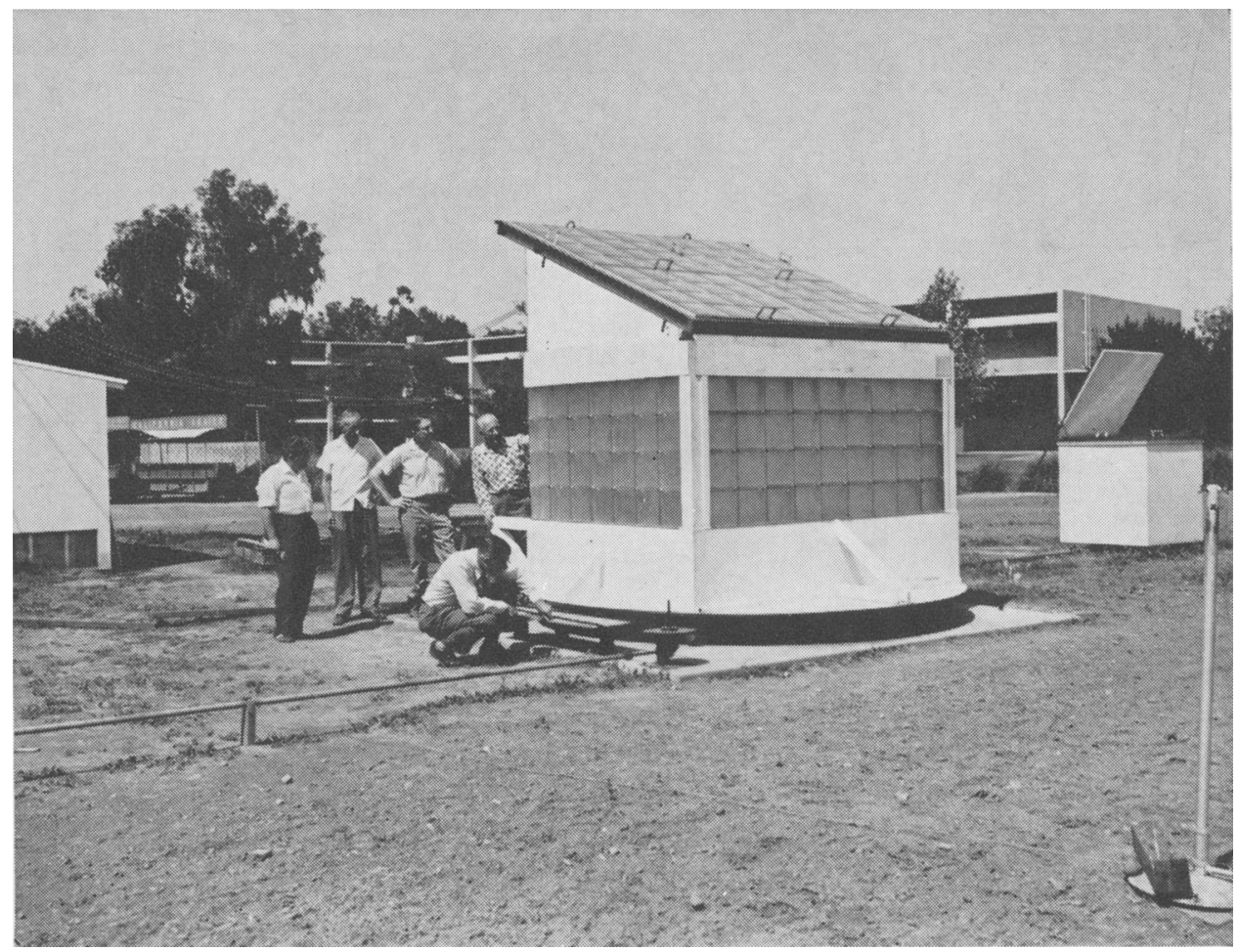

Fig. 15. Small rotating room, facing south, with $23^{\circ}$ sloping roof and walls of glass blocks. Chain drive for heliostat is in foreground, with drive rod extending toward heliostat. 
the glass-roof slope was adjustable from $0^{\circ}$ to $45^{\circ}$. Four steel wheels supporting the unit traveled a circular path on the concrete slab floor. To avoid difficulty with electric wiring, the unit moved clockwise during the day, and counterclockwise at night.

Powered by an electric motor with speed reducer, the phytorotor turned at the same rate as the heliostat. The final drive was by sprocket and chain, the latter attached to the circular peripheral apron around the base of the structure.

To obtain the most nearly accurate estimation of its possibilities, we turned the room by hand every few minutes during the more critical experiments to avoid angular defects in light transmission and to offer the best opportunity for uniform intensity from wall to wall. Light intensities were measured manually and recorded quickly at different elevations ( 1 to 4 ) and in different parts of the room. Results are shown in figures 16 to 22 , and $5 \mathrm{~A}, 6 \mathrm{~A}$, and $11 \mathrm{M}$ to $18 \mathrm{M}$. Level 1 was on the floor, 18 inches below the lower edge of the vertical windows; level 2 was even with the lower edge; level 3 was opposite the center of the windows; level 4 was even with the top of the window or lower edge of the roof.

The upper chart in figure 16 shows

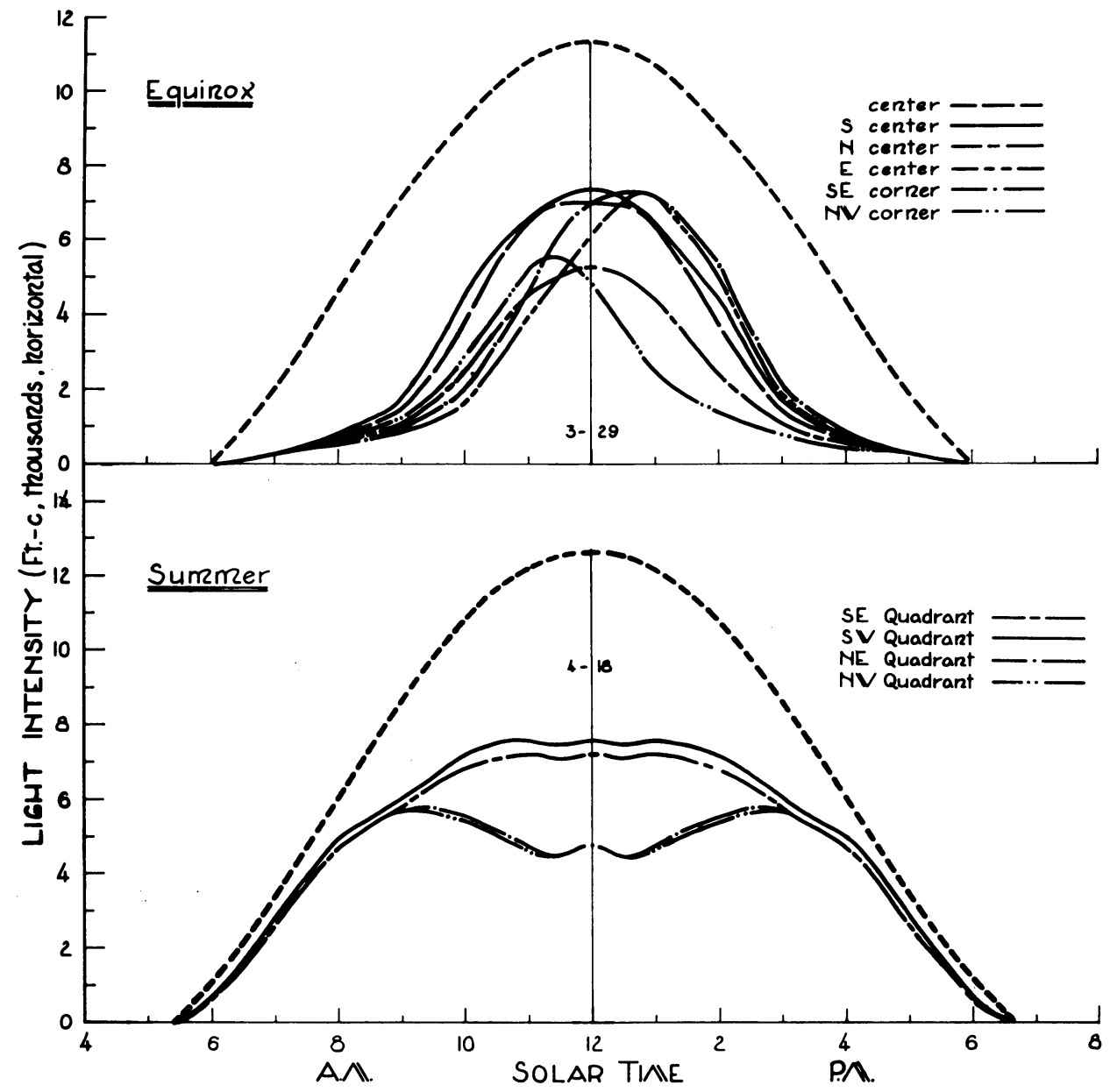

Fig. 16. Light intensities in small room with glass-block roof and wall, orientation $N \rightarrow S$, only "south" wall transparent, meter at level 2. Elevation $23^{\circ}$. Upper chart: room stationary, facing south. Lower chart: room rotated by hand to face sun. 
the extremes of variation. The north locations have distinctly lower intensities than other areas, which are fairly uniform among themselves in terms of ft-c hours. They also reach high intensities of approximately $7,000 \mathrm{ft}-\mathrm{c}$ for several hours per day at equinox.

The lower chart shows similar differences between north and south areas. Here the walls do not affect the result as much as in the upper chart-hence, more uniformity. These curves indicate eight hours of sunlight at approximately 5,000 ft-c in late April.

Figure 1 (p. 498) shows that on the $\mathrm{N} \rightarrow \mathrm{S}$ curve the maximum transmission is at an angle of incidence $45^{\circ}$

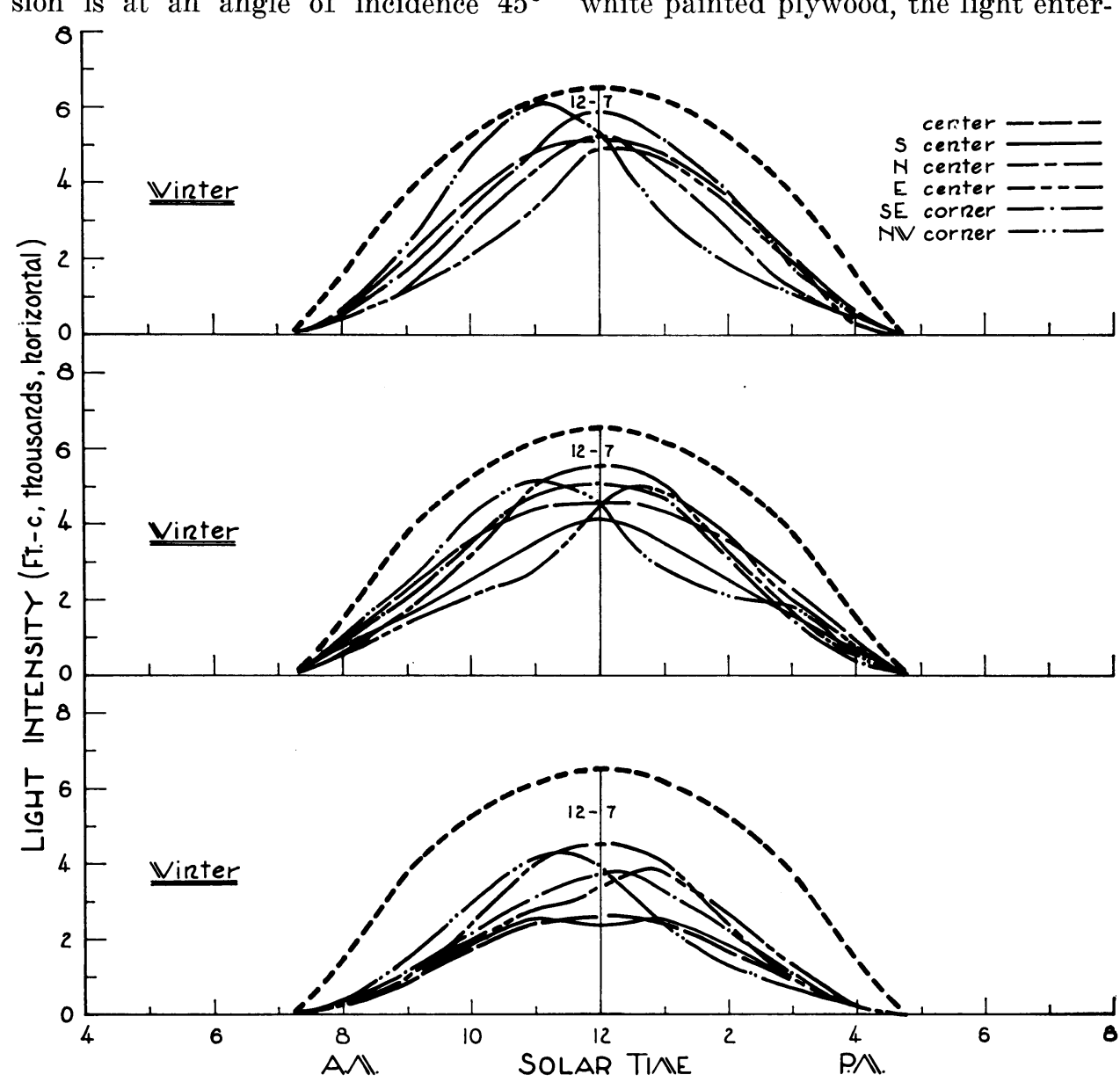

Fig. 17. Light intensities in small room, stationary, facing south, with glass-block roof and walls, orientation $\mathrm{N} \rightarrow \mathrm{S}$, meter at level 2 . Elevation $45^{\circ}$. Upper chart: only "south" wall transparent. Middle chart: three walls transparent-south, east, and west. Lower chart: no transparent walls-light from roof only. tude. Thus the glass-block roof was inclined $45^{\circ}$ toward the south, and a study was made of the relative contributions by roof and walls.

The two upper charts in figure 17 show the same general relationships among the areas involved. With three walls transparent (middle chart), values are in general lower than when only the south wall is transparent, especially near midday. The light meter showed that transparent east and west walls permit more light to pass outward than comes in from darker areas of the sky. When these walls are covered with white painted plywood, the light enter- above the midwinter noon solar alti- 
ing from the roof and south wall and striking the east and west walls does not escape, but is reflected back into the room. The lower chart indicates the contribution by the roof alone. By subtracting these curves from those of the other charts, the values contributed by the walls alone are obtained. Obviously, transparent walls exposed to the sun make valuable contributions to the light in a room of this size, and the south wall is most significant in winter.

\section{Light Intensities from Sides of Room}

Although most measurements of sunlight intensity were made with the light meter held horizontally and facing upward, the photosynthetic portions of the plant are often oriented to take good advantage of light presented horizontally or at angles other than vertical. The over-all effectiveness of light becomes, especially for higher plants, a very complex integration. Some weight should be given to the fate of sunlight after it enters the room and is subjected to one or more reflections from surfaces within the room. From our measurements we concluded that when the room faces the sun, a reflecting surface on the side walls is better than one that transmits light.

With the roof $(\mathrm{N} \rightarrow \mathrm{S}), 23^{\circ}$ inclined, and facing the sun, with a solar elevation of $52^{\circ}$, and with white-painted covers on the side walls, horizontal light intensities in the room were very uniform-near 6,600 ft-c-at different distances above the floor. At the sides of the room, next to the walls, intensities were no less than 6,000 ft-c. This arrangement therefore appeared the best in the interest of both high intensity and uniformity of light. The transparent "south" wall tends to compensate for the decreased intensity from the roof alone as the distance from the roof increases.

The upper chart in figure 18, obtained by mechanical rotation, presents a set of curves which, except for corners, agree closely among themselves and are uniformly high in winter, at times even exceeding outside intensities. The advantages of rotation can be seen by comparison with the upper curve of figure 17 for the same room when stationary. The middle chart shows contributions of the roof alone, indicating that at $45^{\circ}$ elevation, the roof directs considerable light onto the north wall, which reflects it nearby. The south side benefits most from the transparent south wall. The lower chart as compared with the middle one, indicates further the northward direction of the light from the roof, since the south side is better irradiated at this level. More spread among other positions is evident at this level.

From figure 1 (p. 498) it is evident that the $45^{\circ}$ elevation is most helpful in winter. At other seasons the transmission curve of the $\mathrm{N} \rightarrow \mathrm{N}$ orientation would first approach the $90^{\circ}$ incidence angle and then the $\mathrm{N} \rightarrow \mathrm{S}$ curve would be followed. This applies for midday solar altitudes. At early and late hours of the day, the rotating $45^{\circ}$ elevation would be very effective throughout the year.

Figure 5A is directly comparable with figure 17. Allowing for the different dates, the outdoors curve for figure $5 \mathrm{~A}$ is somewhat higher than that for figure 17. In general, these sets of curves are similar, although the corner and east-side curves differ more widely from other curves for the $23^{\circ}$ elevation. Thus the $45^{\circ}$ angle tends to produce more uniformity at level 2 , but this difference might disappear in large rooms where northern portions of the roof would be very high.

Figure $6 \mathrm{~A}$ presents the stationary situation for equinox and summer, and may be compared with the middle chart of figure 5A for the same room in winter. The same wide fluctuations for the east side and corners are evident for winter and equinox. Maximum values 


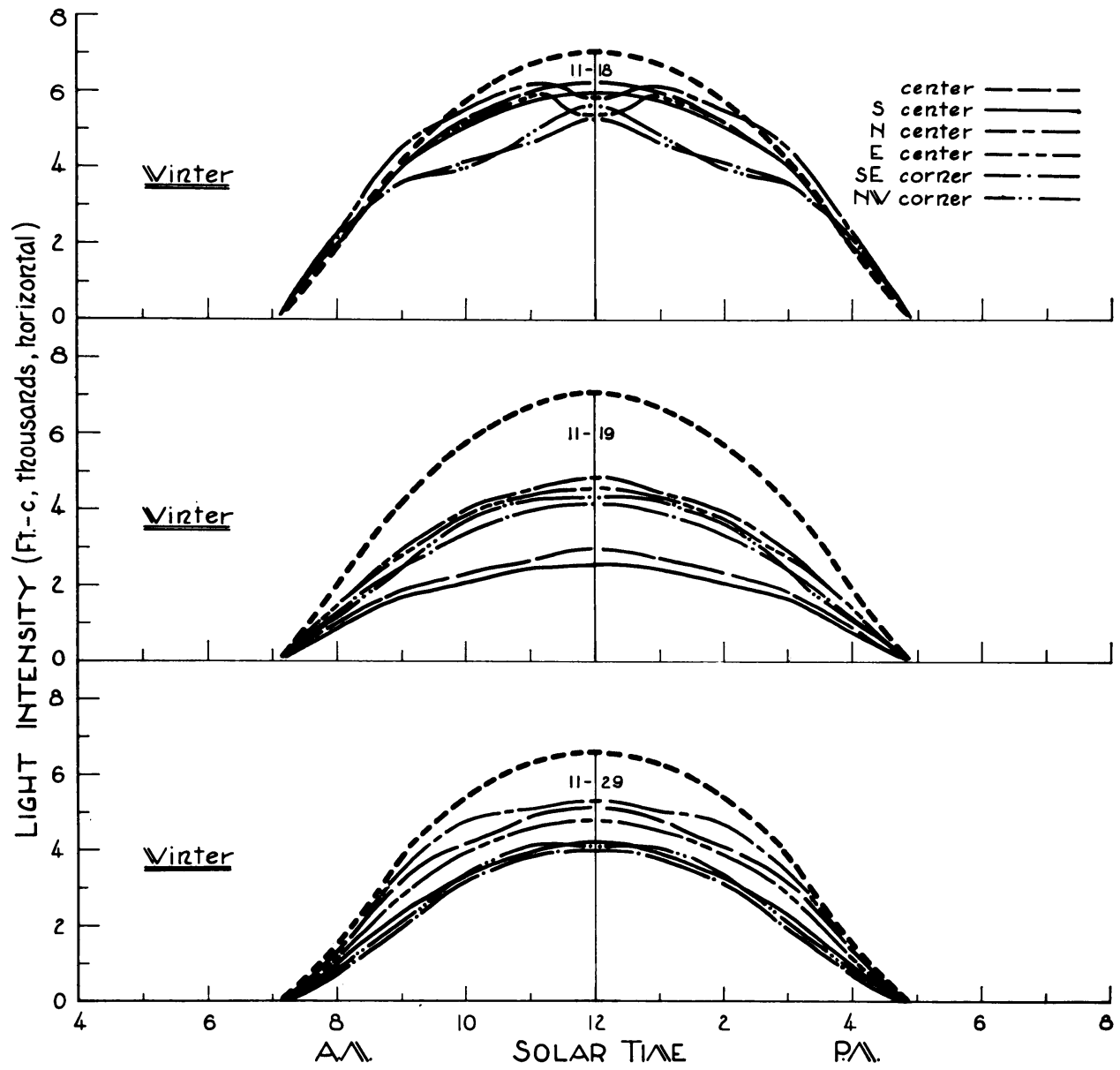

Fig. 18. Light intensities in small room rotated mechanically, with glass-block roof and walls, orientation $\mathrm{N} \rightarrow \mathrm{S}$. Elevation $45^{\circ}$. Upper chart: only "south" wall transparent, meter at level 2. Middle chart: no walls transparent, meter at level 2. Lower chart: no walls transparent, meter at level 4.

are higher at equinox. Areas under the curves (ft-c hours) do not appear greatly different when averaged.

The lower chart for summer (fig. 6A) presents data perhaps more useful from the grower's standpoint. For the four quadrants, ft-c hours are equal, and long days of only moderate intensity are obtained. The condition is to the right of maximum on the curve of figure 1 (p. 498). This arrangement certainly provides good conditions during winter and equinox days, but reduces intensity more than is desirable in summer. Nevertheless, it would be a very useful combination and intensities would be high enough for good growth of many plants.

Results with different angles of the roof indicate, of course, more light interception by the $45^{\circ}$ roof, but on a large scale this would make the "north" wall extremely high, offering more wind resistance and causing undue reflection from the "north" wall. The $23^{\circ}$ roof is reasonable for a 12 -foot depth, and intercepts adequate light.

The proportion of light coming from the roof and from the walls was determined by covering them closely in turn 
with opaque materials-canvas for the roof and white plywood (inside) for the sides.

Observations of light intensities were made at four levels in 13 locations in the stationary room at various periods of representative days during three seasons. The 10-minute observations were made as quickly as possible, with the hand meter held horizontally. Outdoor observations were close to those predicted from the curves used as standards for the seasons. No attempt was made to convert readings to a standard solar intensity, although all observations were made in bright sunny weather. Only one-half day was needed, since symmetrical relationships can be figured from these data for the other one-half day.

Most constant intensities were observed at the center of the room, and these values were approximately equal to the average of the quadrant positions. Variations were maximum at the corners, where the meter was close to walls (about 6 inches). Here shadows from structural elements were most significant. Both altitude and azimuth angles of the sun were important here in the geometrical relationships of irradiation during the day. The results differed considerably from season to season because of azimuth differences. These are not involved when the room is rotated.

In general, the side windows contribute more at levels 1,2 , and 3 when solar elevations are low than when they are high, hence more in winter than in summer, over the day. The lower altitudes occur twice each day throughout the year, while high elevations occur only near midday, and have higher values in summer. In the summer series, at level 4, at 5:00 p.m. when the azimuth angle is such that the roof does not receive direct sunlight, the light from the roof is low. The west wall is the principal source. At noon the roof contributes its maximum.

Note that for the winter conditions the inclination of the roof was $45^{\circ}$, making the potential roof contribution considerably higher than for $23^{\circ}$. On the other hand, more of such light was directed against the north wall, and was thus available more by reflection than directly.

The relative contribution of ceiling and walls was indicated by comparing data obtained with transparent walls and with white walls, in February. Care was taken to compare appropriate positions for the corresponding azimuth angles from the noon position.

On February 22, at noon, with glassblock walls, some directional observations were made from the room center at level 4, with results as follows: meter perpendicular, facing north wall2,600 ft-c; meter perpendicular, facing south wall-3,600 ft-c; meter $45^{\circ}$ upward, facing north wall-3,600 ft-c; meter $45^{\circ}$ upward, facing south wall$4,800 \mathrm{ft}$-c. It is clear that reflection from the north wall contributes appreciably to nearby areas.

In a small room such as this, the corners and areas near the walls are more likely to be utilized for plants, while in a larger room comparable space might be used for access. The light distribution in these areas is more important in a small room. The nature of the experiment and the plant material used will determine the possible efficiency of area use in relation to light intensity.

\section{COMPARISON OF SYSTEMS}

The various systems were compared, at their best, for the equinox period. In decreasing order of ft-c hours per day, they are: (1) rotating room (one wall transparent); (2) rotating room (three walls transparent); (3) stationary room (three walls transparent); (4) rotating mirror system; and (5) 
stationary reflector system (fig. 19). Although the performance of the stationary room is good, that of the rotating room is obviously superior by a considerable margin. Because this type of room also appeared most practical for extension to a moderate size, it was given more detailed study. While the stationary model will always perform less well, it may be a useful design because of its greater simplicity.

Figures 20 and 12M to $14 \mathrm{M}$ show comparable data at four different levels within the room for the six critical areas, with the $23^{\circ}$ roof elevation. At level 2, much less spread is evident among the curves, and greater conformity exists at low solar altitudes in summer. Curves group toward the higher levels. Corner relationships reverse at certain hours.

The chart demonstrates that at all seasons, sunlight intensities of over 2,000 ft-c may be obtained at all levels during most of the day. At levels 2 and 3 , the most important for most plants, intensity levels of $4,000 \mathrm{ft}$-c are provided for a large part of the day. Maximum intensities range up to 7,000 to 8,000 ft-c. An unfavorable characteristic of this glass block for an application at $23^{\circ}$ elevation is the relatively low intensity transmitted near midday. This decreased intensity is pronounced at all levels at midsummer as indicated by comparison with the equinox curves.

Figure 21 presents data for the four quadrants at level 2, all taken when rotation was accurately done (by hand). Comparison may be made with figure 20 for the same level but for more extremely located areas. For solar altitudes below about $33^{\circ}$, all quadrants agree. Midwinter altitudes at Davis never reach $33^{\circ}$, so complete agreement among quadrants is obtained then and for a period of five weeks on each side of the winter solstice. Divergence among the curves is slight at equinox but appreciable during about six hours at midsummer. Intensities obtained at these locations are probably sufficiently high for good plant growth during the entire year.

From figures $15 \mathrm{M}$ to $18 \mathrm{M}$ one may determine intensities available on clear days with this construction at any date for a great many localities, since performance is dependent only upon solar altitude.

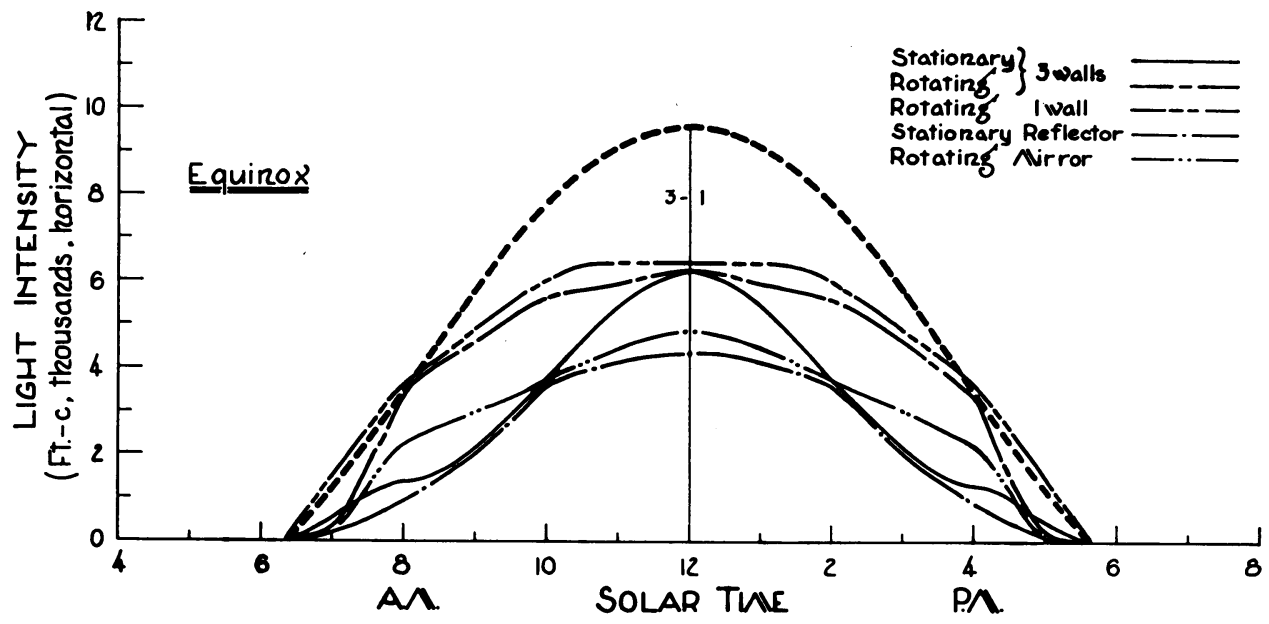

Fig. 19. Comparison of light intensities in small room, reflector cubicle, and mirror cubicle; meter in center location. Small room, stationary and rotating (mechanical), with glass-block roof and three sides transparent, orientation $\mathrm{N} \rightarrow \mathrm{S}$, meter at level 2 . Elevation $23^{\circ}$. Small room, rotation calculated from solar elevation-intensity data, with only "south" wall transparent. Reflector stationary, with glass-block roof, orientation $\mathrm{N} \rightarrow \mathrm{S}$, meter 30 inches below roof. Elevation $0^{\circ}$. Rotating mirror cubicle with glass-block roof, orientation $\mathrm{N} \rightarrow \mathrm{N}$. Elevation $0^{\circ}$. 


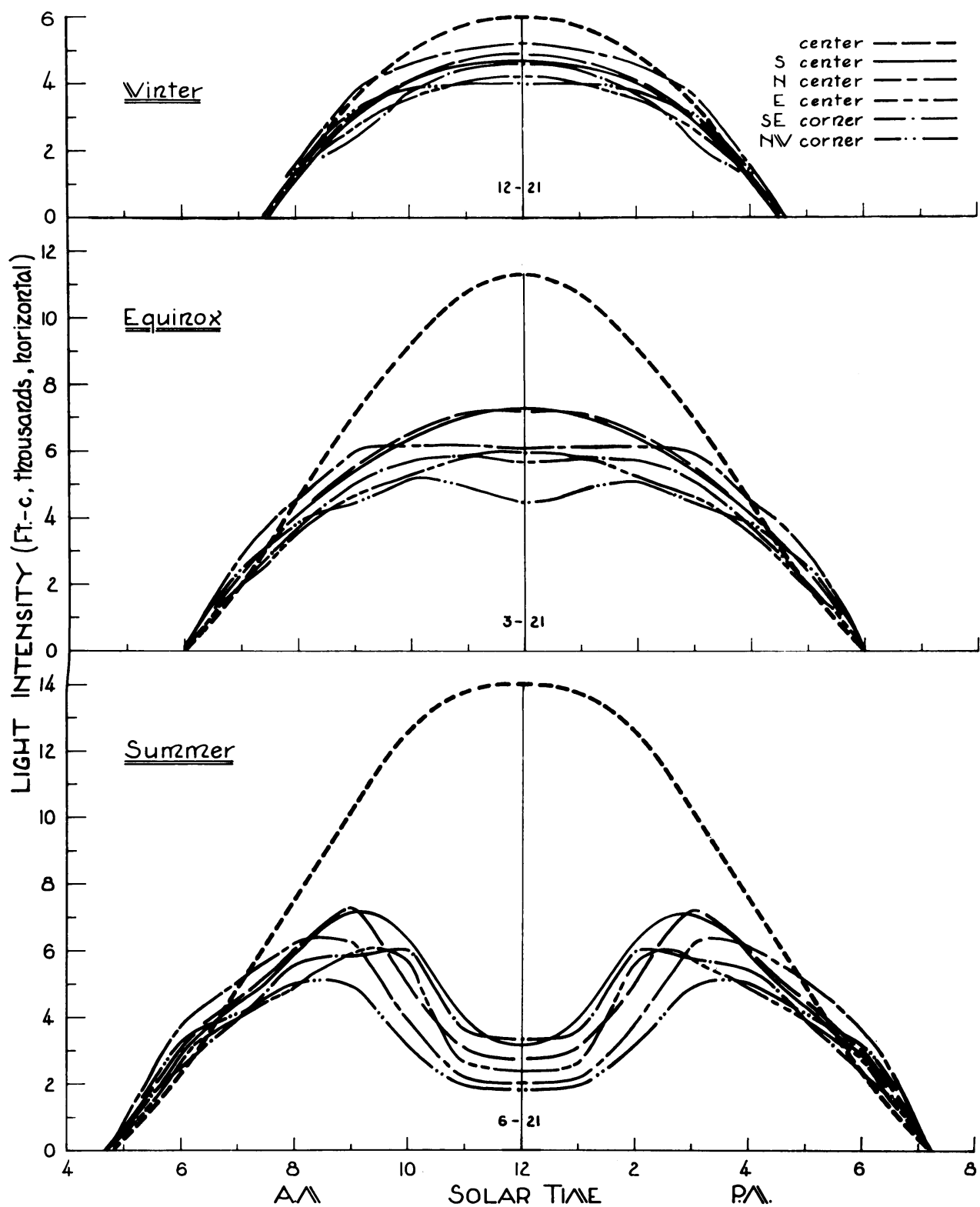

Fig. 20. Light intensities calculated from solar elevation-intensity curves, in small room, rotating, with glass-block roof, orientation $\mathrm{N} \rightarrow \mathrm{S}$, only "south" side transparent, meter at level 2. Elevation $23^{\circ}$. Data for solar elevation 6 to $50^{\circ}$ from mechanical rotation, and for 57 to $74^{\circ}$ from hand rotation.

Figure 22 presents accurately determined intensities for the more central areas of the rotating room, at level 2, normally the level of young or small plants. Uniformity was more prominent here, with no variation until solar altitudes became greater than $40^{\circ}$.
This offers a considerable advantage, particularly at the lower intensities, when light may be the limiting factor for plant growth.

Table 1A compares sunlight energy values admitted at different seasons by four practical designs in terms of maxi- 


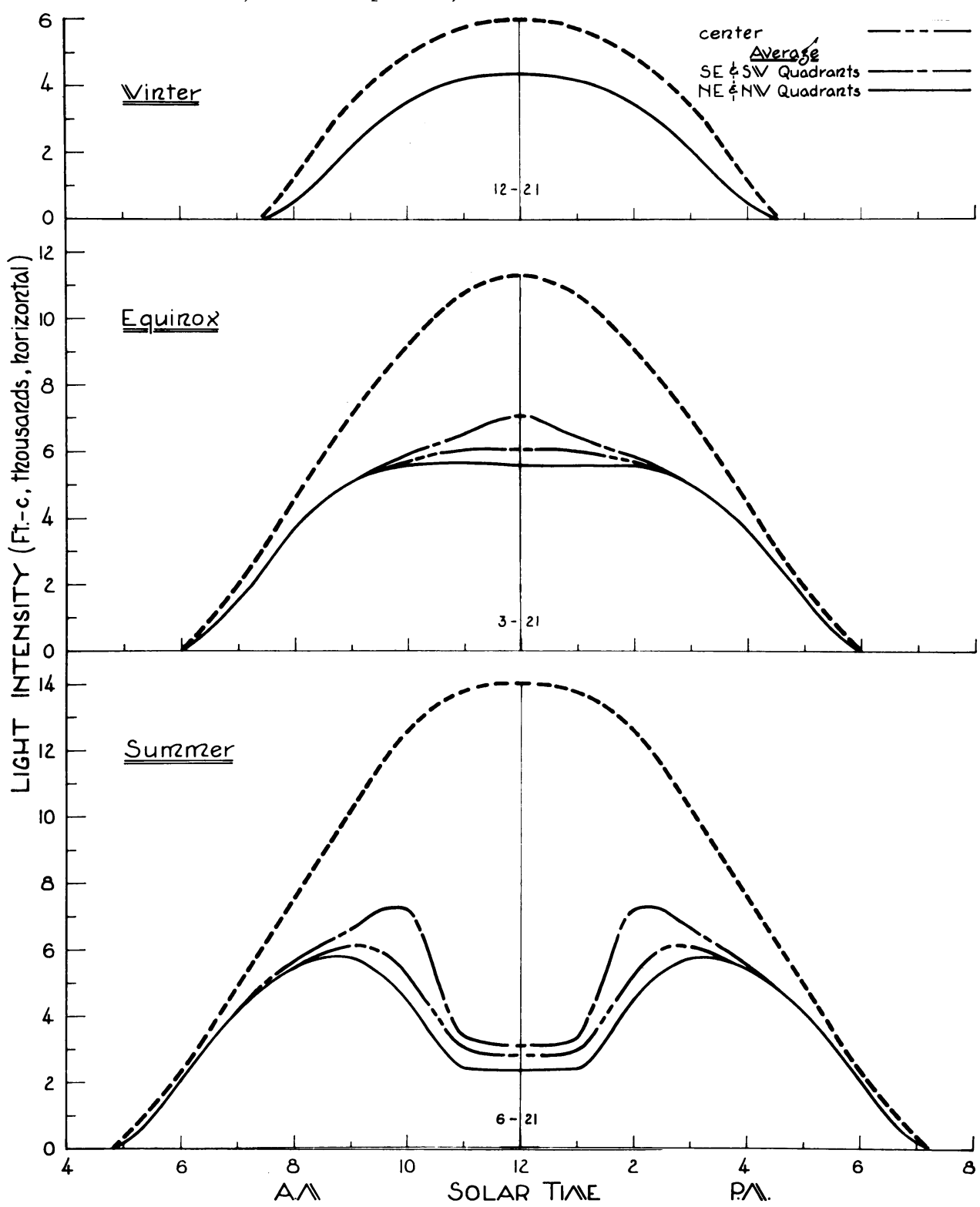

Fig. 21. Light intensities calculated from solar elevation-intensity curves, in small room, rotating, with glass-block roof, orientation $\mathrm{N} \rightarrow \mathrm{S}$, only "south" side transparent, meter at level 2. Elevation $23^{\circ}$. All data from hand rotation.

mum intensities, number of hours above arbitrary values, total ft-c hours per day, average intensity over the day, and percentage of outdoor sunlight.

In the large room, orientation $\mathrm{N} \rightarrow \mathrm{S}$, the maximum intensity decreases about 25 per cent from the 3- to 8-foot distances from the roof, resulting in a 30 per cent decrease in total energy per day, in average intensity, and in percentage of outdoor light. With the mixed orientation of roof blocks, these decreases with distance are very much less, but many of the values involved are also much lower. Since the day provided by the mixed blocks is of more uniform intensity most of the year, from the standpoint of total photosynthesis this con- 


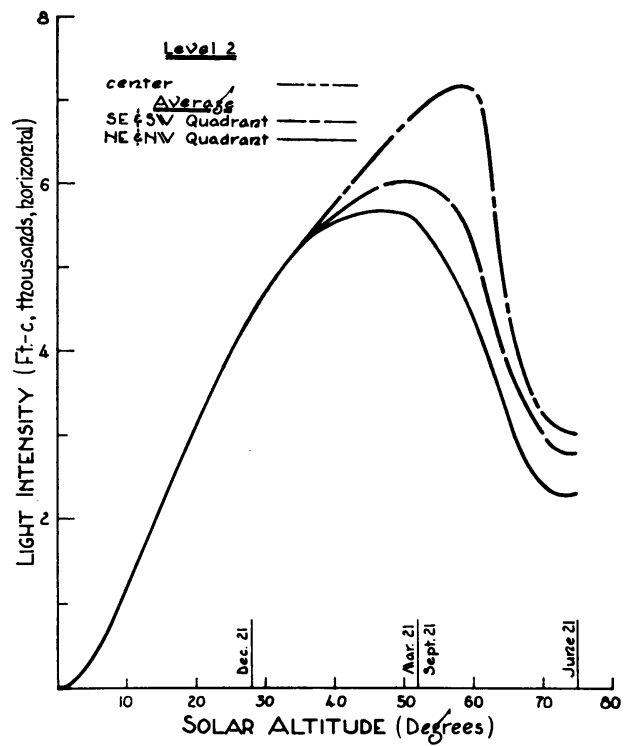

Fig. 22. Sunlight intensities in small room, with glass-block roof, orientation $\mathrm{N} \rightarrow \mathrm{S}$, only "south" side transparent, meter at level 2. Elevation $23^{\circ}$. All data from manual rotation.

figuration may be better for plants with a low threshold of light intensity even though the percentage of outdoor light provided is less than for the $\mathrm{N} \rightarrow \mathrm{S}$ orientation (except for midsummer). For plants with higher light saturation values, for which the total ft-c hours per day is probably a better indication of growth potential, the $\mathrm{N} \rightarrow \mathrm{S}$ orientation is unquestionably superior, as estimated from these figures. However, the fact that the $\mathrm{N} \rightarrow \mathrm{S}$ orientation produces greater inequalities of light intensity over the room area than does the mixed orientation detracts from its practical value. The relatively constant percentage of outdoor light over the year is of interest in some cases, especially for the $\mathrm{N} \rightarrow \mathrm{S}$ orientation. This feature could be significant for certain problems in which imitation of outdoor light relations over the season was important. The average value of over 30 per cent is significantly high, and the daily curve is similar in shape to the outdoor curve.

In the small room, higher maximum values were attained, with values appreciably lower for summer than at other seasons because of the sloping roof; at equinox and the winter solstice, the values are much higher than in the large room at a 3 -foot distance (winter values presented were taken on February 1 , and are thus somewhat different from what they would be on December 21). On the average, rotation greatly increased values of irradiation over those for the stationary room, especially for summer and equinox. In winter, when azimuth angles of the sun deviate least from south, values for the rotating and stationary positions are closest. Inclination of the roof at $23^{\circ}$ greatly increased the percentage of outdoor light in winter and at equinox, but decreased this value in the summer. Rotation increased these values from about 35 per cent (winter) to 130 per cent (summer). Thus, 53 to 83 per cent of outdoor sunlight can be brought inside such a rotating room, with the lowest daily energy value (30,100 ft-c hours in winter) almost as great as the highest value $(35,500 \mathrm{ft}-\mathrm{c}$ hours in summer) obtained with the large stationary room with a flat roof. At other seasons, the corresponding values are nearly twice the highest value in the large room and at all seasons, corresponding values are from 1.7 to 2.6 times as great. The sloping roof tends to equalize the total daily light energy over the seasons, allowing admitted light as a percentage of outdoor light to vary almost threefold, being highest for winter. This relationship is the reverse of that for the flat roof, especially for $\mathrm{N} \rightarrow \mathrm{S}$ orientation and, to a lesser degree, for the mixed orientation. Rotation of the small room increased all values appreciably over the stationary situation. The benefits of this feature appear promising for future development, since availability of higher intensities over all seasons would make possible year-long use of such a room and more rapid experimentation with plants. 


\section{METHODS OF LIGHT CONTROL}

Photocell control. The phytotron room was wired with 36 outlets distributed on the walls around the periphery of the roof in eight groups. These were activated by six magnetic relays, and each controlled six lamp circuits, each with its own toggle switch. Interchangeable circuits provided maximum flexibility in the position of each lamp and in the time sequence of operation. A Minneapolis-Honeywell light-saver system for control of inside space illumination was installed to maintain a minimum light intensity at plant level, adjusted for any value below the full output of the light system. When sunlight was available above a single intensity step, and the regulated total in- tensity was less than the total light output a single group of lights would be turned off by the light-saver. The regulated level could be set higher than the light capacity, but below maximum sunlight values. Thus sunlight was supplemented by incandescent lights only when necessary, at early or late hours or when clouds obscured the sun. Figure 23 shows a typical daily cycle of operation for the two systems of incandescent lights studied. The photocell control was more sensitive with the Quartzline lamps when lower intensities per step were involved. Under this arrangement the control photocell received less than $450 \mathrm{ft}-\mathrm{c}$ and responded to a change in the room of less than
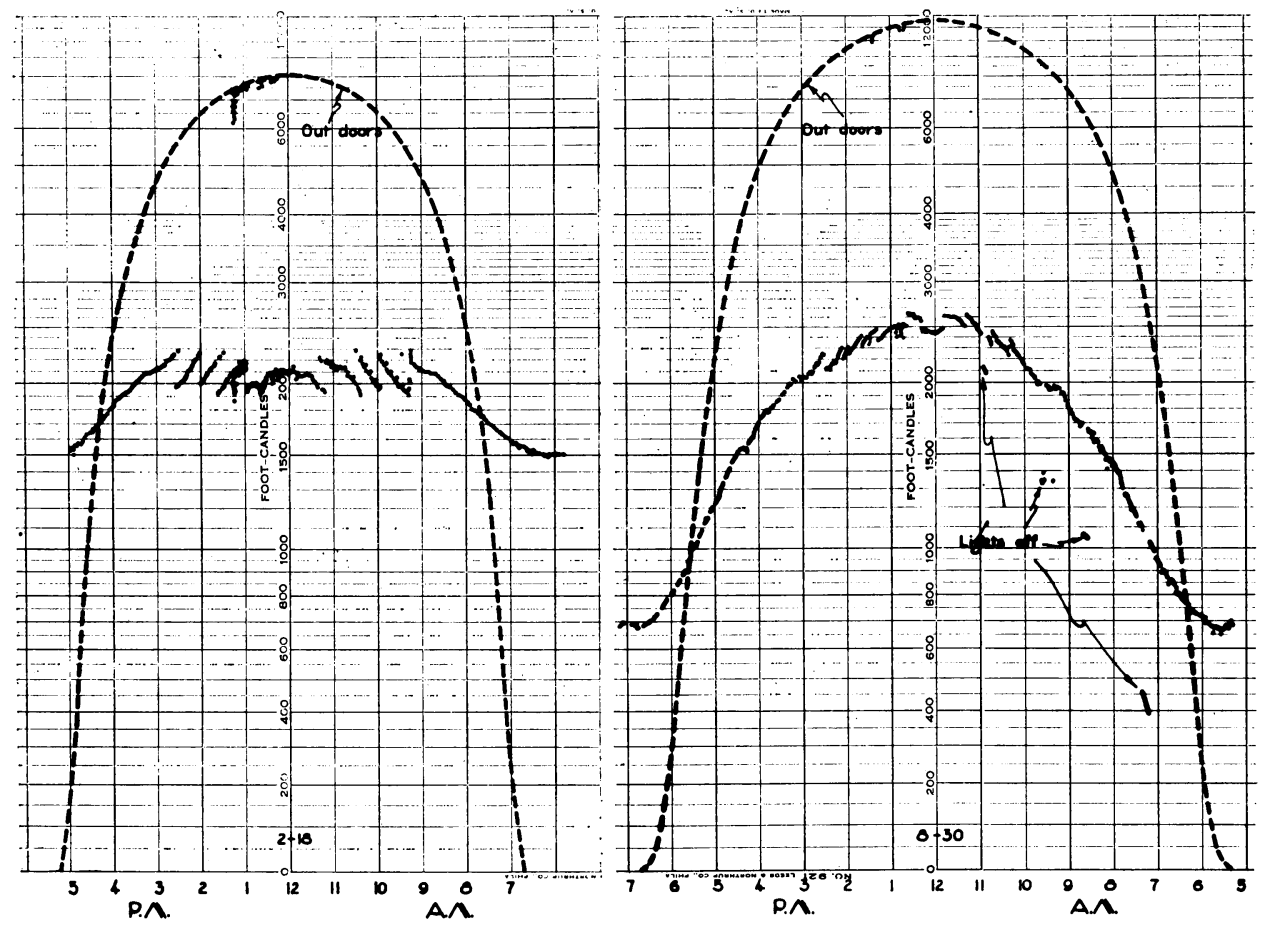

Fig. 23. Typical light-intensity recordings for sunlight supplemented by incandescent light. Short-term decreases caused by small clouds may be noted in early p.m. portions of both curves. Left: Light-saver set for minimum intensity of 2,000 ft-c when sunlight permits. Incandescent lights (thirty-six 1,500-watt lamps without reflectors) alone produced 1,500 ft-c. Changes were approximately $400 \mathrm{ft}$-c per step. Right: Light-saver set for minimum intensity of 2,400 ft-c when sunlight permits. Incandescent Quartzline lamps (twenty-four 500-watt lamps in reflectors) alone produced 750 -ft-c. Changes were about $125 \mathrm{ft}$-c per step. For about 40 minutes at midday all lights were off. 
150 ft-c. This control system is very flexible from the standpoint of intensity ranges and minimum values involved.

The best system of light regulation was obtained by having the light-saver photocell "look" downward through a series of wire screens at a large $\left(81 / 2^{\prime \prime} \times\right.$ $\left.11^{\prime \prime}\right)$ white horizontal surface near the plant level which would sample adequately the light from all sources and directions involved. Different intensity levels required different screens and different electrical settings of the sensitivity knob of the light-saver circuit. The light-saver operated six switches, one for each relay in the lamp circuit. The delay device permits adjustment of the time between intensity decrease and operation of the lamps to prevent action by very small clouds in the sky. The delay from maximum "on" to full "off" may vary from one to many minutes.

Incandescent light. The first lights installed were 36 incandescent tungsten filament lamps, 1,500 watts, 120 volts (bulb PS-52, clear, Class C, Filament C-7A), without reflectors. Suitable reflectors would have been so large as to obstruct sunlight. The filament temperature was $3,033^{\circ} \mathrm{K}$ at the rated voltage. The lamps were mounted inside the room on all four sides of the roof periphery in such a way that admission of sunlight would not be appreciably obstructed. They were inclined downward at an angle of $55^{\circ}$ with the vertical. At night, with all lamps on, intensity 4 feet from the roof varied from $1,400 \mathrm{ft}-\mathrm{c}$ at the center of the room to $3,000 \mathrm{ft}-\mathrm{c}$ in the corners. With this arrangement, a high roof is necessary to achieve uniformity over the lower areas of a room this size. The lights produced approximately 1,500 ft-c (1,260 true ft-c) at the plant level (4 feet from floor) with the same measured total radiation equivalent to 8,200 ft-c of sunshine. Within each group monitored by the light-saver, the lamps were distributed to irradiate the room as equally as possible.

In this room, voltage relationships were such that a minimum of $120 \mathrm{v}$ was reached when 24 lamps were on. With smaller numbers of lamps, the voltage ranged up to the normal $124 \mathrm{v}$ with no lamps on.

A plant-growth experiment with these lamps has been reported by Zscheile, Drever, and Houston (1962), illustrating the light-saver action of the experiment and the visible-infrared relationships under practical conditions of plant experimentation.

This system incidentally provided an excellent heat load to test the refrigeration system and heat-exchange relationships of the entire structure. Considerable light escaped through the roof, as was apparent at night. Readings directly over the roof indicated 500 to $1,600 \mathrm{ft}$-c (average, about 1,000 ft-c) about half the bench-level readings inside. The white "dark" curtain reflected back sufficient light to increase the intensity 8.5 per cent at 8 feet from the ceiling, measured at night. The lamps darken quickly in service as a result of tungsten deposits on the glass bulbs. In our experience this caused a major decline in light intensity at the plant level (20 per cent in several weeks' practical operation). Intensities of 475 ft-c decreased 2 per cent as a result of voltage drop when one $71 / 2$ h.p. compressor was operating, and 1,500 ft-c decreased 65 ft-c, or 4.3 per cent, when two such compressors operated, in spite of the fact that heavy wires supplied the electrical system.

The second system of lights consisted of 25 Quartzline lamps (500-watt) equipped with white porcelain enamelon-steel circular reflectors (13/8-inch radius), in custom-built mountings arranged as in figure $7 \mathrm{~A}$. The sizes of reflectors were compared critically for light distribution on the floor area with a minimum on the walls. Care must be 
taken to avoid placing the lamp at the center of the circular reflector, for reflected radiation would soon melt the filament. Reflectors at the walls are turned to reflect light into the room and not onto the same wall. They produced $650 \mathrm{ft}-\mathrm{c}$ (610 true ft-c) at the plant level (4 feet from floor). Six groups of four lamps each were operated by the light-saver to grow sugar beets. They produced an intensity pattern over the area of the room at plant level (50 inches from floor) as shown in table $2 \mathrm{~A}$. The efficiency of this newer system of easily-focused lights (Quartzline, $50 \mathrm{ft}-\mathrm{c}$ per $\mathrm{kw}$ ) is shown by the factor of 1.8 for new bulbs (bulb PS-52, $28 \mathrm{ft}$-c per kw) and 2.2 for "average-age" bulbs (23.4 ft-c per $\mathrm{kw}$ ) in the ratio of $\mathrm{ft}$-c per kilowatt when compared with the earlier 1,500-watt system. Very little light emerges through the roof. The dark curtain increases the intensity at 8 feet from the ceiling by only 3 per cent. This system was installed to demonstrate the usefulness of this type of filament lamp. The larger, 1,500-watt size of Quartzline was not then available for our voltage supply (120 and $208 \mathrm{v}$ ). Simple multiplication of units would permit higher intensities.

These lamps have a great advantage in that their output remains constant for the life of the lamp $(2,000$-hr rating). In our experience some lamps remained free of any darkening for long periods of time. Others, some of the first manufactured, were defective in this respect. We consider their use very promising. In the experiment with sugar beets, 24 lamps provided 1,250,$000 \mathrm{ft}-\mathrm{c}$ hours at the plant level, with nine lamps burning out. Intensities from incandescent lights, operating on a light-saver (6-step) schedule with the sun in August-October, were recorded as $650 \mathrm{ft}$-c minimum during a 16 -hour day and from 2,000 to 3,000 ft-c at midday, when changes were no greater than $110 \mathrm{ft}$-c at a time with bright sun. This schedule was maintained without interruption for 12 weeks. Intensities of 457 ft-c decreased 2.1 per cent when one 71/2-h.p. compressor operated. A light intensity-voltage study was made with a 1,500-watt Quartzline lamp rated at 277 volts. The intensity decreased in a straight-line relationship as the voltage decreased to 242 volts at the rate of 1.26 per cent per volt undervoltage, or 3.5 per cent per 1 per cent undervoltage.

Aluminum roller shade. In plant studies it is often desirable to irradiate plants for a given daily period that may be shorter than the prevailing natural daylength. A dark curtain was devised to shut out sunlight at such times. It was also found desirable to cover the roof at night to minimize (1) dust accumulation, (2) insect attraction to the light from the room, (3) formation of dew on the outside surface, and (4) escape of incandescent light.

A roof curtain must cover the glass area completely. It must be fitted accurately on all four sides to shut out all light when necessary. It should be as simple as possible, and convenient to operate.

Several types of roof coverings were considered including plastic sheets, canvas, roofing paper, plywood, hardboard, and sheet metal. Each had certain weaknesses.

Finally a flexible aluminum garage door with mechanical controls appeared feasible. The shade selected was "Flexalum" (Astrup Co., Cleveland, Ohio). It was 17.5 feet wide and 14 feet long, and consisted of narrow, interlocking aluminum strips. The shade was rolled on a 3-inch diameter tube at the ridge of the roof. A 1/4 h.p. electric motor rolled and unrolled the shade. Both motor and rolled shade were protected by a sheet-metal housing at the ridge of the roof. The edges of the shade were guided in horizontal wooden slots, extending 4 inches on the upper top side and 2.5 inches on the lower, which were 
painted black inside, and were almost light-tight in bright sun. A tighter construction would doubtless make them truly light-tight. Polyethylene-covered wires were stretched from top to bottom of the sloping roof, at intervals, to support the shade. Small cables and counterweights were placed at the lower edge of the shade to facilitate its move- ment down the gentle slope (1 inch in $24)$. The cables ran over pulleys at the eaves to allow the weights to hang down between plate and ground. Fully extended, the shade covered the glass area completely, 6 inches above its surface. The motor could be switched by hand or automatically by a time-clock.

\section{TEMPERATURE AND HUMIDITY RELATIONSHIPS}

\section{Air-flow System}

The air-flow system design and balance were developed with the following objectives: uniform flow in the room; a minimum acceptable temperature gradient within the room; and convenience of heating, cooling, humidification, and exchange of outside air.

Requirements. Air flow across the

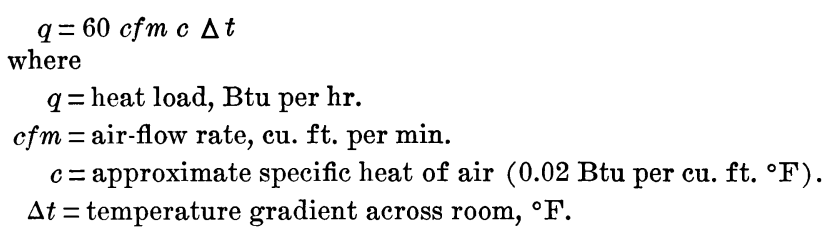

Fortunately, most of the sensible heat from the lights remains near the roof and does not complicate the air temperature at plant level. The maximum heat load at plant levels was observed as that resulting under maximum solar irradiation, estimated, from transmission measurements of the glass blocks, to be 210 Btu per sq. ft. hour for the $\mathrm{N} \rightarrow \mathrm{S}$ orientation. (See report on glass blocks p. 496.) For the room, this load is 210 times 161 sq. ft., the actual glass area of the ceiling (77.5 per cent of total glass panel area), or 33,800 Btu per hour. The plant scientists agreed that a $3^{\circ} \mathrm{F}$ gradient across (variation within) the room (east-west) would be permissible. Using a value of $3^{\circ} \mathrm{F}$ for $\triangle t$, the design air rate was computed (equation 1) as $9,400 \mathrm{cu}$. ft. per min.

Air-flow observations. Air flow was provided by a forward-curved blade fan with a 21-inch diameter wheel, 231/4 room must be of such velocity and flow pattern that each plant in the room will be subjected to the same environmental conditions. The design air rate across the room or the number of room air changes per minute is a function of the permissible temperature gradient across the room, which in turn depends upon the heat load in the room. The equation relating these factors is:

inches wide. The outlet was $285 / 8^{\prime \prime} \times$ $211 / 2^{\prime \prime}$. A 5-h.p. motor drove it at 655 rpm for the initial studies. The air rate was determined by integrating the rate across the refrigeration evaporator face (15 sq. ft.) with a vane anemometer. The air speed varied from 678 to $735 \mathrm{ft}$. per min. (average, $700 \mathrm{ft}$. per min.), thus yielding an air rate of $10,500 \mathrm{cu}$. ft. per min. Static air pressures in the plenum, as inches of water, were: on inlet side (west) of refrigeration coil, -0.175 inch; at fan intake, -0.710 inch; and on pressure side (east) of plenum, +0.170 inch. The air h.p. was computed at 2.09 , indicating a fan efficiency of 42 per cent.

The air-flow pattern in the room under the initial operating condition is shown in figure 24 . These data were secured by measuring the pressure drop across representative holes in the manifold wall (before the plenum was ta- 


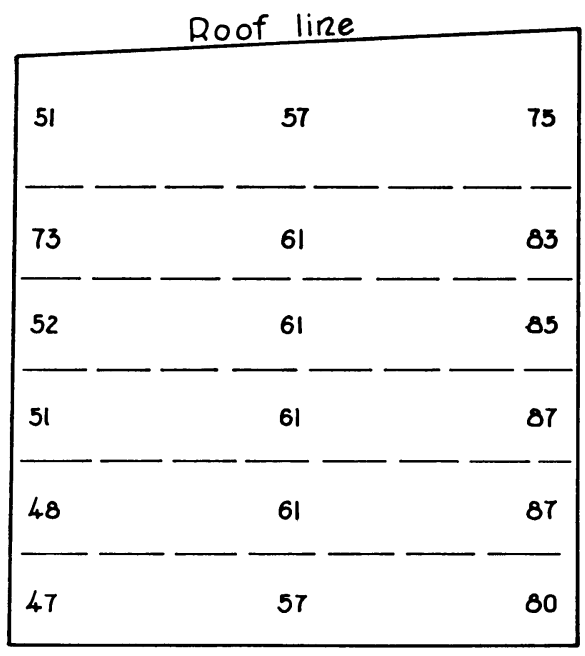

VEST ( Outlet) VALL
Roof line

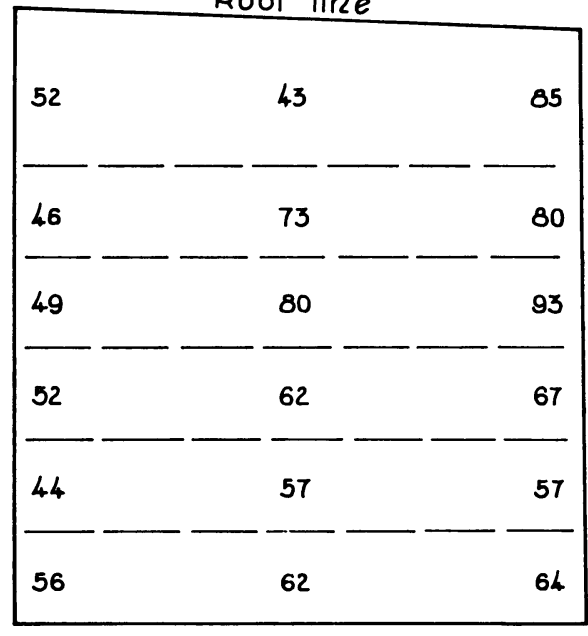

EAST (Inlet) VALL

Fig. 24. Air-flow pattern under initial operating condition. Fan speed $655 \mathrm{rpm}$. Air-duct door completely open. All values in feet per min. near wall surface in open space of room.

pered), computing the air rates through the holes, then referring the rates to the open space in the room. The average rate across the room was $64 \mathrm{ft}$. per min. or $0.72 \mathrm{mph}$. The room is $166 \mathrm{sq}$. ft. in vertical cross-section, which when multiplied by the average air rate, 64 ft. per min., yields $10,600 \mathrm{cu}$. ft. per min. This checks the rate determined at the refrigerator evaporator face. This rate causes the air in the room to be changed 3.8 times per minute.

The optimum air rate past plants in a controlled environment has not been established, but must be at such a level that temperature and relative humidity are essentially uniform in all parts of the room and adjacent to each part of each plant. Some plant scientists consider that the air rate should not be high enough to impart significant motion to plant leaves. The $0.72-\mathrm{mph}$ rate met these objectives-very slight leaf motion was observed occasionally-and is believed to be nearly optimum.

Air-rate and power-input studies were conducted at later dates, since lower air rates would result in lower power costs and less heat from the motor, and reduce noise from air flow. The power input was secured from a watt-hour meter on the input circuit to the project when only the fan was operating. Various fan speeds yielded the following data:

\begin{tabular}{|c|c|c|}
\hline FAN SPEED & AIR RATE & $\begin{array}{l}\text { POWER INPUT } \\
\text { TO MOTOR }\end{array}$ \\
\hline$r p m$ & $c u . f t . / \min$. & $k w$ \\
\hline 655 & 10,600 & 4.25 \\
\hline 505 & 8,150 & 2.00 \\
\hline 419 & 6,830 & 1.30 \\
\hline
\end{tabular}

Basic fan performance relationships are such that on a specific system the air rate varies directly as the fan speed, and the fan input power varies as the cube of the speed. The cube factor holds only approximately for the power input because the motor's efficiency varies with the load.

A number of studies were made of air flow and temperature gradient across the room, with and without artificial illumination, during day and night conditions, with the room either empty or filled with plants. The results were inconclusive with respect to the definition of a fixed gradient pattern, but they did indicate that air flow and tem- 
perature conditions at the plant level were acceptably uniform. Subsequent flow-pattern studies with laboratory smoke showed a turbulent condition from the plants, benches, and lights that mixed the air in such a manner that no specific gradient could exist (fig. 25).

Sensible heat from the lights was concentrated at the roof in an air layer less than 2 feet thick, and thus would not affect ordinary plant-growth conditions.

A fan speed of $505 \mathrm{rpm}$ with an air flow of $8,150 \mathrm{cu}$. ft. per min. was finally decided as optimum for this installation, when all operating factors were considered. Some of the holes in the west wall (air exit) had been covered by tape to equalize air distribution at the west wall in the north-south direction. Tapered ducts in the east wall performed well.

Heating load. The maximum heating demand occurs at night in winter. If a concrete floor on gravel fill, with insulation, is the building base, if walls are insulated, and if a glass-block roof is used, the heat transfer equation may be adapted thus:

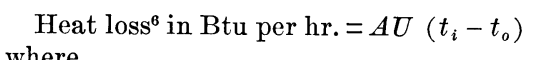

$A=$ element area, sq. ft.

$U=$ over-all heat-conduction coefficient, Btu per sq. ft. hr. ${ }^{\circ} \mathrm{F} .(0.10$ for framed, insulated walls )

$t_{i}=$ room temperature, ${ }^{\circ} \mathrm{F}$

$t_{o}=$ outside temperature, ${ }^{\circ} \mathrm{F}$ (also soil temperature under floor)

$t_{i}=120^{\circ} \mathrm{F}$ and $t_{o}=35^{\circ} \mathrm{F}$. Both were used as representative of design conditions, $35^{\circ} \mathrm{F}$ being the lowest average monthly minimum temperature for Davis. The inside design value of $120^{\circ} \mathrm{F}$ was chosen because it represents maximum summer growing conditions in Davis.

Floor : $18^{\prime} 11^{\prime \prime} \times 18^{\prime} 9^{\prime \prime} \times 0.10(120-55)$

Wall and insulated ceiling areas : 1,120 sq. ft. $\times 0.10(120-35)$

Glass-block roof : $12^{\prime} 5^{\prime \prime} \times 16^{\prime} 9^{\prime \prime} \times 0.55^{7}(120-35)$

Plus 50 per cent (to permit heaters to operate two-thirds of the time when on full load, and to cover unforeseen heating load)

Total

$=2,300 \mathrm{Btu}$ per $\mathrm{hr}$.

$=9,500 \mathrm{Btu}$ per $\mathrm{hr}$.

$=9,700$ Btu per hr. 21,500 Btu per hr.

$10,250 \mathrm{Btu}$ per hr.

DESIGN TOTAL $\quad 31,750 \mathrm{Btu}$ per $\mathrm{hr}$.

Dimensions include all exterior surfaces in the growth room and plenum chamber, combined. A kilowatt of electrical energy will provide $3,415 \mathrm{Btu}$ per hr. Consequently, $9.3 \mathrm{kw}$ were needed. The blower fan motor (fig. 6) is so located that its heat ( 5 h.p. $\times 2,540$ Btu per h.p. hr.), 12,700 Btu per hr., if it were to run at full load, would be used for heating. This, in effect, could reduce the total noted above to 19,050 Btu per hr., or $5.57 \mathrm{kw}$. No attempt was made to estimate the heat load re-

sulting from people or supplementary equipment in the room, even though it is considered significant under certain conditions.

Electrical resistance heating units of $1.56,3.24$, and $4.8 \mathrm{kw}$ were provided. They could be operated independently or in combinations and were connected through relays to a commercial thermostat that can control to $\pm 1.5^{\circ} \mathrm{F}$.

Cooling load. Cooling is a more complex problem because solar heat and artificial illumination heat are added

\footnotetext{
${ }^{6}$ Heating losses or gains by radiation are not included in our calculations. Their significance will vary with the temperature differential.

${ }^{7}$ See Kimble Glass Co. (n.d.) p. 7. Whittle and Lawrence $(1960 a, b)$ measured an over-all heat-transfer coefficient for glasshouses of $1 \mathrm{Btu}$ per sq. ft. hr. ${ }^{\circ} \mathrm{F}$, which was doubled by a 15 $\mathrm{mph}$ wind. They recommended a value of 1.3 for adequate safety margin with sufficient surface of steam pipes.
} 


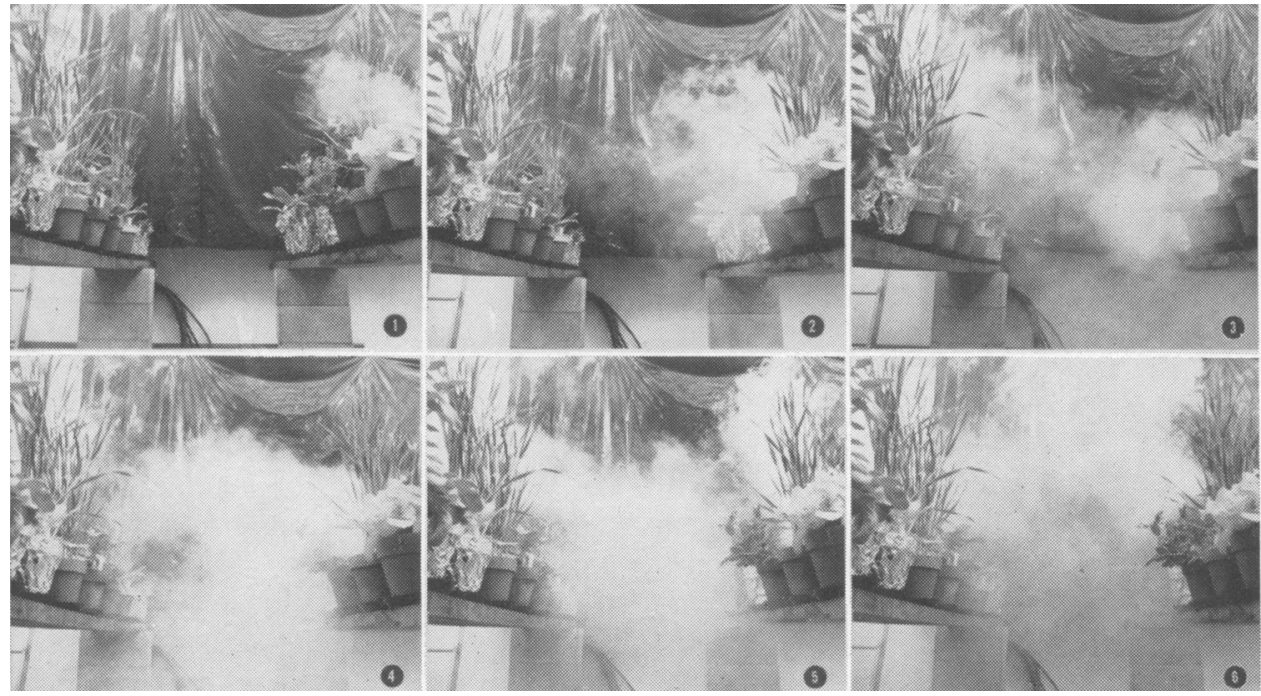

Fig. 25. Rapidity of air circulation in large room shown by smoke bomb initiated at right of pots in photo 1. Air flow was from right to left. Photos were taken approximately one second apart. Smoke originated near east (inlet) wall at bench level. Room quickly filled with smoke, no matter where it originated in the air stream.

to the sensible heat load. The cooling load was computed on the assumption that a $32^{\circ} \mathrm{F}$ room might be operated under $100^{\circ} \mathrm{F}$ outside conditions.

Sensible heat was calculated by equation $(2)$ :
Floor: $18^{\prime} 11^{\prime \prime} \times 18^{\prime} 9^{\prime \prime} \times 0.10(55-32)$

Wall and insulated ceiling areas :

1,120 sq. ft. $\times 0.10(100-32)$

Glass-block roof:

$12^{\prime} 5^{\prime \prime} \times 16^{\prime} 9^{\prime \prime} \times 0.55(100-32)$

Solar heat through roof:

0.775 (glass fraction of roof area) $\times 12^{\prime} 5^{\prime \prime} \times 16^{\prime} 9^{\prime \prime} \times 210^{8}$

Artificial illumination heat: $54 \mathrm{kw} \times 3,415$
$=815$ Btu per hr.

$=\quad 7,610 \mathrm{Btu}$ per $\mathrm{hr}$.

$=7,780 \mathrm{Btu}$ per $\mathrm{hr}$. 16,205 Btu per hr.

$=33,800$ Btu per hr. $=184,500$ Btu per hr.

The total daytime cooling load, which did not include the artificial illumination heat, was 50,000 Btu per hr. The highest cooling requirement, not including solar heat, was 200,705 Btu per hr., of which' 92 per cent resulted from artificial illumination. To this must be added the heat from the fan motor, 12,700 Btu per hour, thus providing a total demand of 213,405 Btu per hour plus 50 per cent (for the same reason noted in the heating computations) or 106,703 Btu per hour.

This is equivalent to 26.6 tons of refrigeration.

Design Total $\quad=320,108$ Btu per hr.

Since considerable experimentation was anticipated on the subject of the amount of incandescent radiation required by plants and how to supply it in the most efficient manner, two compressors of 7.5 tons each were installed. These would permit control of sensible heat, maximum solar radiation, and approximately 40,000 Btu per hour, or $12 \mathrm{kw}$ of incandescent heat load. For this load we employed twenty-four 500watt Quartzline lamps, but the calculations should suffice for greater incandescent loads if required.

Rates of heating and cooling. The temperature of the air, as measured at

${ }^{8}$ Value calculated for the $\mathrm{N} \rightarrow \mathrm{S}$ orientation from data of Kimble Glass Co. (n.d.) and considerations of section on introduction of sunlight through the single glass block (p. 497). 
emergence and detected by the thermoregulators, may be changed rapidly, although the room walls and contents may require considerably longer to reach thermal equilibrium for the new conditions. In midafternoon of a bright May day (glass-block orientation $\mathrm{N} \rightarrow \mathrm{S}$, fan $419 \mathrm{rpm}$ ), one compressor, operating continuously, lowered the emerging air temperature $16^{\circ}$ $\mathrm{F}$ per hr. (from ambient $76^{\circ}$ to $38^{\circ} \mathrm{F}$ ). The heating rate (from $38^{\circ}$ to $73^{\circ} \mathrm{F}$, ambient $65^{\circ} \mathrm{F}$ ) on a similar day, in early afternoon, was about the same with $9.6 \mathrm{kw}$ of heat. In midwinter, on a cloudy day, this same quantity of heat $(9.6 \mathrm{kw})$, with fan speed $505 \mathrm{rpm}$, raised the air temperature at an average rate of $5^{\circ} \mathrm{F}$ per hour (from ambient $60^{\circ}$ to $120^{\circ} \mathrm{F}$ ). In reducing temperature from $120^{\circ}$ to $46^{\circ} \mathrm{F}$ (ambient $48^{\circ}$ to $54^{\circ} \mathrm{F}$, cloudy morning of November 30 ), an average cooling rate of $42^{\circ} \mathrm{F}$ per hour was obtained with the room empty.

The temperature of the air emerging from the room is probably the best indication of the effective leaf temperature, since under these conditions air convection is doubtless the most significant means of heat removal from the leaf; this latter conclusion was also reached by Wolpert (1962), from theoretical studies, and by Ansari and Loomis (1959) from experimental measurements. Thus leaf temperatures may be changed rapidly in the room, even though thermal "equilibrium" within the entire system requires a considerable time.

Removal of heat from lights. The maximum heat from the lights represents 95 per cent of the total cooling demand. This engineering feature must therefore receive considerable study because of its impact on both initial and operating costs and possible operating management complications. Numerous procedures or devices may be employed to minimize or solve this problem.

Artificial irradiation for plant growth can be provided most simply by incandescent lamps or a combination of incandescent and fluorescent lamps. The combination is superior from the standpoint of heat added to the room because fluorescent lamps are more efficient than incandescent lamps, and their ballasts can be located externally, thus dissipating considerable heat outside the room. Because of certain disadvantages, however, fluorescent lamps were not included in this study. They require a large area for mounting; their intensity decreases continually with age; and their performance varies with ambient temperature. Installation of these lamps is not physically compatible with the admission of sunlight.

Filters can be used to remove a significant portion of the undesirable longwave radiation produced by incandescent lamps. A 2-inch layer of water will remove about 85 per cent of the radiant heat produced without depleting the amount and quality of the useful illumination. If refrigeration is required for removing heat from the water, the same amount of heat could be removed from the room air by the refrigeration machine without complicating details necessary to confine and circulate the water. This was done in the light experiments described here. Thus, the only advantage of the water filter is that much of the long-wave radiation is not permitted to impinge on the plants under study. A water filter of reasonable thickness would not reduce infrared to zero. Since any possible long-wave ( $>$ approximately $800 \mathrm{~m} \mu$ ) effect upon plant growth is not well known, the utility (beyond comfort of the worker in the growth room) of a water filter within the room is questionable. We have not studied construction of water filters to this date, but we anticipate considerable difficulty in their practical use with incandescent lights that will be economically advantageous on a large scale.

Coated glass filters that have wavelength selectivity are available. Technically, they can meet the require- 
ments, but the filter size currently available is inadequate for our purpose, the coating is not sufficiently stable, and cost is high.

Controlled local ventilation can remove a portion of the circulating air most intensely heated by the lights. Studies on temperatures of air discharging from the west wall ducts (fig. 9 ) showed that the hot air from the lamps stratifies near the roof, and is handled mainly by the top section. Only a small temperature gradient exists from channel 1 to 5 when many lights are on; in sunshine it is negligible.

Table 3A presents air temperatures observed at the exit ducts under many conditions of regulated temperature and solar and artificial light loads when the outside temperature was high. This demonstrates the capacity of the refrigeration system and the range of conditions available in this room. It is also apparent that faster fan speeds are more effective in reducing temperature differentials. The high temperature differentials between the upper two ducts and the lower five, with artificial lighting, suggest that much heat from the lamps could be removed from the air conditioning system by a suitable exchange of hot air from duct 7 for fresh outside air at ambient temperatures.

The vents in the west wall (figs. 6 to 10) were designed to remove a portion of the heated air. With the gate from the upper duct closed and both vents open, the pressure differential between the outside air and the west (exit) plenum is adequate to cause air to flow into the building and a like quantity to escape through the upper vent in the growth-room wall.

Tables $4 \mathrm{~A}$ and $5 \mathrm{~A}$ present temperature differentials across the room and across the cooling coil under different light conditions at the ends of the "off" and "on" phases of the refrigeration cycle. Mercury thermometers were placed in holes in the pegboard, where radiant heat could not strike them directly from the lamps or sun. The maximum range and differential found with sunlight are doubled when the 36 lamps operate. These are functions of the heat load. The ranges in time at the inlet and outlet are essentially identical, indicating the relationships of the surface of the cooling coil to the refrigeration capacity and the air volume through the coil, and showing the adequacy of the refrigeration capacity with the vents open.

With lamps operating on hot days, temperatures as high as $135^{\circ} \mathrm{F}$ have been observed in the exit air from the upper vent on duct 7 . On a cool day ( $55^{\circ} \mathrm{F}$ outside; foggy, no sun) in February, 35 (1,500 watt) lamps were left on for two hours with vents open but with no refrigeration. The air temperature in exit duct 3 increased $28^{\circ} \mathrm{F}$. The entrance-exit temperatures were $84.5^{\circ}$ and $88.5^{\circ} \mathrm{F}$. The air leaving through the vent was $128^{\circ} \mathrm{F}$. When two compressors were turned on, the air temperature of the room decreased $5^{\circ} \mathrm{F}$ in 10 minutes.

The following observations were made on June 8, 1961, at 7:15 p.m., with twenty-three 500-watt lamps operating and both vents completely open:

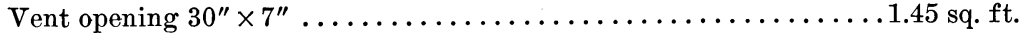

Air velocity through vent (by vane anemometer) $\ldots \ldots \ldots \ldots \ldots 467 \mathrm{ft}$. per min.

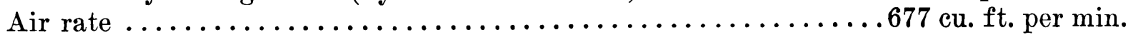

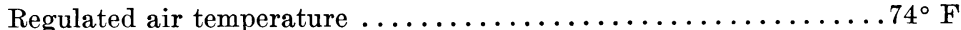

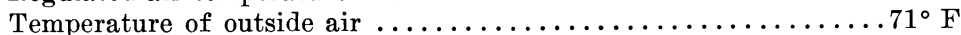

Temperature of air leaving building $\ldots \ldots \ldots \ldots \ldots \ldots \ldots \ldots \ldots .5^{\circ} \mathrm{F}$

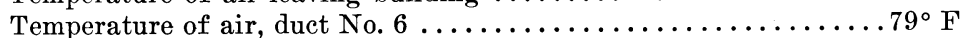

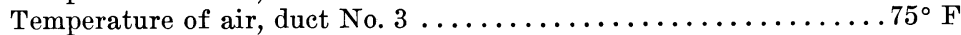

Heat from lights $=23 \times 0.5 \times 3,415 \times 0.89 \quad=35,000 \mathrm{Btu}$ per hr.

From equation (1), heat removed by vents : $60 \times 677 \times 0.02(83.5-71)$ 
These data indicate that 29 per cent of the heat produced by the lamps was removed by the vent system under these conditions. The portion removed could be increased by raising the flow rate with an additional fan at the exit vent. These studies also indicated that the procedure could be improved and would be reasonably effective. High humidities could not have been maintained with such a high rate of air exchange.

Extensive exchange of air intensifies the problem of humidity control, since the moisture removed with the discharging air must be replaced by a humidifier. The outside air temperature is usually different from that in the room, and additional heating or cooling energy is needed to bring it to room conditions.

Consequently, since equipment and operating complications would tend to negate the over-all benefits, additional studies directly along these lines were not considered but effort was directed toward mounting lights outside the room and filtering out much of the radiant heat with water filters.

The outside air is a continuous source of insects and detrimental organisms that can destroy the effectiveness of a controlled study of plants; suitable filtering of air would control this problem.

Carbon dioxide requirements of plants were not studied, since sufficient air for $\mathrm{CO}_{2}$ renewal was easily admitted from the west vent, and roof leaks let out enough air for the limited plant populations studied to date.

Humidity control. Humidity is defined as pounds of water vapor per pound of dry air. Relative humidity is the ratio of water vapor pressure in the air to the water vapor pressure if the air were saturated at the same temperature.

Plant scientists at Davis generally agree that the humidity level in growth rooms may need to be raised frequently, but that a reduction in humidity will seldom be required. Dehumidifying installations for large-scale growth rooms are not generally recommended. A small-scale experiment that requires air of low moisture content can be conducted in a glass or plastic box to which a small dehumidifier is attached.

Humidity in the growth room is raised by plant transpiration, by evaporation from soil surfaces, by wash water and by spilled irrigation water. It is usually reduced by the operation of the refrigeration system, since the temperature of the cooling coil is usually below the dew-point temperature of the room air, and by ventilation air if the outside air humidity is below that of the room. Figure $8 \mathrm{~A}$ shows the effect of the refrigeration system on humidity when humidification is not occurring.

Moisture can be added to the air in the room by injecting steam into the air stream, by atomizing water either with high-pressure air or by a highspeed wheel, by spraying water onto a hot plate, thus forming steam, or by forcing air through wet pads to cause evaporation. Each method is controlled by a humidistat which brings the device into operation when moisture is needed. Such devices are available commercially.

We used an atomizing wheel-type humidifier (Model WJ, duct type, Walton Laboratories, Inc.), with measured adjusted capacity 6.05 pounds water per hour. This type of unit (available from a number of companies) ejects a very fine mist which evaporates promptly into the air. The unit was located 4 feet above the floor in the fan plenum ahead of the fan, and was controlled by a Minneapolis-Honeywell humidity controller, Model H63A (hair element-type, 2 per cent differential) located near discharge duct 3 of the west wall in the west plenum.

The following equation defines the humidifying (or dehumidifying) process: 
where

$$
w=c f m \times 60 \times 0.075\left(H_{2}-H_{1}\right)
$$

$w=l b$. moisture (water) required per $\mathrm{hr}$.

cfm $=$ air rate, cu. ft. per min.

$0.075=$ approx. wt. (lb.) of a cu. ft. of dry air

$H_{1}=$ humidity of air entering system (lb. water per lb. of dry air)

$H_{2}=$ desired system humidity (lb. water per lb. of dry air)

The equation implies that outside air is entering the room at a rate specified by $c f m$, and that it is a tight room in which the volume would be represented by $c f m$, and moisture would be removed either by refrigeration absorption or some other process as defined by $H_{2}-H_{1}$.

Humidifier capacity $=6.05 \mathrm{lb}$. water per hr. $=c f m \times 60 \times 0.075(0.0106-0.006)$,

from which $\mathrm{cfm}$ is 292 . This computation does not allow for air leakage around doors, utility service vents, and other points.

A small vent in the west plenum wall, $3^{\prime \prime} \times 83 / 4$ " provided a measured air exchange of $172 \mathrm{cfm}$. Humidification was as noted above. A vent $63 / 4^{\prime \prime} \times 7^{\prime \prime}$ with an estimated air exchange of $310 \mathrm{cfm}$ did not permit relative humidity to be maintained. With a smaller vent opening $\left(178^{\prime \prime} \times 834^{\prime \prime}\right)$, supplying $>74$ (probably about 100) $c f m$ of exchange air, the humidity was maintained over long periods of time, with the room area planted to sugar beets. About 35 gallons of water were needed per week. Note that a small air exchange can destroy humidity control if humidifying rates are not high.

Control of the humidity within narrow limits is difficult because the air usually dehumidifies whenever the re-
For example, on a summer day when outside air had an $H$ value of 0.006 , relative humidity could be maintained at 80 per cent in a $65^{\circ} \mathrm{F}$ room. $H$ for the room was noted as 0.0106 from standard psychrometric charts. Thus, the air-rate exchange, room to outside air, computed from equation (3) is

frigeration is turned on. A portion of the condensate formed on the cooling coil during that period may evaporate when the refrigeration is off. (See fig. $8 \mathrm{~A}, \mathrm{~B}$.) The humidistat is sensitive to this cycle but will lag somewhat behind it and will reflect the sensitivity tolerance. Also, the humidifying rate shown by the humidifier will usually be different from the dehumidifying rate shown by the refrigerator. To maintain close control by conventional equipment is difficult. Figure $8 \mathrm{~A}$ shows a humidity record of the effect of refrigeration and humidification on room conditions. Techniques are available for providing more uniform air conditions in the situation noted above, but they are not recommended here because of cost and operating complications. The control achieved here is considered adequate for most types of plant-growth experiments.

\section{MISCELLANEOUS STUDIES}

\section{SPECTRAL QUALITY OF LIGHT IN THE ROOM}

The well-known emission spectrum of the incandescent tungsten filament lamp has a maximum near $1,000 \mathrm{~m} \mu$ on a linear wavelength scale, the exact position depending on the filament temperature. About 89 per cent of the total energy lies above $700 \mathrm{~m} \mu$ in the infra- red region. In the spectrum of sunlight (maximum at considerably shorter wavelengths) approximately 44 per cent of the energy lies in the visible region (400 to $700 \mathrm{~m} \mu$ ) and about 53 per cent in the infrared. These emission relationships are shown in figure 26 . 


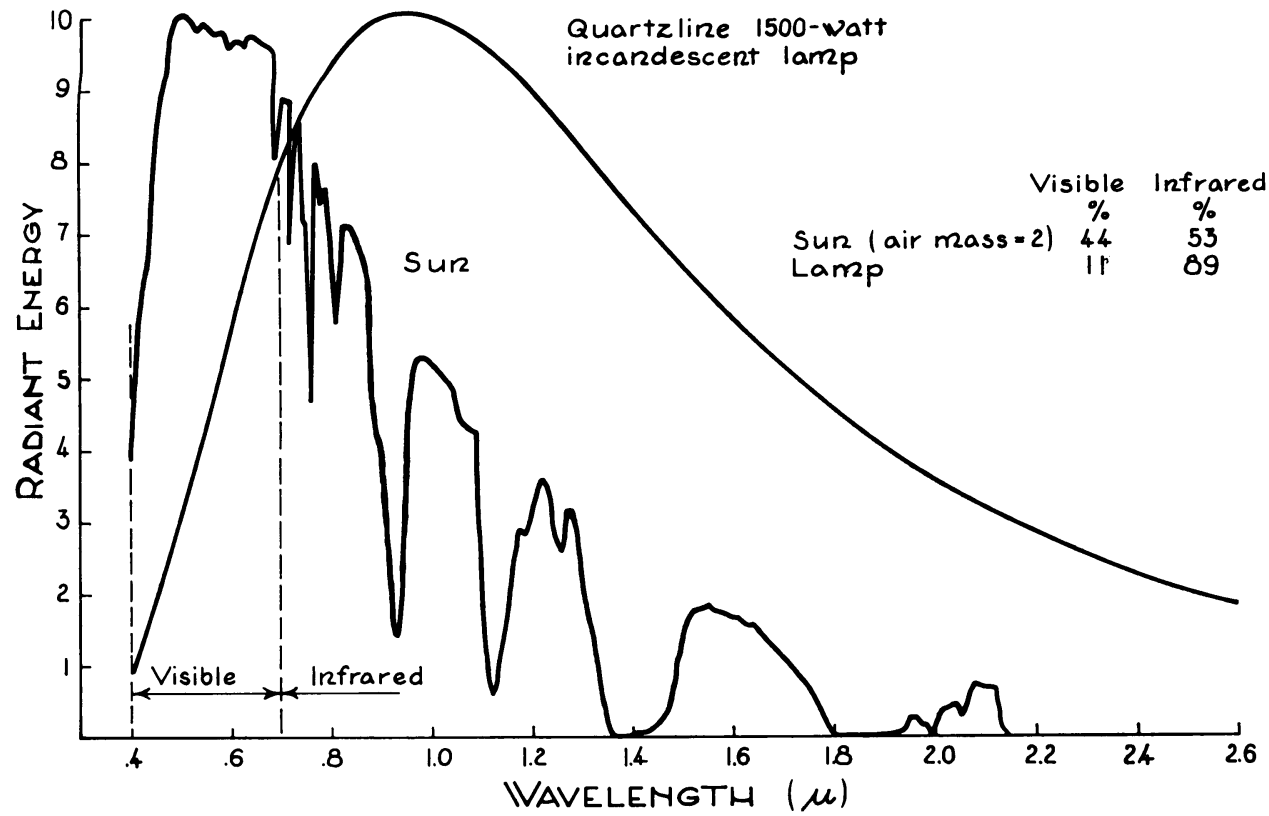

Fig. 26. Relative emission spectra of sun, as received at sea level, and of incandescent filament lamp in quartz envelope. Principal maxima were made identical in energy value for purposes of comparison.

Only the visible region is of importance in photosynthesis, our main concern in phytotron design. The ultraviolet portion (about 3 per cent) of sunlight is absorbed effectively by glass and is of no photosynthetic importance. The region in the near infrared (700 to 800 $\mathrm{m} \mu$ ) is important to plant growth from the photoperiod and developmental standpoint. Both solar and incandescent radiation are so rich in infrared energy, and plant requirements are so low that sufficient intensity will be supplied normally when photosynthesis demands are satisfied. The prime factor, therefore, in our consideration of artificial light to supplement sunlight, is attainment of a similar ratio of visible to infrared radiation. The possible increase of this ratio is of great importance for ease of temperature control in the room, and its economic implications are considerable.

By means of a Beckman Model DK-2 recording spectrophotometer, solar radiation was sampled by an integrating sphere at the 4-foot level (from floor) inside the room, and immediately afterward directly from the sun. It was shown in early September, 1959, that the spectral quality of sunlight (400 to $2,700 \mathrm{~m} \mu$ ) passing into the room through the Toplite glass blocks was changed relatively little, with no sharply selective absorption. The blocks transmit about 80 per cent as much infrared as visible radiation, which is favorable. The ratio of transmitted radiation at wavelength 500 to that at $450 \mathrm{~m} \mu$ remained constant from 10:00 a.m. to 4:00 p.m.

\section{ABSORPTION (VISIBLE vs. INFRARED)}

The removal of the incandescent tors could be cooled in the atmosphere lights to the exterior of the growth room would have great thermal advantages in that the hot bulbs and reflecrather than in the air stream of the phytotron. Furthermore, heat-absorbing filters might then be used effectively 
to remove much of the infrared from the radiation before it enters the room.

Numerous types of glasses, plastics, and liquid filters were studied by measuring their absorption spectra and by taking readings of ft-c and total radiation transmitted from both incandescent and solar sources. Results of the latter are given in table $10 \mathrm{~A}$.

Water appears to be the best filter medium for removal of heat from these light sources. Our measurements are in general agreement with the studies of Curcio and Petty (1951) on the absorption spectrum of water. Probably low concentration of copper sulfate would act as an algicide and also add to the heat-absorbing properties of the system.

A system of water-filled double-pane cells to transmit sunlight was also considered. Geometrical considerations regarding reflection on sides of the vessel contributed to minor inaccuracies in the measurements. (Incandescent radiation was not parallel.) The resulting fractionation values were calculated from measured transmission values of visible and total radiation. For sunlight, 1 inch of water removed one-half of the infrared, but the second and third inches removed only 5.7 per cent for each additional inch. Thus 1 inch would be worthwhile from the filtering standpoint alone, but when the physical difficulties and the lost insulating value of the ceiling or wall are considered, the filtration of sunlight becomes of marginal value.

For incandescent radiation the situation is very different. Here the original proportion of infrared is 68 per cent greater and the fraction of infrared absorbed is 48 per cent greater, making the absorbed values very high. The first inch of water is most important, but additional second and third inches absorb 6.8 and 3.3 per cent, respectively. Filtration of incandescent radiation with 2 inches of water converts the proportion of visible to infrared radiation to essentially the same value as that for unfiltered solar radiation, although the visible region will still not be as rich in the blue region as is sunlight, for the spectral distribution in the visible region would not be changed. Certain glass filters, in addition, could make the incandescent approach the spectral quality of sunlight more closely, although some intensity would be lost. This has been rather effectively done by Elliott, Hysell, and Meikleham (1960).

Coated glass mirrors, of the so-called "hot" or "cold" types, were investigated. Suitable metallic coatings on glass cause hot mirrors to transmit visible light and reflect infrared; cold mirrors transmit infrared and reflect visible light. The hot mirror's only application might be as a transmission filter for incandescent light. Its efficiency is considerably below that of 1 inch of water, but it does decrease the infrared by nearly 50 per cent. Its cost would probably be higher than that of a water filter, and its light transmission is appreciably lower. Moreover, such filters tend to have lower transmission at the blue end of the spectrum, which should not be tolerated for our application.

The cold mirror might be used as a reflector for incandescent lights or as a stationary mirror for the heliostat using sunlight. In the latter case, the mirror increases the visible light proportion by 50 per cent and reflects visible light well. It transmits two-thirds of the infrared, which would never enter the growth chamber. Calculations were made on the combined use of both mirrors, assuming the cold mirror bent in a parabolic shape with the Quartzline lamp at its focus, mounted (outdoors) like the porcelain steel reflector. The infrared transmitted by the mirror would enter the outdoors, while the light and remaining infrared could pass through the hot mirror, with reflected infrared also rejected in part from the growth room. Results, calculated on the assumption that 75 per cent of the orig- 
inal radiation from the Quartzline lamp strikes the reflector and 25 per cent strikes the hot mirror directly, show a favorable proportion of light to total radiation, but with 16 per cent loss of light. This result is not so favorable as for 1 inch of water. Furthermore, present methods do not permit manufacture of curved surfaces for these coated mirrors. The water filter appears by far the best means of reducing infrared content of incandescent radiation.

\section{REFLECTION (VISIBLE vs. INFRARED)}

Reflecting surfaces on the walls are important. Numerous wall-covering materials were studied in search of a highly reflective surface for the visible region (especially at the blue end of the spectrum, where both sources emit relatively little), combined if possible with low infrared reflectance ( 800 to 2,700 $\mathrm{m} \mu$ ). Many materials were studied over a period of two years. The data were taken from recordings of a Beckman DK-2 spectrophotometer measuring total reflectance of incandescent radiation compared with standards of $\mathrm{MgCO}_{3}$ or $\mathrm{MgO}$ in an integrating sphere. The materials tested were suggested by various sources either of high reflectivity in the visible or low reflectivity in the near infrared regions of the spectrum. Five materials had high values $(>88$ per cent) in the visible region: white enamel paint; white porcelain on steel; metallized Melinex (a silver-colored film) ; glass mirror; and specular aluminum lighting sheet. The glass mirror is not practical on a large scale. The aluminum sheet and Melinex reflect infrared so well that their comparative advantages are slight. White porcelain would be the best selective reflector, but it is expensive. We concluded that the white paint was the most practical material for indoor surfaces of large area, where maximum visible reflection is important. Special applications might make other materials more suitable. White enamel proved very satisfactory for reflection of light from the Quartzline lamp. It would also probably be the material of choice for an outdoor reflector of solar energy, of large area, on the north side of a growth room. The infrared-absorbent paint would also be good for this purpose if its low reflectance in the red region were acceptable.

\section{TIME CLOCKS}

Efficient phytotron circuitry required time-clock operation of temperature regulators for day-night conditions, of artificial lights for daylength control, of the dark curtain to shorten daylength, and of light recorders for the effective actual daylight hours. Control was achieved with standard clocks, operating on daily cycles. Humidity changes could also be so regulated if desired. A time clock with automatic adjustment for changing daylength throughout the year (Series $4000 \mathrm{SZ}$ with Astro Dial, by Paragon Electric Co., Two Rivers, Wisconsin) was especially helpful for the light recorder. If temperature or other schedules should coincide with natural daylength, such control could be effected with this clock, which would simply shift electrical activation from one thermoregulator to another at sunrise and sunset. The settings of the regulators thus remain undisturbed and constant.

\section{ROOF-CLEANING PROBLEMS}

An outdoor surface in Davis becomes visibly dusty in a few hours under average conditions. Strong winds and dry weather increase dust accumulation. The most troublesome source of dirt is insects, in our case principally 
bees, which drop pollen. Light transmission is not decreased as much inside the phytotron room as might be expected from a dusty appearance outside. However, a very dusty roof will transmit 5 per cent more light after cleaning. Whittle and Lawrence (1959) reported a decrease of 16 per cent in light admitted by glasshouses following several weeks' accumulation of dirt on the roofs. The roof of our room safely supports the weight of a man, and dust is easily removed with a wet cloth (advisable once a week).

A soil retardant, based on deposit of colloidal silica in microscopic surface pores (E. I. duPont de Nemours \& Co.) was studied. Horizontal and sloping surfaces of glass samples were treated with the retardant suspension, dried in air, and wiped lightly with a cloth while still slightly moist. After two weeks, dirt had settled noticeably more on the untreated surfaces. When wiped with a cloth, this retardant does not change sunlight transmission of the glass. However, the relative ease with which the surface could be cleaned by water made special retardants or cleaners impractical.

\section{PLANT-GROWTH EXPERIMENTS}

The large room was tested with regulated air temperatures to make certain that no design feature was harmful to plant growth. The additive effects of light intensity (sunlight) as received in different portions of the room are doubtless related to photosynthesis saturation values. Accordingly, many plants were grown in the summer of 1959 with sunlight only-when such light was near its maximum in the phytotron. Some of these plant experiments have been described by Zscheile, Drever, and Houston (1962).

The effect of considerable infrared from incandescent radiation on plants in a horizontal air stream was not known. Our experiments showed that if the air temperature is controlled, no obvious adverse effects follow exposure to large amounts of infrared radiation from incandescent lamps (equivalent in intensity to 77 per cent of direct summer sunshine and extending over more time per day than sunlight).

In the phytotron, about two-thirds of the total light reaching the plants was from the incandescent lights, which ex- tended the daylength; the remaining one-third was from the sun. About 15 per cent of total outdoor sunlight reached the plants. These plants received the equivalent of about one-half the total outdoor light (quantity per day).

Sugar beets were grown in vermiculite, in 5-gallon cans placed uniformly over the area of the room, from August 8 to November 3, 1961. Some signs of etiolation, such as long petioles, were evident. Incandescent light was supplied to supplement sunlight admitted by the glass-block roof $(2 / 3 \mathrm{E} \longleftrightarrow \mathrm{W}$; $1 / 3 \mathrm{~N} \rightarrow \mathrm{S}$ ) to the extent of 21 per cent of average outdoor values. About 55 per cent of the total light received by the plants was solar. The Quartzline lamps supplied $650 \mathrm{ft}-\mathrm{c}$, and extended the daylength to 16 hours. Day temperature was $73^{\circ} \mathrm{F}$, night temperature, $63^{\circ}$ F. Relative humidity was above 70 per cent. Statistical studies of the yield data did not indicate any great effect of location within the room. ( $R$. S. Loomis and Gary Ritenour conducted this study.)

\section{ENERGY-EXCHANGE FACTORS}

The energy requirements to maintain a controlled temperature within the room must satisfy, at one time or another, the opposition of one, two, or three extremely variable thermal loads, or even of all three at once. These are: 
(1) sensible heat differences across the exterior walls, roof, and floor; (2) energy added from the admission of sunlight through the transparent portions of the roof; and (3) energy added by artificial lights within the room. All solar energy admitted was considered as heat, and effects of solar radiation on the outside temperature of insulated walls was ignored. Although approximately 44 per cent of solar radiation is in the visible spectral region, so little GROWTH ROOM:

Roof (glass block)

Ceiling of air channels

Floor (cement)

South wall

East and west walls

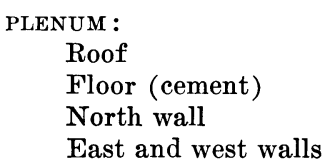

\begin{tabular}{|c|c|c|c|}
\hline & & & \\
\hline & $\begin{array}{l}\text { Subtotal } \\
\text { TOTAL: }\end{array}$ & $\begin{array}{r}642 \\
1,691\end{array}$ & $\begin{array}{r}38.0 \\
100.0\end{array}$ \\
\hline AREA : & \multicolumn{2}{|c|}{ AMOUNT OF HEAT LOST ${ }^{*}$} & $\begin{array}{l}\text { PER CENT OF } \\
\text { HEAT LOST }\end{array}$ \\
\hline Glass roof & \multirow{2}{*}{\multicolumn{2}{|c|}{$\begin{array}{r}209 \times 0.55=115 \mathrm{Btu} / \mathrm{hr} .{ }^{\circ} \mathrm{F} \\
1,482 \times 0.10=148 \mathrm{Btu} / \mathrm{hr} .{ }^{\circ} \mathrm{F} .\end{array}$}} & 43.5 \\
\hline All others & & & 56.5 \\
\hline
\end{tabular}

* $\mathrm{U}$ value is 0.10 for all surfaces except glass roof, for which it is 0.55 .

Note that the roof, which is only 12.3 per cent of the area exposed to the outdoors, accounts for 43.5 per cent of the total sensible heat loss because of its higher $U$ value (Btu per sq. ft. hr. ${ }^{\circ} \mathrm{F}$ ), that is, its lower insulation value. The average $\mathrm{U}$ value for the room was thus calculated as $0.155 \mathrm{Btu}$ per sq. ft. hr. ${ }^{\circ} \mathrm{F}$. This contrasts with the value of 1 or more Btu per sq. ft. hr. ${ }^{\circ} \mathrm{F}$, for conventional glasshouses, as measured by Whittle and Lawrence $(1960 a, b)$. Rooms with lower roofs would have even higher roof percentages but lower total heat losses. These figures provide a basis for cost computations of sensible heat losses in operation. is used for photosynthesis, by plants, that for our present purposes, essentially all is converted to heat within the room, by absorption processes. Likewise, energy liberated in the form of heat by respiration of plants is negligible compared with the energy levels considered here.

The areas subject to heat loss and the sensible heat lost across the exterior surfaces are shown below.

\begin{tabular}{|c|c|}
\hline $\begin{array}{l}\text { AREA } \\
s q . f t \text {. }\end{array}$ & PER CENT OF \\
\hline 209 & 12.3 \\
\hline 25 & 1.5 \\
\hline 237 & 14.0 \\
\hline 245 & 14.5 \\
\hline 333 & 19.7 \\
\hline 1,049 & 62.0 \\
\hline 132 & 7.8 \\
\hline 122 & 7.2 \\
\hline 222 & 13.2 \\
\hline 166 & 9.8 \\
\hline 642 & 38.0 \\
\hline 1,691 & 100.0 \\
\hline $\operatorname{LosT} T^{*}$ & $\begin{array}{l}\text { PER CENT OF } \\
\text { HEAT LOST }\end{array}$ \\
\hline $\begin{array}{l}\text { tu } / \mathrm{hr} .{ }^{\circ} \mathrm{F} \\
\mathrm{tu} / \mathrm{hr} .{ }^{\circ} \mathrm{F} . \\
\text { tu } / \mathrm{hr} .{ }^{\circ} \mathrm{F}\end{array}$ & $\begin{array}{l}43.5 \\
56.5\end{array}$ \\
\hline
\end{tabular}

Over a period of several years, many measurements of solar intensities were made with the Weston sunlight-intensity meter both in the horizontal position and with direct orientation toward the sun, regardless of altitude. Figure $9 \mathrm{~A}$ shows the excellent correlation obtained between the horizontal measurement observed and the value calculated from the observed direct measurement.

Sunlight intensities, measured directly with the meter perpendicular to the sun's rays, vary in this locality during the year. The distance from the sun is least in winter and greatest in summer, with a resulting total intensity difference of 7 per cent. To partially 
offset this effect, more moisture is generally present in the winter atmosphere, causing more scattering of light and absorption of infrared. Dust and smoke in the air are more abundant in the late summer and fall. Hourly fluctuations of atmospheric conditions may sometimes be extreme. When direct sunlight is highly scattered, other areas of the sky may become brighter, and total irradiation at the earth's surface not greatly changed. Windy periods are often followed by the brightest days if the weather is clear. These exceptionally clear days occur more often in spring and fall, sometimes in winter, less often in summer.

In Davis, over a 15-year period, the average maximum (June) total solar radiation was 700 cal per sq. $\mathrm{cm}$. day and the average minimum (December) 125 cal per sq. cm. day. For clear days the corresponding values were 810 and 265 cal per sq. cm. day, respectively. Sixty-two per cent of the days in the average year are clear $(=1.4$ to $1.7 \mathrm{cal}$ per sq. cm. min. at noon), and 80 per cent have more than 50 per cent clear sunshine during the day; 19.5 per cent are cloudy (less than 20 per cent of clear day's radiation). Forty-three per cent of the cloudy days occur in two months (winter). During the 10 bright months, only 12 per cent of the days are cloudy.

Boyd (1958) studied daylight availability for one year in Ann Arbor, Michigan, which has one of the lowest incidences of possible sunshine in the country. He considered 2,000 ft-c a reasonable yearly average for a horizontal surface, with overcast sky conditions. The average horizontal illumination outdoors from 8:00 a.m. to 5:00 p.m. varied from 1,140 ft-c in January to 6,400 ft-c in August, with an average of 3,950 ft-c. Percentage of possible sunshine varied from 31 to 76 .

According to Withrow and Withrow (1956), the highest total sunshine irradiance at sea level is about 1.5 cal per sq. cm. min., or a visible irradiance of $10,000 \mathrm{ft}-\mathrm{c}$; at high elevations in dry air, values 20 per cent higher are occasionally observed. These maxima correspond well with the highest values we have observed. They report the average daily total of solar energy in the United States in summer as 400 to $600 \mathrm{cal}$ per sq. $\mathrm{cm}$. and for the entire year as 250 to 450 cal per sq. cm., depending upon the local climate. Black (1957) quotes a record 14,000 ft-c intensity observed at Cheyenne, Wyoming.

Artificial lights employed here were all of the incandescent hot-filament type. About 11 per cent of the radiation emitted by such lamps at their rated voltages is in the visible region; the remainder is infrared. For purposes of heat calculations, the wattage rating of the lamps is considered to be the heat equivalent. The 1,500-watt lamps used first were rated for 125 volts. Available voltage was 120 to 123 (depending on external load conditions), decreasing the light production and the wattage. When 36 lamps operated, the power drawn was 1,260 watts each. At 5 feet from the floor, at the center of the room, 1,850 ft-c were obtained from the lamps alone. Corrections were estimated for the lamps' radiant energy escaping by intensity measurements of light emerging through the roof at night and by noting indoor changes of intensity when the dark curtain was closed at night, with the lights on. For these lights, the loss is about 15 per cent. For the Quartzline lamps in reflectors, the loss is only about 4 per cent.

Sensible heat losses for the room as a whole were determined at several temperatures by operation of the fan and heaters only. The heaters were controlled by a thermoregulator, for periods of 15 to 18 hours, with curtain open and vents closed, during night periods, with very little daylight time involved, and during cloudy winter weather. The points indicated by $\bigcirc$ in 


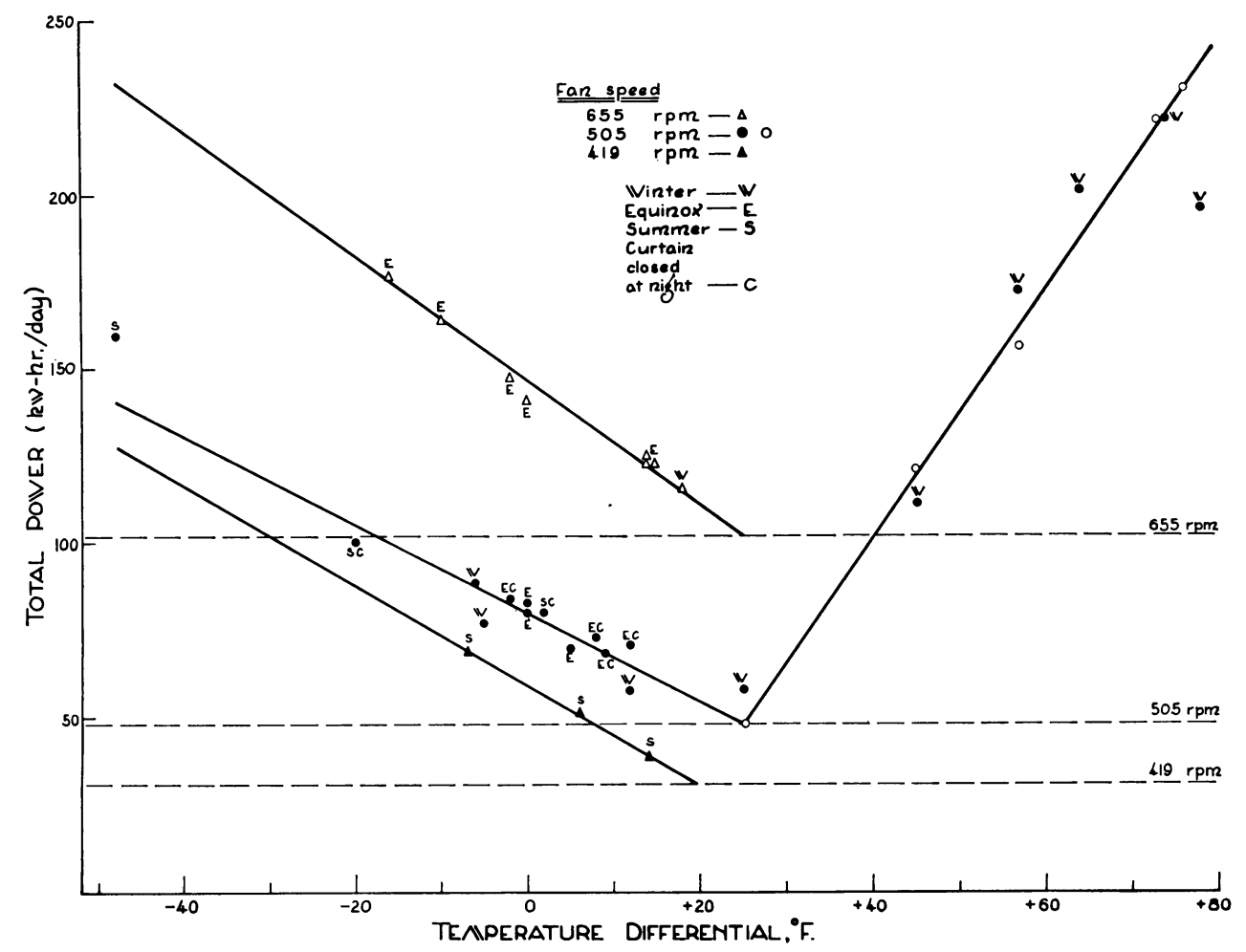

Fig. 27. Power consumption of large room in relation to average temperature differential (between interior and outdoors) at three speeds of fan for air circulation. Heating curve of temperature above $25^{\circ} \mathrm{F}$ was determined at night in cloudy weather (runs of 15 to 18 hours) points represented by ${ }^{\circ}$. Solid points represent runs of 24 to 68 hours under practical conditions of winter weather. Glass-block orientation $2 / 3 \mathrm{E} \longleftrightarrow \mathrm{W}, 1 / 3 \mathrm{~N} \rightarrow \mathrm{S}$. Cooling curves for all speeds represent runs of 24 to 311 hours under daytime conditions of bright sunlight most of the time.

Glass-block orientations:

$655 \mathrm{rpm}: \mathrm{N} \rightarrow \mathrm{S}$, except $-10^{\circ} \mathrm{F}$ point was $2 / 3 \mathrm{E} \longleftrightarrow \mathrm{W}, 1 / 3 \mathrm{~N} \rightarrow \mathrm{S}$

Room temper-

$505 \mathrm{rpm}: 2 / 3 \mathrm{E} \leftrightarrow \mathrm{W}, 1 / 3 \mathrm{~N} \rightarrow \mathrm{S}$

$419 \mathrm{rpm}: \mathrm{N} \rightarrow \mathrm{S}$

atures $\left({ }^{\circ} \mathrm{F}\right)$

40-76

$38-74$

60-100

Air vents closed and roof curtain open unless indicated otherwise by "C."

figure 27 , at the higher temperatures, were the most easily interpreted, since sunlight was not involved. The lower point for $25^{\circ} \mathrm{F}$ was obtained without heating or refrigeration, by recording outdoor and indoor temperatures during a week when only the fan operated. Since the fan motor was inside the circulating air system, its power was entirely converted to heat through motor heat and friction of the air stream. The temperature differential was $25^{\circ} \mathrm{F}$ and its power consumption (505 rpm) 2 $\mathrm{kw}$. These points form a straight line, indicating a power requirement of 3.57 kw-hr. per day ${ }^{\circ} \mathrm{F}$, or 149 watts per ${ }^{\circ} \mathrm{F}$ above the temperature differential from outdoors as a result of the fan heat. Outdoor temperatures were averaged from recordings by the United States Weather Bureau Station at Davis, California.

Rate of heat loss for the room $=$

$\frac{(2 \mathrm{kw} \text { per hr. } \times 3415 \mathrm{Btu} \text { per } \mathrm{kw})}{25^{\circ} \mathrm{F}}=273 \mathrm{Btu}$ per hr. ${ }^{\circ} \mathrm{F}$ at $25^{\circ} \mathrm{F}$. 
This is slightly higher than the value of 263 calculated on page 536 because it includes radiation losses added to sensible-heat loss. At higher temperature differentials, radiant heat becomes more important.

Power consumption for refrigeration operations was measured at all three fan speeds; values are plotted in figure 27. These values were calculated from runs of 24 hours or longer, with bright daylight conditions characteristic of the seasons indicated by the small letters beside each point. Thus considerable sunlight entered the room through the roof during the runs. These values indicate practical working curves under operating conditions. Refrigeration removed heat from the fan, sensible heat, and solar radiation. The straight lines were drawn for best fit to the points available. Their slopes would be identical only if sunlight conditions were constant. Thus, actual values would fall above these lines if greater amounts of sunlight were admitted to the room, and below for darker, cloudy weather or for night conditions only.

The points indicated by a solid dot

$\begin{array}{cc}\text { FAN SPEED } & \mathrm{KW}-\mathrm{HR} / \mathrm{DAY}{ }^{\circ} \mathrm{F} \\ r p m & \\ & \\ 655 & 1.77 \\ 505 & 1.28 \\ 419 & 1.44\end{array}$

Since the refrigeration and fan-power meter had a high capacity, power readings of short duration (less than 24 hours) under normal sunlight conditions were not sufficiently accurate for heat transfer measurements. To provide greater refrigeration loads without extreme temperature differences, incandescent lights were operated within the room, near the peripheral edges of the roof and/or just below the roof, in reflectors. Refrigeration equivalents, in terms of Btu moved out of the room per kw-hr. of power consumed, could then be calculated. The most nearly accurate above $+25^{\circ} \mathrm{F}$ differential indicate similar working runs where only heat was involved. These were for periods of 24 to 68 hours. Sunlight varied considerably among these days-points would fall below the line when sunlight contributed considerably to maintenance of the controlled temperature.

Different temperatures for day and night (differing by $6^{\circ}$ to $11^{\circ} \mathrm{F}$, and quickly attained) were averaged for eight of the points on the refrigeration curve for $505 \mathrm{rpm}$ fan speed. This did not affect their distribution among other points for which one constant temperature was maintained, nor did the closing of the curtain over the roof at night change the power consumption appreciably, although this cannot be strictly evaluated from these data. Four points for the region from $-5^{\circ}$ to $+12^{\circ}$ $\mathrm{F}$ (505 rpm) involved small amounts of heat, for which corrections were made on the refrigeration power values, assuming 12,000 Btu per kw hour refrigeration power.

The slopes of the cooling curves (below $20^{\circ}$ to $25^{\circ} \mathrm{F}$ differential) are as follows:

\begin{tabular}{cc} 
WATTS $/{ }^{\circ} \mathrm{F}$ & HEATING COST \\
\cline { 2 - 2 } & $\begin{array}{c}\text { COOLING COST } \\
\text { RATIO }\end{array}$ \\
73.9 & 2.02 \\
53.3 & 2.79 \\
60.0 & 2.48
\end{tabular}

calculations were made in two runs of 25 and 17 hours' duration, with temperature differentials of $8.5^{\circ}$ and $15^{\circ} \mathrm{F}$, 200 and $154 \mathrm{kw}-\mathrm{hr}$. of incandescent radiant heat, and total thermal loads of 796,800 and $574,500 \mathrm{Btu}$, respectively, with inside temperatures of $73^{\circ} \mathrm{F}$ (day) and $63^{\circ} \mathrm{F}$ (night). The air vents and curtain over the roof were closed, eliminating outdoor influences except transfer of sensible heat and longwave radiation. Quartzline lamps were employed, and a fan speed of $505 \mathrm{rpm}$. For these experiments the calculated values of Btu per kw-hr. of refrigera- 
tion were 12,700 and 12,500 , respectively -in good agreement with the customary value of 12,000 used by refrigeration engineers for the refrigerated temperature range employed in this study.

Lower apparent values were obtained when the dark curtain was open, because sunlight entered the roof and added to the refrigeration load. No attempt was made to assess accurately the Btu contributed by sunlight, although in general, larger sunlight loads were associated with lower values of Btu per kw-hr., and larger incandescent loads with higher values of Btu per $\mathrm{kw}$-hr. These practical values with 36 lamps ranged from 9,000 in daylight to 11,300 at night, with the fan speed 419 rpm; from 8,300 to 11,900 in runs of several days with Quartzline lamps monitored with sunlight and a fan speed of $505 \mathrm{rpm}$; and from 8,300 to
9,900 with the larger lamps monitored with sunlight, with fan speed of 655 rpm.

For one run of 14 days, including one cloudy day, with Quartzline lamps monitored with sunlight to provide a 16-hour day of minimum $650 \mathrm{ft}$-c from lights alone, or 2,000 ft-c with help of bright sunlight, the value was 9,050 . The temperatures were $73^{\circ} \mathrm{F}$ in the day and $63^{\circ} \mathrm{F}$ at night (eight hours); the average differential was $-1.3^{\circ} \mathrm{F}$. The latter run was part of an experiment on the growth of sugar beets. It was conducted during the last two weeks of August, and represented a practical "average" condition with this facility in the summer. Only one day was cloudy. An average of $31,000 \mathrm{ft}-\mathrm{c}$ hours per day of sunlight was admitted through the roof (this did not all reach the level of the plants).

\section{OPERATING COSTS}

The power consumptions per week and approximate costs at Davis (at 1.1

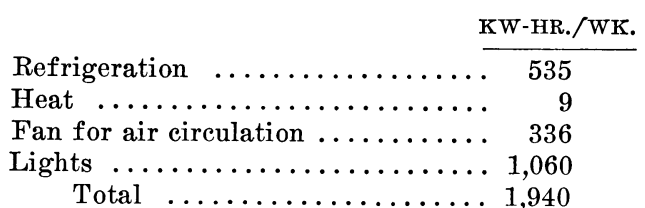

This averaged $\$ 3$ per day. Power for light was 55 per cent of the total. Cost for heat was negligible, and that for removal of heat from sunlight by refrigeration (estimated as about 31,000 ft-c hours or 163,000 Btu per day entering the room) was a small part of the total-about 16 cents per day or $\$ 1.12$ per week. In such an experiment the cent per kw-hr.) for the above experiment were as follows:

\begin{tabular}{|c|c|c|}
\hline KW-HR./DAY & $\operatorname{cosT} / \mathrm{wK}$. & $\operatorname{COST} / \mathrm{DAY}$ \\
\hline 76.5 & $\$ 5.90$ & $\$ 0.840$ \\
\hline 1.3 & 0.10 & 0.014 \\
\hline 48.0 & 3.70 & 0.530 \\
\hline 152.0 & 11.70 & 1.670 \\
\hline 277.8 & $\$ 21.40$ & $\$ 3.054$ \\
\hline
\end{tabular}

cost of fan operation may appear as a major item simply because other costs are so low. Over-all cost of power is very low. The advantage of a wellinsulated room and of sunlight as an economical source of light are obvious. Refrigeration costs were divided as follows:

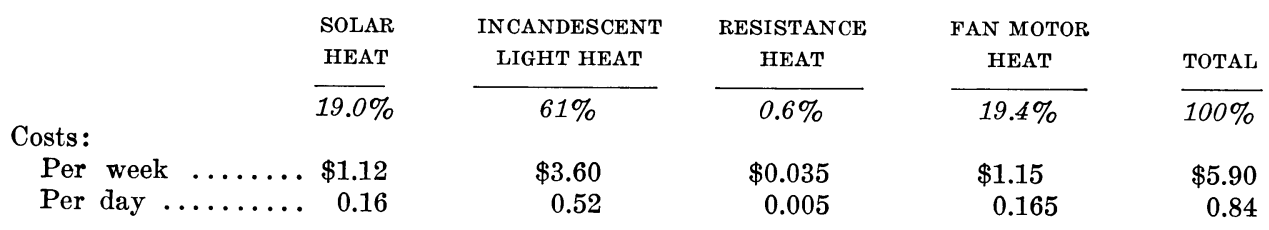

In this experiment, since the net period was small $\left(-1.3^{\circ} \mathrm{F}\right)$, sensibleaverage temperature differential for the heat transfer was neglected in the cal- 
culations above. From figure 27 it may be calculated that for each $-10^{\circ} \mathrm{F}$ average differential the additional refrigeration power requirement would be 12.8 kw-hr. per day, costing 14 cents per day.

It is apparent that removal of heat resulting from admitted sunlight is not the major item in power consumption of such a facility. The operating cost (of refrigeration) for sunlight was 0.515 cent per $1,000 \mathrm{ft}$-c hours for the entire room. In comparison, the incandescent light energy cost 20.3 cents + refrigeration energy of 6.3 cents, for a total of 26.6 cents per 1,000 ft-c hours (at the level of plants, 4 to 5 feet from the floor). Good insulation reduces the power needed for sensible heat, and makes the cost of electrical heating very economical. Fan motor heat could mostly be removed by locating the fan motor outside the plenum chamber. Artificial light, however supplied, is the most expensive part of the entire operation, and the refrigeration of the resulting heat, when internally located incandescent lights are used, is the second most expensive operating cost. The relationship of these factors makes the use of sunlight especially economical. Its heat is often useful in maintaining temperatures above ambient $\left(25^{\circ} \mathrm{F}\right.$ above outdoor in this installation).

Few cost data are available for comparison, but the economies of operation for the two weeks of growing sugar beets in August may be compared, roughly, with those of an experiment described by Davis and Hoagland (1928, table II). Basically, the two sets of conditions are surprisingly parallel. The total light energies and average temperature differences are almost equal. However, for an expenditure of only 4.2 times the electric power used by the small units of Davis and Hoagland, our larger room, 21 times greater in useful area and 54 times greater in volume, was air-conditioned. These factors reflect the better insulation and more efficient light source (solar) in the large room. Such factors can effect considerable savings over a long period of time. In addition, larger plants and a wider variety of problems can be accommodated by such a large room.

\section{Use of Air Vents to Economize on Refrigeration}

Table 6A shows refrigeration power needed to maintain average temperature differentials when different amounts of sunlight and/or incandescent radiation entered the room with air vents open or closed. The areas opened were 7 by 30 inches in the west plenum chamber, to admit outside air, and in the top air duct, west side, center, to discharge inside air; and duct 7 was closed off from the plenum chambers by a door, to promote discard of the heated air from the lamps.

It is evident that admission of fresh air can be very effective in removing heat of incandescent lights, especially when many lights are on continuously and when outdoor air has nearly the same temperature as the regulated value. If air exchange is considerable during dark periods or when outdoor air is very warm, its advantage decreases, and it may even prove uneconomical under certain conditions. We installed a differential thermoregulator to control damper motors that opened the vents when the indoor (duct 7) -outdoor temperature differential was advantageous. However, it proved difficult to regulate and somewhat slow in response.

\section{Labor Costs}

Labor costs for care of such a room are minimal, for all operations may be automatically operated on time-clock schedules. The room described here has been so operated for many weeks at a time, with regulated conditions maintained satisfactorily. The large size of the room permits the same ease in 
caring for plants that is possible in a greenhouse. Fumigation problems are easily solved, and cleanliness is simply a matter of care and attention.

\section{Initial Cost}

The experimental nature and stepwise method of construction necessary for this large room prevent an accurate assay of cost for the room and equip- ment. The cost of many individual items, however, can be determined readily. It is our considered opinion that initial costs for this type of room, based on the square footage available for irradiated plants under experimental conditions, will not exceed that of the conventional growth room lighted with fluorescent light and commercially available today.

\section{ACKNOWLEDGMENTS}

The authors appreciate and acknowledge the help of many people, both on and off the campus, in solving the numerous problems encountered in a project of this kind. We are also grateful for the various gifts of materials.

Members of the Phytotron Committee from 1953 to 1962 were most helpful during the progress of this work. They include: D. G. Aldrich, Jr. (1955-61); S. F. Bailey (1958-60); F. N Briggs (1957-62); V. I. Cheadle (1957-58); J. A. Cook (1961-62) ; A. S. Crafts (1953-62, Chairman 1958-59); L. D. Davis (1955-62) ; B. R. Houston (1955$62)$; L. K. Mann (1953-61) ; L. Rappaport (1961-62) ; P. R. Stout (1961$62)$; A. J. Winkler (1955-61); and F. P. Zscheile (1953-62, Chairman 1953-58, 1959-62).

We especially appreciate the guidance and continual encouragement given by Dean F. N Briggs of the College of Agriculture, Davis Campus, who initiated the work of the Phytotron Committee in 1953, and helped arrange financial support on several occasions when needed most. Vice-President $\mathrm{H}$. R. Wellman, Dean D. G. Aldrich, Jr., and chairmen of the plant science departments helped to provide funds for the early stages of the work. The National Science Foundation (Grant No. G-13525) provided funds to equip the room with humidity and air-exchange controls, to develop the Quartzline light system, to record light-intensity results, and to develop the small rotating and reflector rooms.
Several individuals gave advice and suggestions on technical matters. Mr. Allen E. Baker, Regional Manager, Kimble Glass Co., arranged for a gift of all glass blocks used in the experimental studies. Dr. R. A. Boyd, University of Michigan, who designed the Toplite block, also gave us much useful information.

Professor D. M. Finch, College of Engineering, Berkeley, provided much good advice on lighting problems and calibration of light meters. Mr. Gerry Howard of the Engineering Field Station, Richmond, calibrated the master sunlight illumination meter, which was used as the standard for light measurements throughout the studies.

Dean Roy Bainer, College of Engineering, Davis, and C. F. Kelly, Associate Director of the Experiment Station, have aided and encouraged our work in many ways. We are indebted to Professor F. A. Brooks for many suggestions and references regarding micrometeorology and measurement of radiant energy. Professor H. B. Schultz helped with certain measurements with the Eppley pyrheliometer, and provided us with weather data recorded at Davis. The staffs of both the Agricultural Engineering and Plant Service shops at Davis gave many helpful suggestions, constructed and assembled both rooms and their controls, and installed much of the instrumentation. J. V. Galindo prepared final drafts of the figures for publication; L. H. Hardaker and Sons and D. N. Holt did the 
photographic work. Professor C. O. Chichester, Food Science and Technology, Davis, lent us the recording spectrophotometers and provided technical assistance in the study of transmission and reflection spectra of material samples and the spectral quality of sunlight admitted to the large room through the glass blocks.

For gifts of materials we are particularly indebted to the following:

Owens-Illinois for the glass-block panels and the individual blocks used in the wall of the rotating room. Paragon Electric Co., Two Rivers, Wisconsin, for time clocks. E. I. duPont de Nemours \& Co., Inc., for Soil Retardant Concentrate. Westinghouse Electric Corp., Emeryville, California, for spot lamps for experimental study.

The many generous samples of materials given for study of light transmitting or reflecting properties are acknowledged in the footnotes to tables $10 \mathrm{~A}$ and $9 \mathrm{M}$.

Alberda, Th.

\section{LITERATURE CITED}

1958. The phytotron of the Institute of Biological and Chemical Research on Field Crops and Herbage at Wageningen. Acta Bot. Neerlandica 7(2): 265-77.

American Society of Heating ANd Air-Conditioning Engineers, Inc.

1960. Heating, ventilating and air-conditioning guide, 38th ed. New York. Ch. 13, table 4, p. 187.

ANSARI, A. Q., and W. E. LoOmis

1959. Leaf temperatures. Amer. Jour. Bot. 46(10): 713-17.

BERNIER, C. J.

1962. Measurement techniques for the radiant energy requirements of growing plants. Presented at the National Technical Conference of the Illuminating Engineering Soc., Dallas, Texas, Sept. 9-14.

BLACK, J. N.

1957. The influence of varying light intensity on the growth of herbage plants. Herbage Abstracts 27(2): 89-98.

BOTTLÄNDER, W.

1959. Wirtschaftliche Klimatisierung von Gewächshäusern und Hallenbauten mit Hilfe der

Boyd, R. A. Taschenklappe. Heizung-Lüftung-Haustechnik 10(7): 185-90.

1953. A tabulation of the brightness and transmission data of the Kimble Toplite. Daylighting Laboratory, Engineering Research Institute, Univ. of Michigan, Ann Arbor.

1958. Studies on daylight availability. Industry Program of the College of Engineering, Univ. of Michigan, Ann Arbor, IP-279.

n.d. An analysis of the brightness and transmission characteristics of the 363 block. Daylight Laboratory, Engineering Research Institute, Univ. of Michigan, Ann Arbor.

Boyd, R. A., and J. L. ReID

1954. Daylighting with a new kind of functional skylight. Illum. Engin. 49(4): 199-203.

BraAK, J. P., and L. Smeets

1956. The phytotron of the Institute of Horticultural Plant Breeding at Wageningen, Netherlands. Euphytica 5(2): 205-21.

Carpenter, G. A., and L. J. Moulsley

1960. The artificial illumination of environmental control chambers for plant growth. Jour. Agr. Eng. Res. 5(3): 283-306.

Curcio, J. A., and C. C. PetTy

1951. The near infrared absorption spectrum of liquid water. Jour. Optical Soc. Amer. 41(5): $302-04$.

Davis, A. R., and D. R. HoAGLAND

1928. An apparatus for the growth of plants in a controlled environment. Plant Physiol. 3(3): 277-92.

Ditchman, J. P.

1955. What's happening to horticulture? Light 24(1): 1-8.

Elliott, J. F., R. E. Hysell, and V. Meikleham

1960. Laboratory sun. Jour. Optical Soc. Amer. 50 (7) : 713-17.

HAND, I. F.

1950. U. S. Weather Bureau, Milton, Mass. (January). 
Hiesey, W. M., and H. W. MilneR

1962. Small cabinets for controlled environments. Bot. Gaz. 124 (2) : 103-18.

Hudson, J. P. (Editor)

1957. Control of the plant environment. Butterworths Scientific Publications, London, pp. 1-240.

Kimble Glass Company (subsidiary of OWens-Illinois)

n.d. Prefabricated Toplite panels, A. I. A. File No. 12-J, pp. 1-8.

Life Magazine

1953. Bright blocks. 34(21): 87-90.

1957. School of skylights. $43(21): 119-20$.

LOCKHART, J. A.

1961. Photoinhibition of stem elongation by full solar radiation. Amer. Jour. Bot. 48(5): 387-92.

MatThews, D. J.

1956a. Daylight research house for R. A. Boyd. Architectural Record 120(11): 233-37.

1956b. Make your house come alive with light. Better Homes and Gardens 34(11) : 72-75.

Moon, P.

1940. Proposed standard solar-radiation curves for engineering use. Jour. Franklin Institute $230(5): 583-617$.

Morse, R. N., and L. T. Evans

1962. Design and development of Ceres-an Australian phytotron. Jour. Agr. Eng. Res. $7(2): 128-40$.

PARKER, M. W.

1946. Environmental factors and their control in plant experiments. Soil Sci. 62(1): 109-19.

Platt, R. B.

1957. Growth chamber with light of solar intensity. Science 126(3278): 845 .

Thompson, Boyce

1925. Organization-equipment-dedication. Contributions from Boyce Thompson Institute for Plant Research, Inc. 1: 1-58.

UlRich, A.

1954. Controlled climate facilities for agricultural research. Dept. of Plant Nutrition, Univ. of California, Berkeley. (Mimeo.)

U. S. Weather Bureau Climatological Data, National Summary. U. S. Dept. of Commerce, WASHINGTON, D.C.

WENT, F. W.

1950. The Earhart Plant Research Laboratory. Chron. Bot. 12(3) : 89-108.

1957. The experimental control of plant growth. Chron. Bot. 17. 343 pp. Chronica Botanica Company, Waltham, Mass.

1961. The broad function of a modern botanical garden. Garden Journal (New York Botanical Garden) 11(4): 126-28.

Whittle, R. M., and W. J. C. LAWrence

1959. The climatology of glasshouses. I. Natural illumination. Jour. Agr. Eng. Res. 4(4): $326-40$.

1960a. The climatology of glasshouses. III. Air temperature. Jour. Agr. Eng. Res. 5(2): 16578.

$1960 \mathrm{~b}$. The climatology of glasshouses. V. The heat consumption of glasshouses. Jour. Agr. Eng. Res. 5(4): 399-405.

Withrow, R. B., and Alice P. Withrow

1956. Generation, control, and measurement of visible and near-visible radiant energy. In Radiation biology, vol. III, A. Hollaender (ed.). McGraw-Hill Book Company, Inc., New York. Ch. 3.

WOLPERT, A.

1962. Heat transfer analysis of factors affecting plant leaf temperature. Significance of leaf hair. Plant Physiol. 37(2): 113-20.

Zscheile, F. P., S. M. Henderson, A. S. Leonard, L. W. Neubauer, and I. J. Szluka

1961. New Davis phytotron follows the sun. California Agriculture 15(11) : 1-3.

Zscheile, F. P., H. R. Drever, and B. R. HoustoN

1962. Light quality for plant growth excellent in new phytotron. California Agriculture $16(1): 13-15$

Zscheile, F. P., S. M. Henderson, A. S. Leonard, and L. W. Neubauer

1963. Phytotron modification admits more sunlight through plastic panels. California Agriculture $17(1)$ : 10-11. 


\section{APPENDIX}

\section{CALIBRATION OF RECORDING INSTRUMENTS}

Photocell calibration. To measure visible light intensities, a master photronic photocell (Weston Sunlight Illumination Meter, Model 756) was calibrated against a standard incandescent lamp which produced 2,231 candle power when operated at a color temperature of $3,049^{\circ} \mathrm{K}$. This lamp served for the two lower scales up to 1,000 ft-c. Another lamp was used for the higher scale (to $10,000 \mathrm{ft}-\mathrm{c}$ ), and comparisons were made in direct sunlight, with a previously calibrated photocell having a green filter and a cosine filter. Our master meter with quartz cosine filter, but without green viscor filter, was the reference standard for all work reported here. The cosine filter increases a reading of sunlight by 11 per cent at a solar altitude of $32^{\circ}$ and by 13 per cent at $40^{\circ}$. The green filter customarily used in foot-candle illumination meters was not used here because it de-emphasizes the blue and red ends of the visible spectrum in order to make the sensitivity curve (maximum in the green) match that of the human eye. This curve is directly opposed to the photosynthetic efficiency curve of plants, which has a minimum in the green and maxima in the blue and red regions. Therefore, the unfiltered ft-c reading is more indicative of light's photosynthetic utility to the plant than is the true (filtered) ft-c evaluation. This problem and its relation to plant responses have been discussed by Bernier (1962). The ft-c intensities reported here are thus higher than true ft-c values by 6 per cent for values less than 1,000 ft-c and by 19 per cent for values above $1,000 \mathrm{ft}-\mathrm{c}$.

For readings above 10,000 ft-c, neutral gray glass filters were used, which had transmission factors of 0.66 to 0.42 , and were calibrated with both sunlight and incandescent light. Direct sunlight readings as high as $15,000 \mathrm{ft}-\mathrm{c}$ have been recorded on the clearest days. Simultaneous readings with the meter held horizontal were always recorded; thus all readings within the phytotron structures may be corrected to show the maximum potential intensity values possible if sunlight were available at the maximum intensity. Such readings indicate actual comparative performance at different solar positions. In the interest of practical application, however, most of our observations are reported as made when the sky was reasonably clear. Unless otherwise noted, all radiation intensities were taken with the receiver horizontal and unobstructed by shadows.

For continuous recording of radiant intensities, a Leeds and Northrup Speedomax Recorder, No. 60980, was employed, with four Leeds and Northrup Illuminometers, No. 6580, that could be placed in different locations. This equipment uses Weston photocells of the same type as those in the master meter. The four multicolored pens record for each cell in turn at 15 -second intervals, forming a continuous curve on a chart traveling $1 / 2$ inch per hour and recording directly in ft-c on a logarithmic scale extending to 12,000 ft-c. These photocells are covered with iris diaphragms and have cosine correction filters; only one is equipped with a green filter for comparison purposes. All were adjusted to agree with the master meter to within 2 per cent at 9,600 ft-c. All meters were placed horizontal in open sunlight near midday, and the diaphragms of each meter were adjusted so that the reading agreed with the master meter at a high intensity. All diaphragms can be quickly connected to the same meter for this adjustment. Agreement at higher values can also be achieved by pointing 


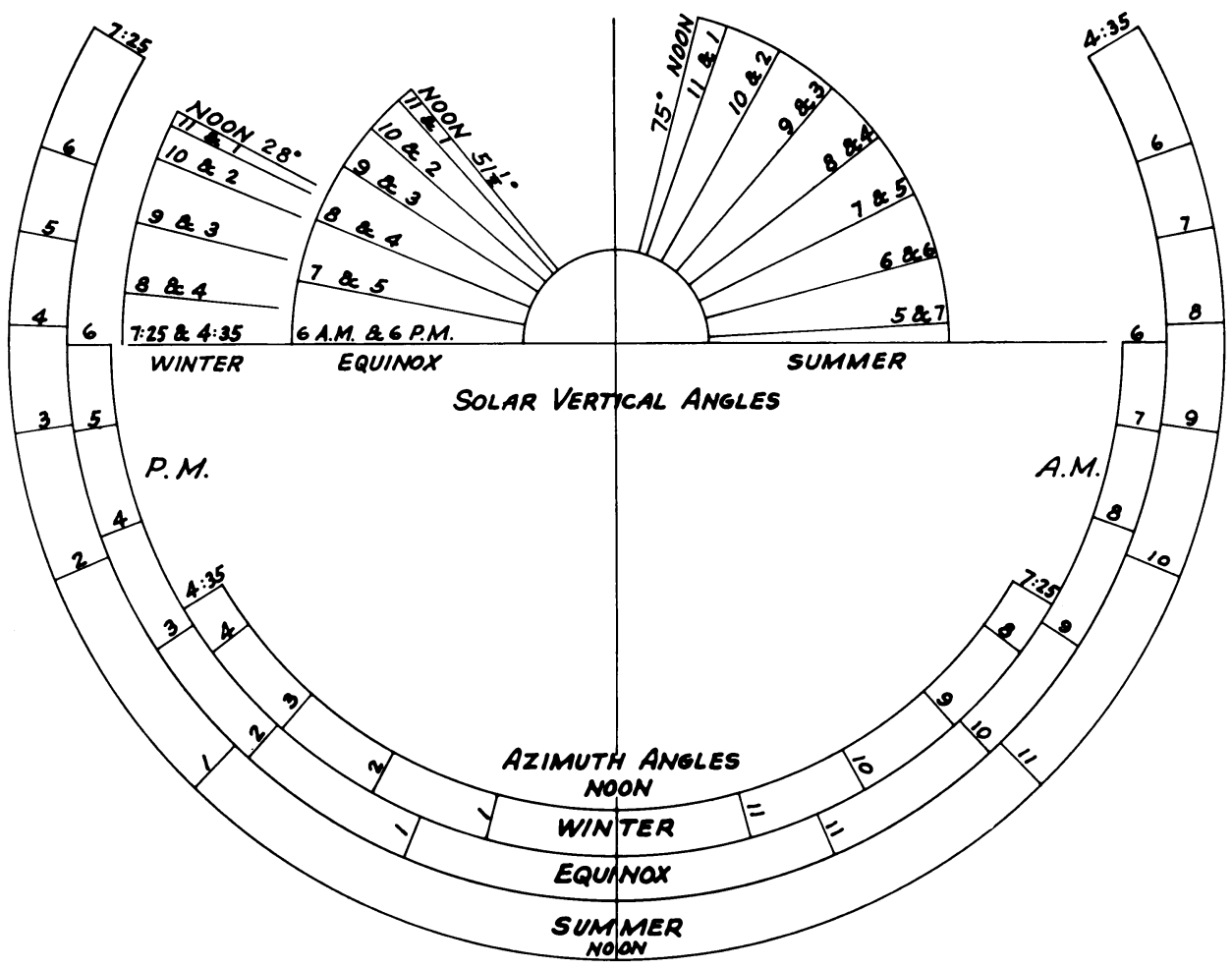

\section{DAVIS, CALIFORNIA}

LAT, 3B! $\frac{1}{2} \mathrm{~N}$.

Fig. 1A. Solar azimuth and elevation angles for the seasons (Davis, California).

the receiver directly at the sun for setting of the diaphragm. All four recordings from the different photocells were superposed during an entire day, following the critical adjustment, and exposed outdoors to sunlight at intensities from 0 to $12,000 \mathrm{ft}-\mathrm{c}$, in late April. This test indicated that, in clear weather, the spectral composition of sunlight does not change sufficiently in the visible region to cause differences in response among the four photocells, with or without the green viscor filter.

Pyrheliometer calibration. Total radiation (light + infrared) was measured with an Eppley pyrheliometer (with hemispherical quartz envelope), at times with a Leeds and Northrup Micromax recorder. Its sensitivity was $2.38 \mathrm{mv}$. per (cal per sq. cm. minute), and the recorder was used at 1.35 to $1.85 \mathrm{mv}$. per (cal per sq. cm. minute).

The master photocell readings as compared with Eppley readings were 9,700 and 10,400 ft-c per (cal per sq. cm. minute) for horizontal and direct sunlight, respectively. Recordings were made outdoors and at different levels in the large phytotron structure. This combination of instruments was very useful for comparing possible materials for window construction as well as filters or reflectors for increasing light intensity and decreasing infrared radiation.

\section{TRANSMISSION OF TOP PLATE}

Figure 2A indicates the amount of light lost because of the lower diffusing plate of the block as compared with that in figure 2 of the text (p. 499). The top 


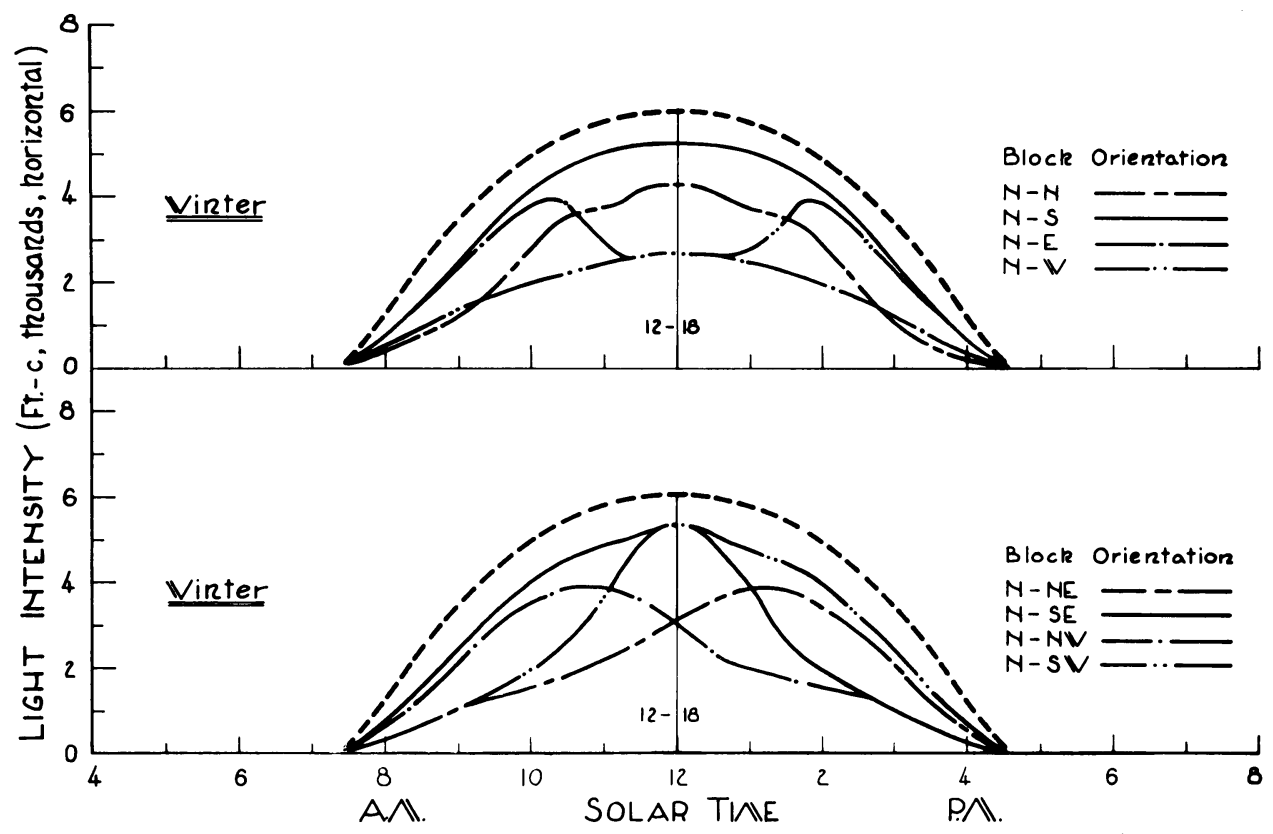

Fig. 2A. Sunlight transmission by top plate of glass block (No. 1180), smooth side up. Winter only. Elevation $0^{\circ}$.

plate alone transmits considerably more light (about 10 to 12 per cent) than does the complete block, but the light is not diffused well by the top plate alone-it is only directed downward in a similar manner. No transmission advantage would result from making the lower layer of plain glass.

The lower (diffusing) plate has the interesting property of transmitting more light in one direction than the other, as measured by placing the meter next to the plate, with both perpendicular to a light beam. Approximately 45 per cent more light is transmitted when the rough surface faces the source (normal usage of the block) than when the smooth surface faces the source.

\section{ADMISSION OF SUNLIGHT INTO HELIOSTAT}

The following table illustrates the good uniformity of light intensity obtained on March 30 and June 14 in the center of the four quadrants of the heliostat, 38 inches below the glass-block roof, when the mirrors were in good adjustment. The glass block was not the best roof material for this application (see fig. 4A), in which all the reflected light was directed onto the roof at a constant angle.

\begin{tabular}{|c|c|c|c|c|c|c|}
\hline \multirow{2}{*}{ TIME } & \multirow{2}{*}{$\begin{array}{c}\text { SOLAR } \\
\text { ELEVATION }\end{array}$} & \multirow{2}{*}{$\begin{array}{c}\text { SOLAR } \\
\text { AZIMUTH } \\
\end{array}$} & \multicolumn{4}{|c|}{ QUADRANTS } \\
\hline & & & $\underline{\mathrm{SE}}$ & sw & $\mathrm{NE}$ & $\mathrm{NW}$ \\
\hline & degrees & degrees & $f t-c^{*}$ & $f t-c$ & $f t-c$ & $f t-c$ \\
\hline $12: 00 \mathrm{M}$ & 54 & 180 & 4,100 & 3,950 & 4,250 & 4,250 \\
\hline 1:00 p.m. & 50 & 208 & 3,780 & 4,160 & 4,110 & 4,110 \\
\hline 1:45 p.m. & 46 & 220 & 3,260 & 3,460 & 3,300 & 3,570 \\
\hline 3:00 p.m. & 35 & 240 & 3,090 & 2,750 & 2,800 & 2,970 \\
\hline 5:25 p.m. & 7 & 265 & 502 & 523 & 448 & 502 \\
\hline 12:00 M & 74 & 180 & 5,200 & 4,780 & 5,100 & 5,100 \\
\hline
\end{tabular}

\footnotetext{
* Foot-candle values corrected for standard outdoor curves.
} 


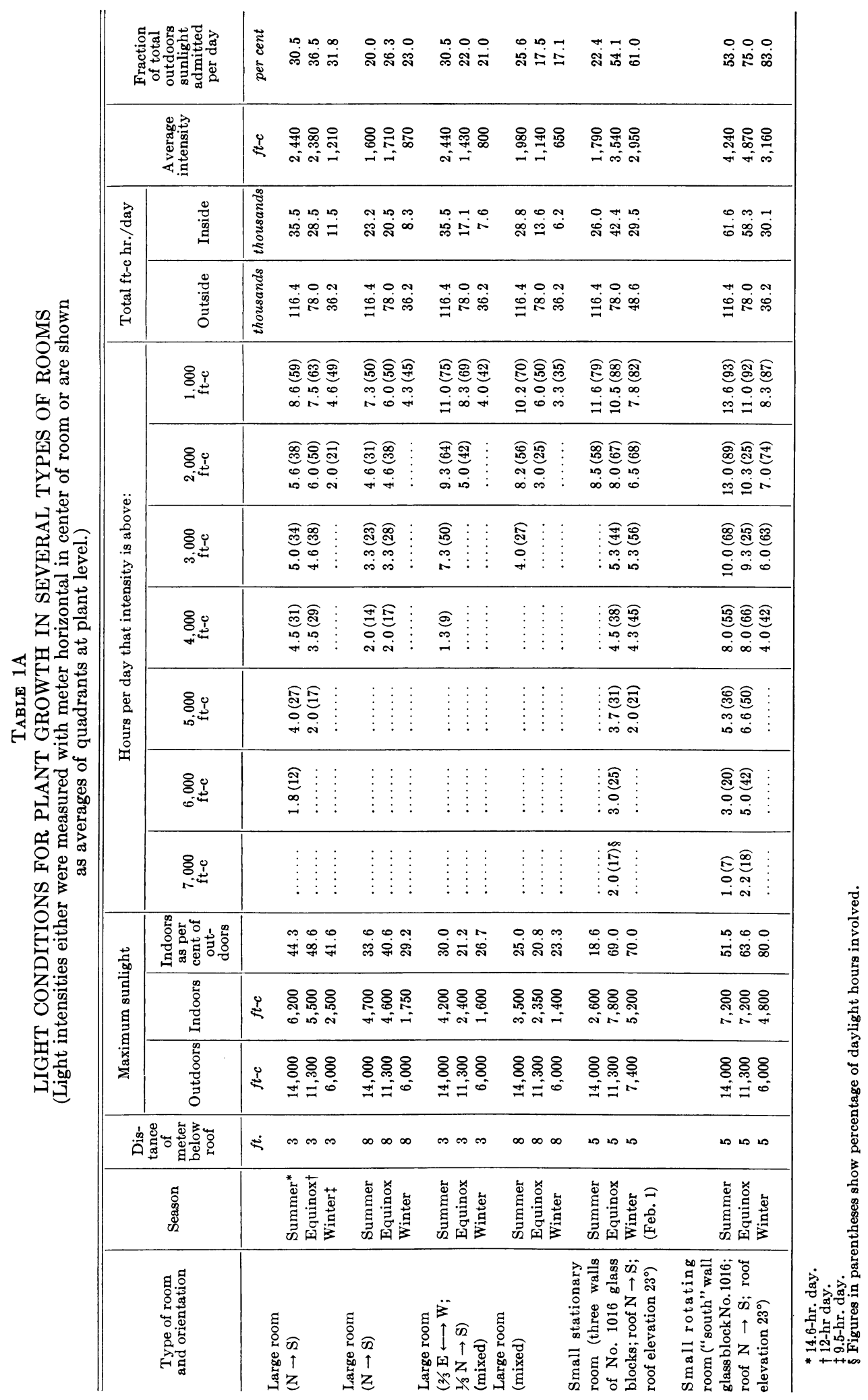




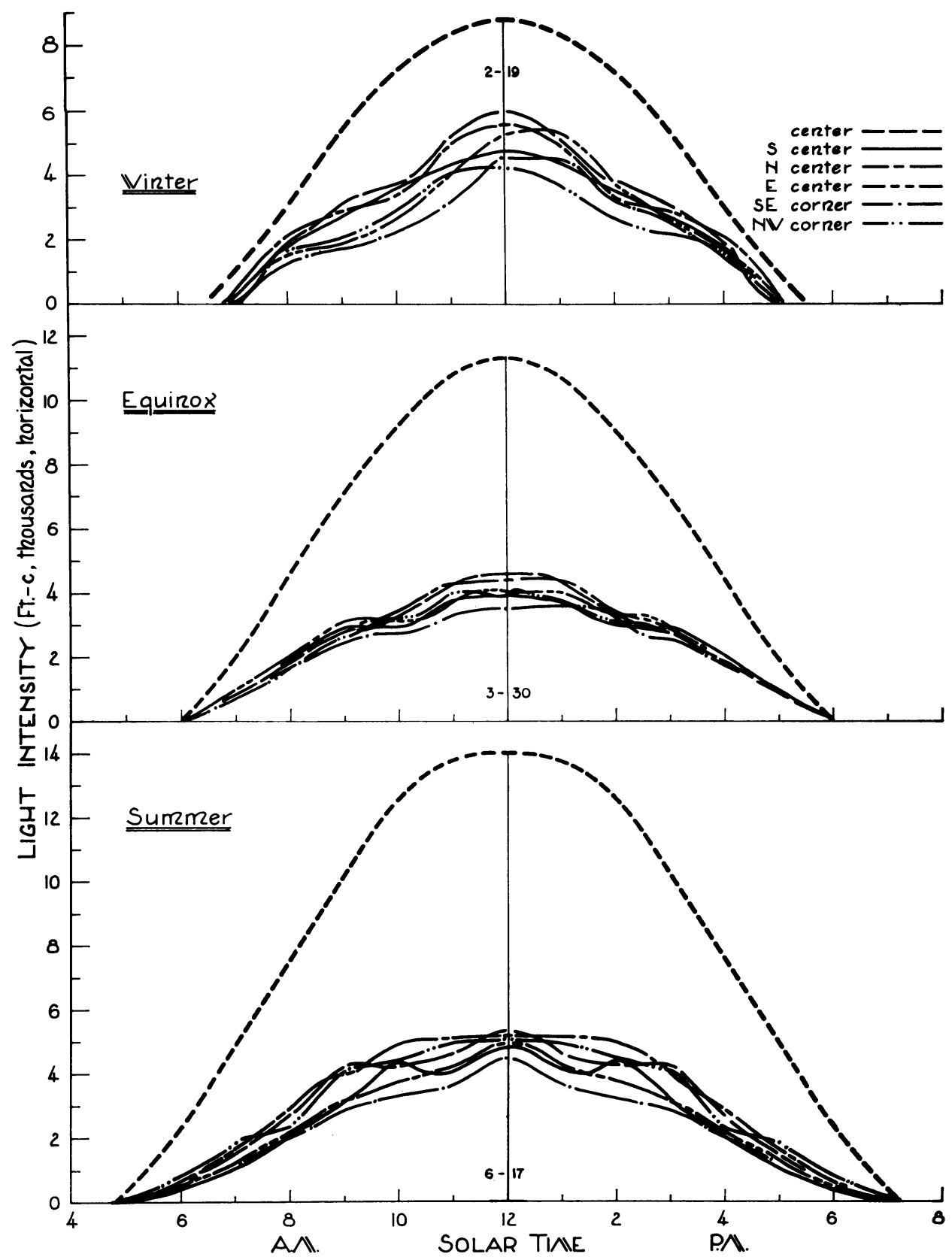

Fig. 3A. Sunlight intensities in cubicle irradiated from rotation mirror system. Glass-block roof, orientation $\mathrm{N} \rightarrow \mathrm{N}$, meter placed 3 feet 2 inches below roof, at different locations in cubicle. Elevation $0^{\circ}$. 


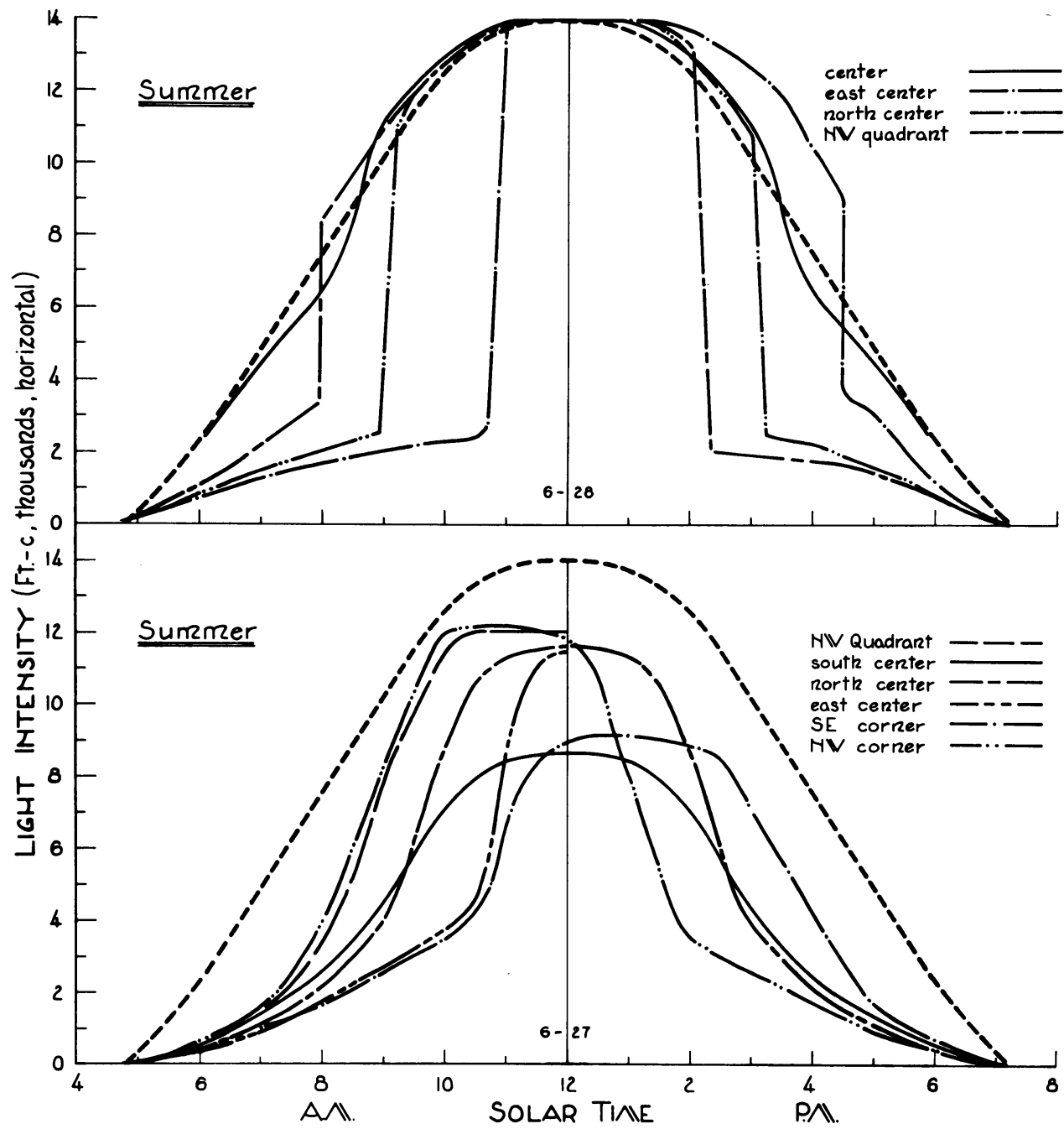

Fig. 4A. Upper chart shows sunlight intensities at four meter locations, the center one with rotating mirror and flat plastic-panel (Plexiglas P-4) roof, other three with neither roof nor mirror. (The latter situation is, of course, impractical.) Note that with plastic roof, the light curve over the day follows the outdoor curve closely. Lower chart shows light intensities with meter at various locations, with flat plastic-panel roof, but without mirror.

\section{REMOVAL OF HEAT FROM LIGHTS}

Refrigeration power values required for maintenance of temperature differentials, with various amounts of radiation entering the large room, were compared. Either 18 or 36 1,500-watt incandescent lights were used continuously except in runs 8 to 12 (table $6 \mathrm{~A}$ ) in which the light saver operated during daylight hours to maintain a mini- mum intensity. Power consumed was metered, and averaged for the period. Power for light consumption was reduced 15 per cent to correct for the estimated loss through the roof. All daylight periods had bright sunlight except run No. 5, when sunlight intensity was only moderate. Inside temperatures were from $58^{\circ}$ to $76^{\circ} \mathrm{F}$ for runs 1 to 5 . 
and $60^{\circ} \mathrm{F}$ for runs 6 to 14 . Heat was supplied by the fan motor, lights, and sunlight.

With no lights (runs 6 and 7), refrigeration power was $3.79 \mathrm{kw}-\mathrm{hr}$./hr. higher with the vents open. Of that amount, only $1.03 \mathrm{kw}-\mathrm{hr}$./hr. was required to maintain the temperature difference between the differentials; the remaining $2.76 \mathrm{kw}-\mathrm{hr}$. $/ \mathrm{hr}$. were used to remove solar heat and to cool the fresh air from outside. Runs 1 and 2 had nearly equal refrigeration requirements, the difference accounting somewhat for the temperature differentials, but No. 2 (open vents) had twice as much light as No. 1 (closed vents). This indicates that approximately one-half the heat from the lights was effectively removed by the air exchange. Similar comparisons of nos. 1 and 2 with 3 indicate the same conclusion.

Greater sensible heat losses occur through the roof and, to a lesser degree, through the walls, due to local heating of the surfaces by convection and radiation from the nearby, hot light bulbs. Therefore, exact calculations of sensible heat losses cannot be made under these light conditions.

No. 4 indicates a considerable saving of power (by open vents) over No. 3 , in

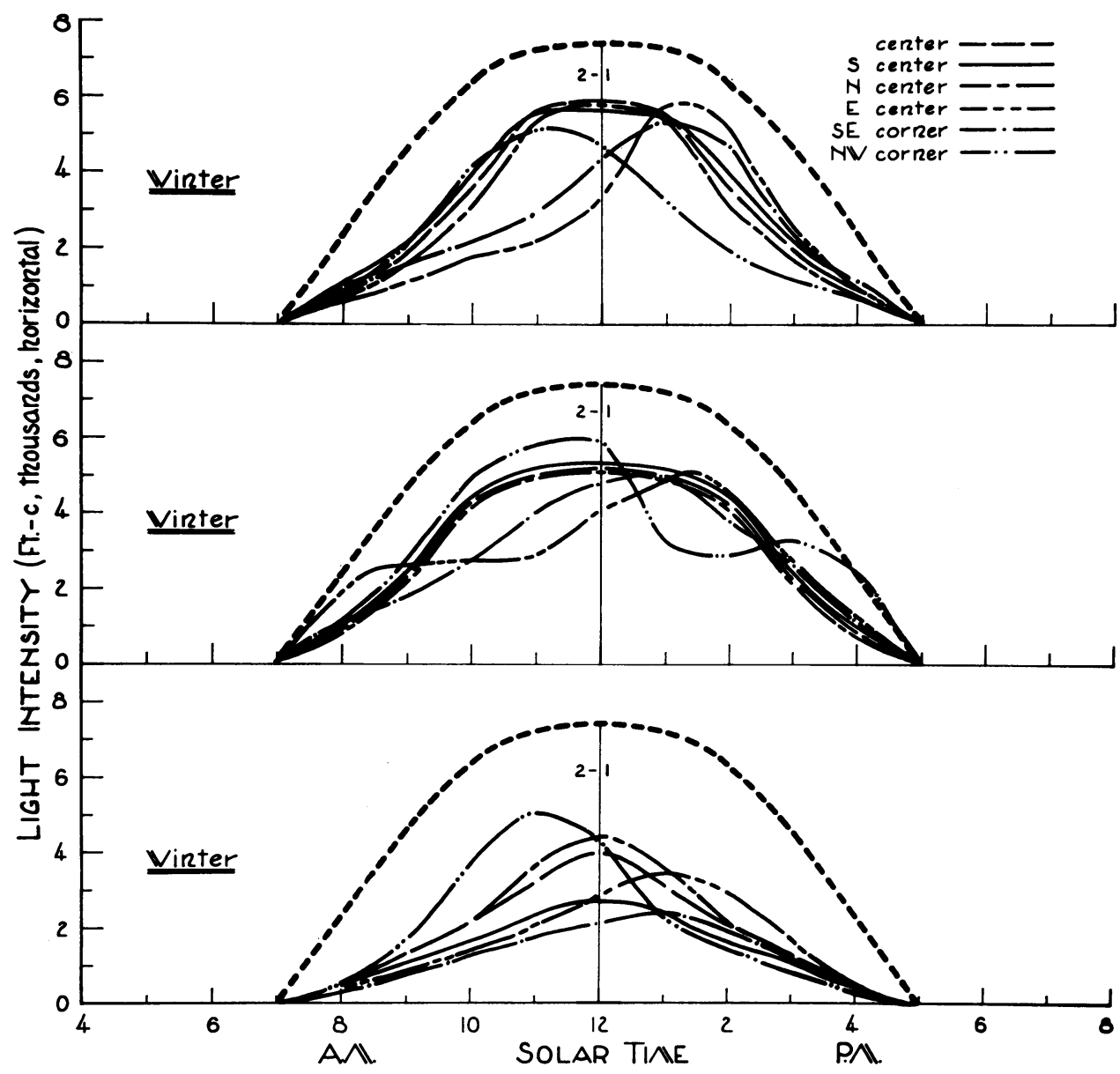

Fig. 5A. Light intensities in small room, stationary, facing south, with glass-block roof and walls. Orientation $\mathrm{N} \rightarrow \mathrm{S}$, meter at level 2. Upper chart, only south wall transparent; middle chart, three walls transparent-south, east, and west; lower chart, no walls transparent. Elevation $23^{\circ}$. 


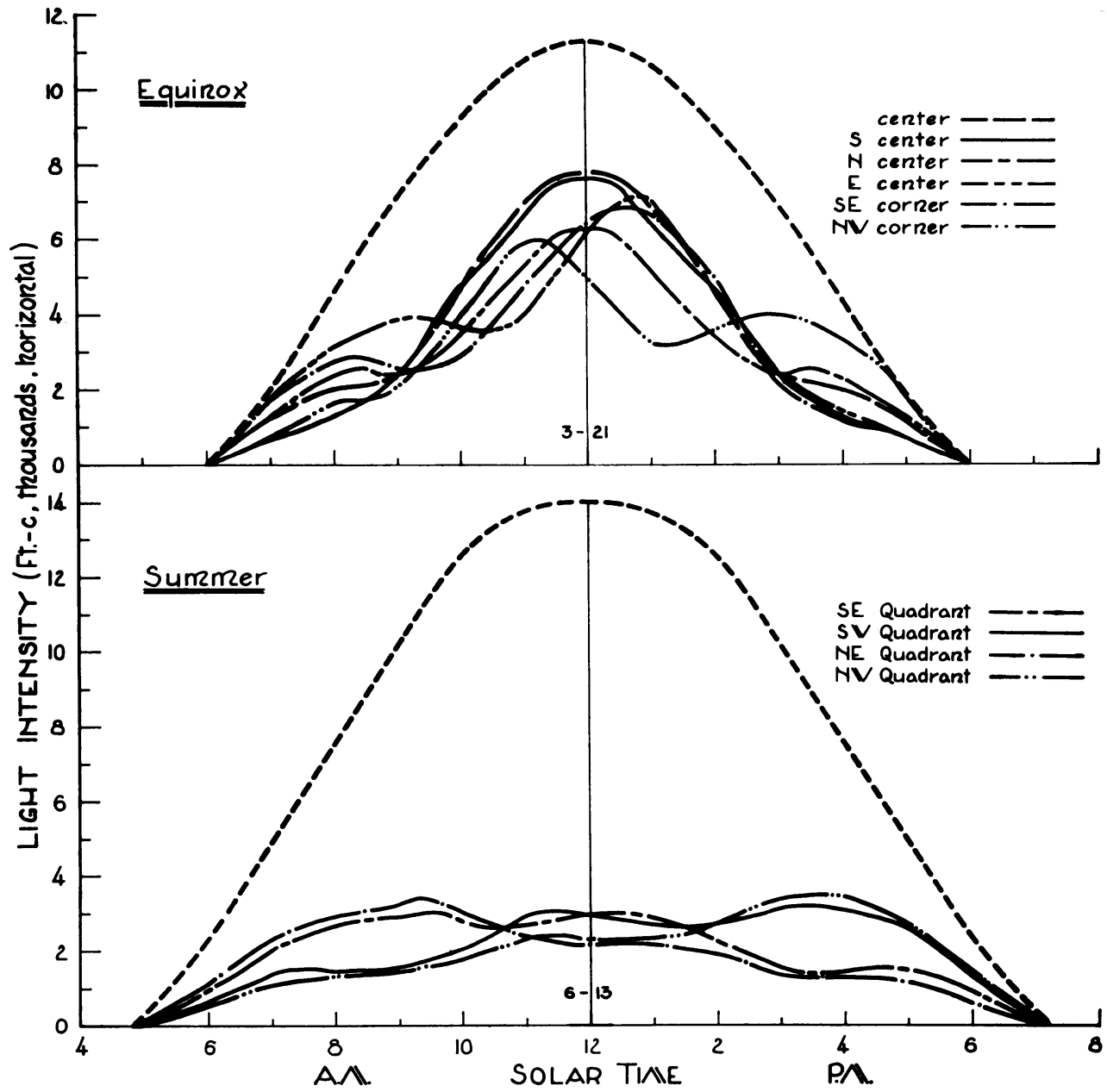

Fig. 6A. Light intensities in small room, stationary, facing south, with glass-block roof and walls. Orientation $\mathrm{N} \rightarrow \mathrm{S}$, meter at level 2 . Three walls transparent--south, east, and west. Elevation $23^{\circ}$.

spite of a lower temperature in No. 4. Numerous calculations may be made to estimate the relative values of the re- frigeration energy used to neutralize heat from the several sources in the runs of table $6 \mathrm{~A}$.

\section{SUNLIGHT INTENSITIES}

An essentially straight-line relationship exists between sunlight intensity on a horizontal surface and solar elevation (figure 9A), which does not depart far from the corresponding portion of the sine curve. The small deviations at the two extremes are presumably due to imperfect cosine correction by the filter.

To obtain a relation between our observed direct solar intensity values in ft-c and the estimated total solar energies presented at the growth chamber roof, we plotted as abscissae in figure $10 \mathrm{~A}$ the energy values presented by the American Society of Heating and AirConditioning Engineers (1960) against our observed values at Davis as ordinates. Corrections were made for the solar distance (correction factor, 1.0 for summer, 1.035 at equinox, and 1.07 for 


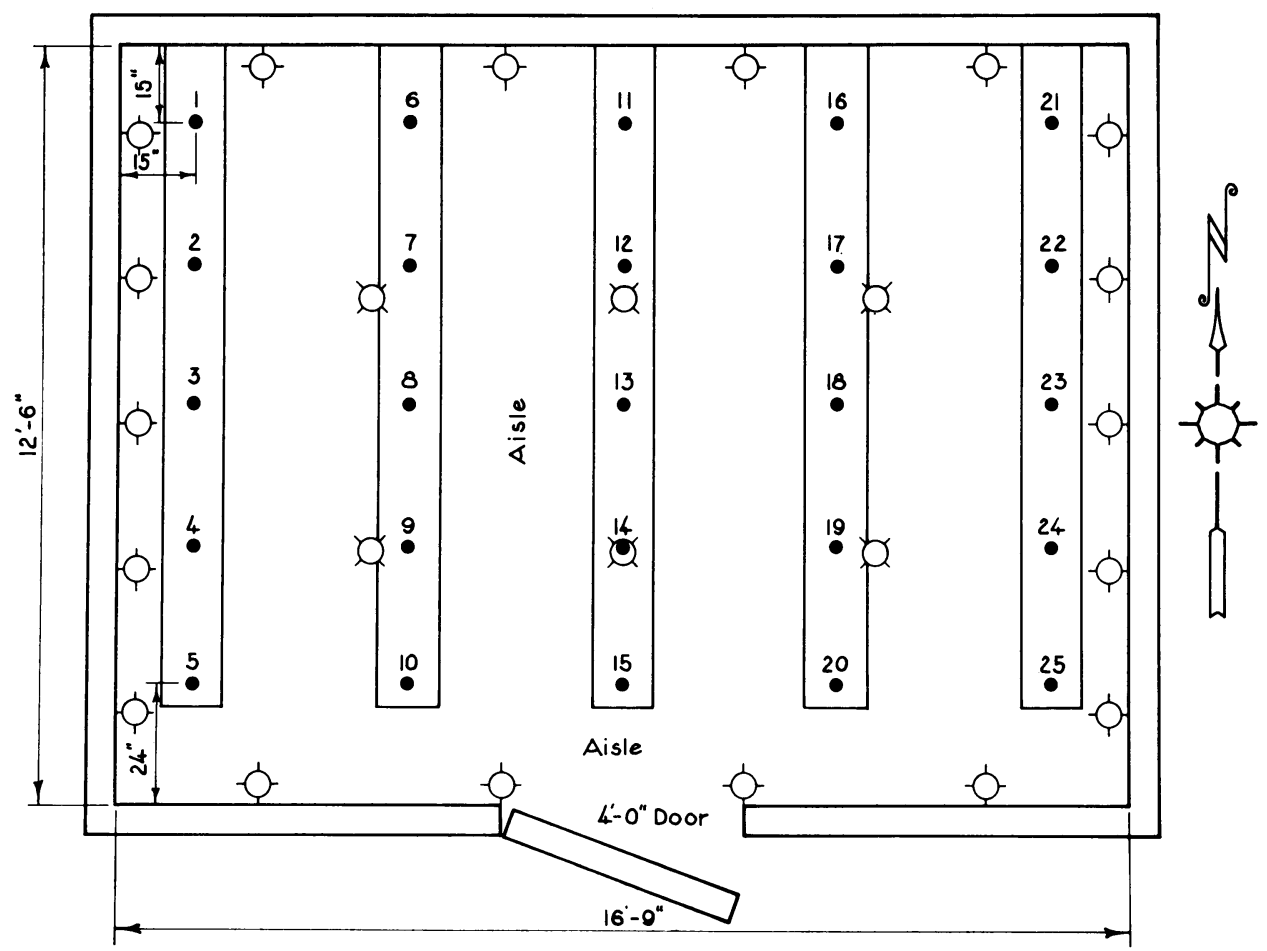

Fig. 7A. Light intensity positions over plant-growth area at level of sugar beet plants nos. 1 to 25 , about 50 inches from floor, from 24 Quartzline lamps (500 watts each) placed on ceiling and on walls near ceiling.

TABLE 2A

LIGHT INTENSITY DISTRIBUTION (50 INCHES FROM FLOOR, LEVEL OF SUGAR BEET PLANTS NOS. 1 TO 25) OVER PLANT GROWTH AREA FROM 24 QUARTZLINE LAMPS (500 WATTS EACH) PLACED AS INDICATED IN FIGURE 7A

\begin{tabular}{|c|c|c|c|}
\hline Position & Intensity & Position & Intensity \\
\hline & $f t-c$ & & $f t-c$ \\
\hline $1(\mathrm{NW}) \ldots$ & 655 & $14 \ldots \ldots$ & 650 \\
\hline $2 \ldots \ldots \ldots$ & 670 & $15 \ldots \ldots$ & 620 \\
\hline $3 \ldots \ldots$ & 675 & $16 \ldots \ldots$ & 635 \\
\hline $4 \ldots \ldots \ldots$ & 645 & $17 \ldots \ldots$ & 650 \\
\hline $5(\mathrm{SW}) \ldots$. & 640 & $18 \ldots \ldots$ & 660 \\
\hline $6 \ldots \ldots$ & 630 & $19 \ldots$ & 635 \\
\hline $7 \ldots \ldots$ & 650 & $20 \ldots \ldots$ & 615 \\
\hline $8 \ldots \ldots$ & 660 & $21(\mathrm{NE}) .$. & 620 \\
\hline $9 \ldots$ & 640 & $22 \ldots \ldots \ldots$ & 650 \\
\hline $10 \ldots$ & 625 & 23. & 670 \\
\hline $11 \ldots \ldots \ldots$ & 625 & $24 \ldots \ldots$ & 645 \\
\hline $12 \ldots \ldots \ldots$ & 650 & $25(\mathrm{SE})$ & 630 \\
\hline \multirow[t]{2}{*}{13 (Center) } & \multirow[t]{2}{*}{660} & A vergofe & 644 \\
\hline & & Average & 044 \\
\hline
\end{tabular}

winter) and probable diffuse sky value at the time of the direct ft-c reading at Davis. (Only clear days with bright sun were cited.) These observations extend over all seasons. Interpolations were made in the table of total energies to determine values corresponding to the solar altitudes at the time of the ft-c observations.

Similar data for horizontal measurements (figure 11A) provide an excellent straight-line relationship. This corresponds to $162 \mathrm{ft}$-c $\mathrm{hr}$., equivalent to 1 cal per sq. $\mathrm{cm}$. Whittle and Lawrence (1959) found an approximate average value of 164 , using essentially spherical receivers and filters to approximate a wavelength sensitivity curve like that of photosnythesis efficiency.

These factors were checked at Davis by simultaneous measurements with the ft-c meter and an Eppley pyrheliometer. 
TABLE 3A

AIR TEMPERATURES OUTDOORS, INDOORS, AND AT EXIT DUCTS IN WEST WALL OF LARGE ROOM AT VARIOUS DATES AND TIMES OF DAY (Glass block orientation $\mathrm{N} \rightarrow \mathrm{S}$. Outside vents closed.)

\begin{tabular}{|c|c|c|c|c|c|c|c|c|c|}
\hline \multirow{2}{*}{$\begin{array}{l}\text { Date and } \\
\text { time of day }\end{array}$} & \multirow{2}{*}{$\begin{array}{c}\text { Fan } \\
\text { speed }\end{array}$} & \multirow{2}{*}{ Source of light } & \multirow{2}{*}{$\begin{array}{l}\text { Con- } \\
\text { dition } \\
\text { of air } \\
\text { ducts* }\end{array}$} & \multicolumn{2}{|c|}{ Air temperature } & \multicolumn{3}{|c|}{ Air temperature at exit of: } & \multirow{2}{*}{$\begin{array}{l}\text { Differ- } \\
\text { entialf }\end{array}$} \\
\hline & & & & Outside & $\begin{array}{c}\text { Inside } \\
\text { (regulated) }\end{array}$ & $\underset{7 \dagger}{\text { Duct }}$ & $\underset{6 \dagger}{\text { Duct }}$ & $\underset{1-5 \dagger}{\text { Ducts }}$ & \\
\hline $5-19-60$ & rpm & & & ${ }^{\circ} \mathrm{F}$ & ${ }^{\circ} \mathrm{F}$ & ${ }^{\circ} \mathrm{F}$ & ${ }^{\circ} \mathrm{F}$ & ${ }^{\circ} F(a v)$. & ${ }^{\circ} \mathrm{F}$ \\
\hline 3:10 p.m.... & 419 & Sun & Open & 84 & 40 & 44 & 40 & 39 & 5 \\
\hline $5-20-60$ & & & & & & & & & \\
\hline $\begin{array}{l}4: 30 \text { p.m..... } \\
5-20-60\end{array}$ & 419 & Sun & Adj. & 80 & 40 & 48 & 44 & 43.5 & 4.5 \\
\hline 3:30 p.m.... & 419 & $\begin{array}{l}\text { Sun }+36 \text { lamps } \S \\
(1500 \text { w. })\end{array}$ & Open & 74 & 40 & 82 & 56 & 45 & 37 \\
\hline $4: 00$ p.m..... & 419 & $\begin{array}{l}\text { Sun }+36 \text { lamps } \S \\
(1500 \text { w. })\end{array}$ & Adj. & 72 & 40 & 82 & 59.5 & 43 & 39 \\
\hline $6-13-60$ & & & & & & & & & \\
\hline $\begin{array}{r}10: 45 \text { a.m.... } \\
6-14-60\end{array}$ & 419 & Sun & Open & 89 & 49 & 60 & 55 & 54 & 6 \\
\hline 8:55 a.m.... & 419 & Sun & Adj. & 82 & 49 & 57 & 54.5 & 54 & 3 \\
\hline $4: 35$ p.m.... & 419 & $\begin{array}{l}\text { Sun }+18 \text { lamps } \delta \\
(1500 \text { w. })\end{array}$ & Open & 96 & 49 & 81 & 60 & 53 & 28 \\
\hline $4: 15$ p.m.... & 419 & $\begin{array}{l}\text { Sun }+18 \text { lamps } \S \\
(1500 \text { w. })\end{array}$ & Adj. & 97 & 49 & 74 & 58.5 & 54.5 & 20 \\
\hline 5:00 p.m..... & 419 & $\begin{array}{l}\text { Sun }+36 \text { lamps } \S \\
(1500 \text { w. })\end{array}$ & Open & 94 & 49 & 95 & 62 & 50 & 45 \\
\hline $8: 30$ a.m.... & 419 & $\begin{array}{l}\text { Sun }+36 \text { lamps } \\
(1500 \mathrm{w} .)\end{array}$ & Adj. & 80 & 49 & 84 & 59.5 & 53 & 31 \\
\hline $6-15-60$ & & & & & & & & & \\
\hline 11:25 a.m... & 655 & Sun§ & Open & 89 & 49 & 59 & 54.5 & 53 & 6 \\
\hline 10:50 a.m... & 655 & Sun & Adj. & 88 & 49 & 60 & 55 & 54 & 6 \\
\hline $2: 30$ p.m.... & 655 & $\begin{array}{l}\text { Sun }+18 \text { lamps } \\
(1500 \text { w. })\end{array}$ & Open & 95 & 49 & 69 & 57 & 54 & 15 \\
\hline $2: 45$ p.m..... & 655 & $\begin{array}{l}\text { Sun }+18 \text { lamps } \\
(1500 \text { w. })\end{array}$ & Adj. & 95 & 49 & 72 & 58 & 53 & 19 \\
\hline 9:30 a.m... & 655 & $\begin{array}{l}\text { Sun }+36 \text { lamps } \\
(1500 \text { w. })\end{array}$ & Open & 86 & 49 & 86 & 60 & 52 & 34 \\
\hline 9:15 a.m.... & 655 & $\begin{array}{l}\text { Sun }+36 \text { lamps } \\
(1500 \text { w. })\end{array}$ & Adj. & 85 & 49 & 80 & 58.5 & 53 & 27 \\
\hline $6-16-60$ & & & & & & & & & \\
\hline 10:15 a.m... & 655 & Sun & Open & 94 & 70 & 70 & 74 & 72 & 5 \\
\hline $11: 15$ a.m.... & 655 & Sun & Adj. & 99 & 70 & 79 & 74 & 72 & 7 \\
\hline 4:00 p.m..... & 655 & $\begin{array}{l}\text { Sun }+18 \text { lamps } \\
(1500 \text { w. })\end{array}$ & Open & 88 & 70 & 92 & 77 & 72 & 20 \\
\hline $3: 45$ p.m..... & 655 & $\begin{array}{l}\text { Sun }+18 \text { lamps } \\
(1500 \text { w. })\end{array}$ & Adj. & 94 & 70 & 90 & 78 & 73 & 17 \\
\hline $4: 10$ p.m..... & 655 & $\begin{array}{l}\text { Sun }+36 \text { lamps } \\
(1500 \text { w. })\end{array}$ & Open & 89 & 70 & 97 & 78 & 72 & 25 \\
\hline $4: 15$ p.m.... & 655 & $\begin{array}{l}\text { Sun }+36 \text { lamps } \\
(1500 \text { w. })\end{array}$ & Adj. & 88 & 70 & 103 & 80 & 73 & 30 \\
\hline $5-27-60$ & & & & & & & & & \\
\hline $\begin{array}{l}\text { 4:30 p.m..... } \\
\text { 5-31-60 }\end{array}$ & 419 & Sun & Open & 83 & 82 & 88 & 85.5 & 84.5 & 3.5 \\
\hline $\begin{array}{l}1: 00 \text { p.m.... } \\
6-1-60\end{array}$ & 419 & Sun & Adj. & 92 & 82 & 87 & 85 & 82.5 & 4.5 \\
\hline 8:50 a.m.... & 419 & $\begin{array}{l}\text { Sun }+18 \text { lamps } \\
(1500 \mathrm{w} .)\end{array}$ & Open & 85 & 81 & 99 & 92 & 81.5 & 17 \\
\hline 9:30 a.m.... & 419 & $\begin{array}{l}\text { Sun }+18 \text { lamps } \\
(1500 \mathrm{w} .)\end{array}$ & Adj. & 87 & 81 & 100 & 96 & 80 & 20 \\
\hline
\end{tabular}

* Open = all 7 air ducts on each side of room fully open. Adj. = ducts 1, 2, 6, and 7 on each side of room fully open;

ducts 3,4 , and 5 open $7 / 8,5 / 8$, and $3 / 4$, respectively.
+ Duct 7 is upper channel, nearest lights and roof, 11.5 in. high $\times 7.5$ in. wide. Duct 6 is below 7,18 in. high $\times 6.5$ in. wide. Ducts 1 to 5 ranged no more than 5 to 6 degrees in temperature under all conditions, each being 22 in. high $\times 9.5$

in. wide when open.

\& Considerable cloudiness. 
TABLE 3A-Continued

\begin{tabular}{|c|c|c|c|c|c|c|c|c|c|}
\hline \multirow{2}{*}{$\begin{array}{l}\text { Date and } \\
\text { time of day }\end{array}$} & \multirow{2}{*}{$\begin{array}{l}\text { Fan } \\
\text { speed }\end{array}$} & \multirow{2}{*}{ Source of light } & \multirow{2}{*}{$\begin{array}{l}\text { Con- } \\
\text { dition } \\
\text { of air } \\
\text { ducts* }\end{array}$} & \multicolumn{2}{|c|}{ Air temperature } & \multicolumn{3}{|c|}{ Air temperature at exit of: } & \multirow{2}{*}{$\begin{array}{l}\text { Differ- } \\
\text { ential }\end{array}$} \\
\hline & & & & Outside & $\begin{array}{c}\text { Inside } \\
\text { (regulated) }\end{array}$ & $\underset{7 \dagger}{\text { Duct }}$ & $\underset{6 \dagger}{\text { Duct }}$ & $\underset{1-5 \dagger}{\text { Ducts }}$ & \\
\hline & $r p m$ & & & ${ }^{\circ} \mathrm{F}$ & ${ }^{\circ} \mathrm{F}$ & ${ }^{\circ} \mathrm{F}$ & ${ }^{\circ} \mathrm{F}$ & ${ }^{\circ} F(a v)$. & ${ }^{\circ} \mathrm{F}$ \\
\hline 10:30 a.m... & 419 & $\begin{array}{l}\text { Sun }+36 \text { lamps } \\
(1500 \text { w. })\end{array}$ & Open & 90 & 81 & 115 & 104 & 82 & 33 \\
\hline 9:50 a.m.... & 419 & $\begin{array}{l}\text { Sun }+36 \text { lamps } \\
(1500 \text { w.) }\end{array}$ & Adj. & 88 & 81 & 100 & 96 & 81 & 19 \\
\hline \multicolumn{10}{|l|}{$6-8-60$} \\
\hline 4:30 p.m.... & 419 & Sun & Open & 84 & 100 & 108 & 104.5 & 103 & 5 \\
\hline 2:30 p.m.... & 419 & Sun & Adj. & 81 & 100 & 109 & 105 & 103 & 6 \\
\hline 4:35 p.m.... & 419 & $\begin{array}{l}\text { Sun }+18 \text { lamps } \\
(1500 \text { w. })\end{array}$ & Open & 84 & 100 & 114 & 106 & 102.5 & 11 \\
\hline 4:40 p.m... & 419 & $\begin{array}{l}\text { Sun }+18 \text { lamps } \\
(1500 \text { w. })\end{array}$ & Adj. & 84 & 100 & 124 & 110 & 103 & 21 \\
\hline 5:35 p.m.... & 419 & $\begin{array}{l}\text { Sun }+36 \text { lamps } \\
(1500 \text { w. })\end{array}$ & Open & 83 & 100 & 150 & 118 & 105 & 45 \\
\hline 5:15 p.m..... & 419 & $\begin{array}{l}\text { Sun }+36 \text { lamps } \\
(1500 \text { w. })\end{array}$ & Adj. & 83 & 100 & 141 & 113 & 102 & 39 \\
\hline \multicolumn{10}{|l|}{$6-17-60$} \\
\hline 2:15 p.m.... & 655 & Sun & Open & 89 & 100 & 105 & 101.5 & 98.5 & 6.5 \\
\hline 2:00 p.m.... & 655 & Sun & Adj. & 89 & 100 & 105 & 102 & 98.5 & 6.5 \\
\hline 2:30 p.m.... & 655 & $\begin{array}{l}\text { Sun }+18 \text { lamps } \\
(1500 \mathrm{w} .)\end{array}$ & Open & 89 & 100 & 115 & 103.5 & 99 & 16 \\
\hline $2: 40$ p.m.... & 655 & $\begin{array}{l}\text { Sun }+18 \text { lamps } \\
(1500 \mathrm{w} .)\end{array}$ & Adj. & 89 & 100 & 117 & 105 & 99 & 18 \\
\hline $3: 45$ p.m..... & 655 & $\begin{array}{l}\text { Sun }+36 \text { lamps } \\
(1500 \text { w. })\end{array}$ & Open & 85 & 100 & 130 & 104 & 95 & 35 \\
\hline 3:30 p.m. & 655 & $\begin{array}{l}\text { Sun }+36 \text { lamps } \\
(1500 \mathrm{w} .)\end{array}$ & Adj. & 86 & 100 & 125 & 107 & 98 & 27 \\
\hline
\end{tabular}




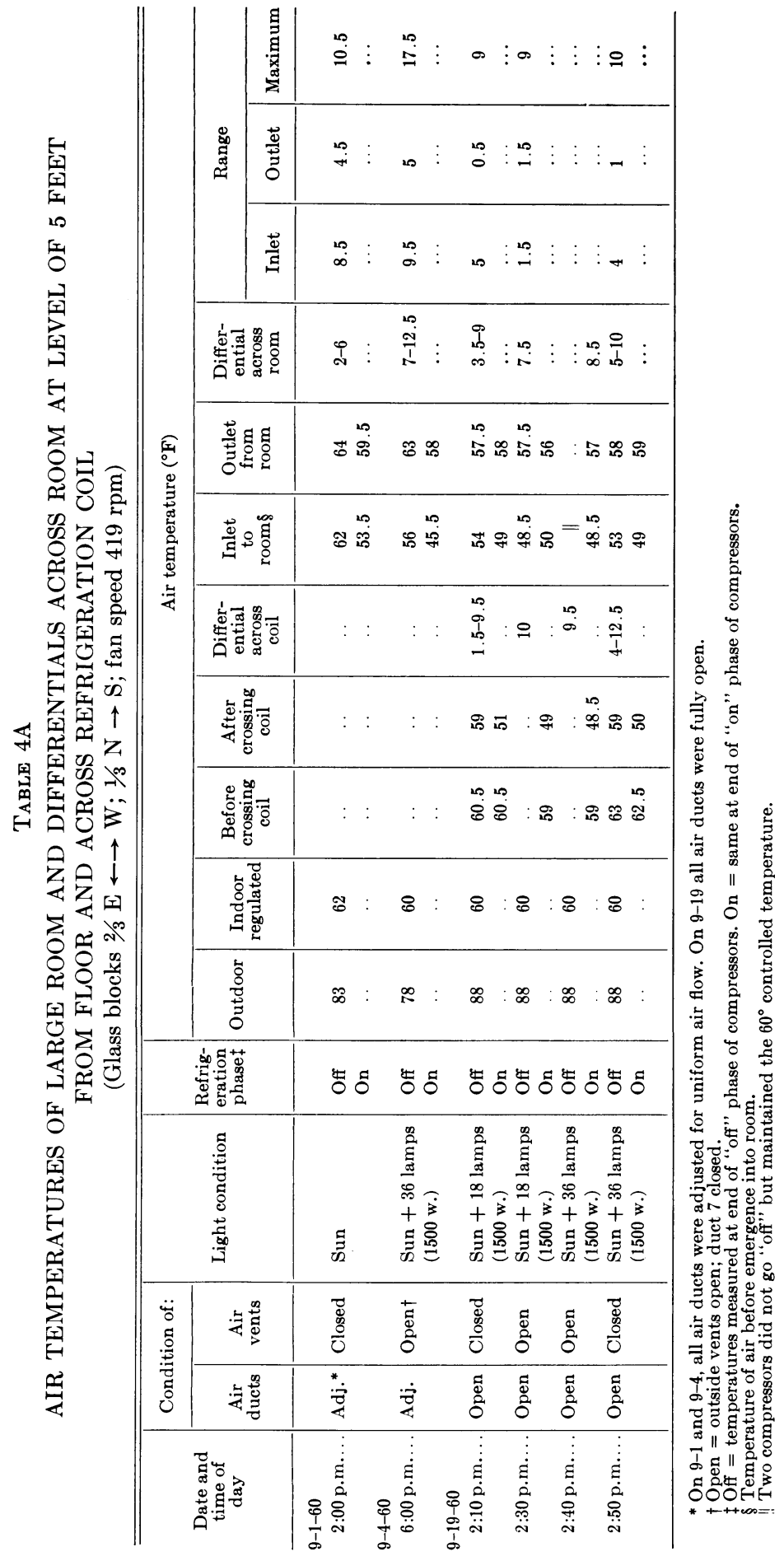




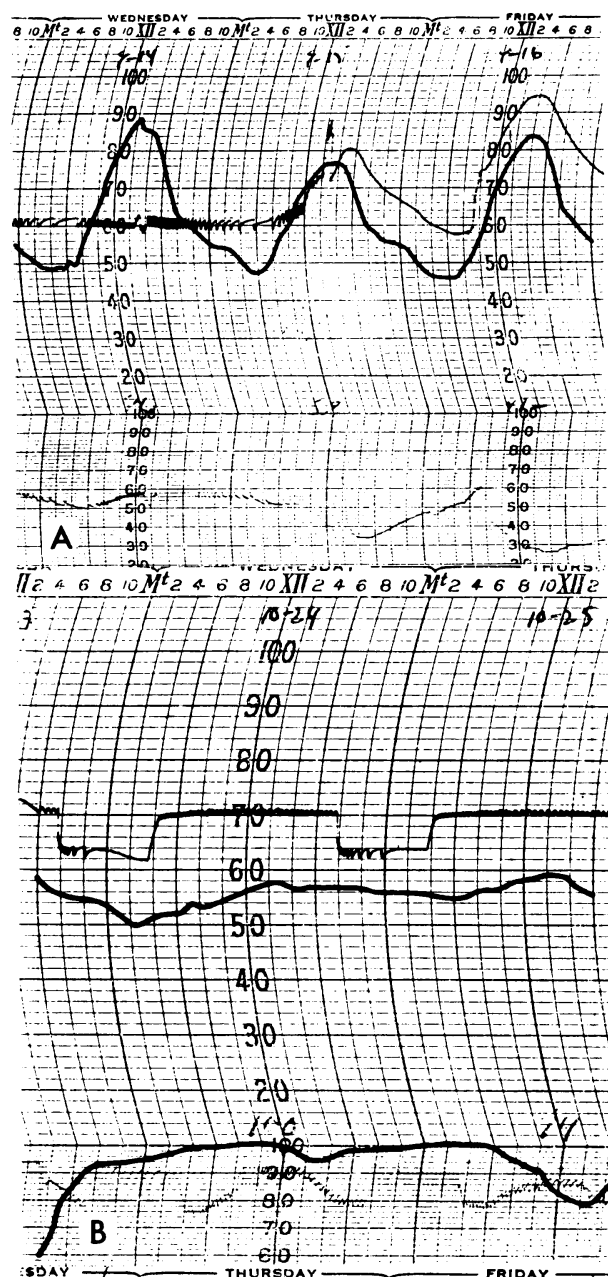

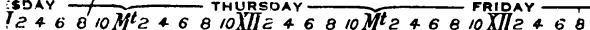

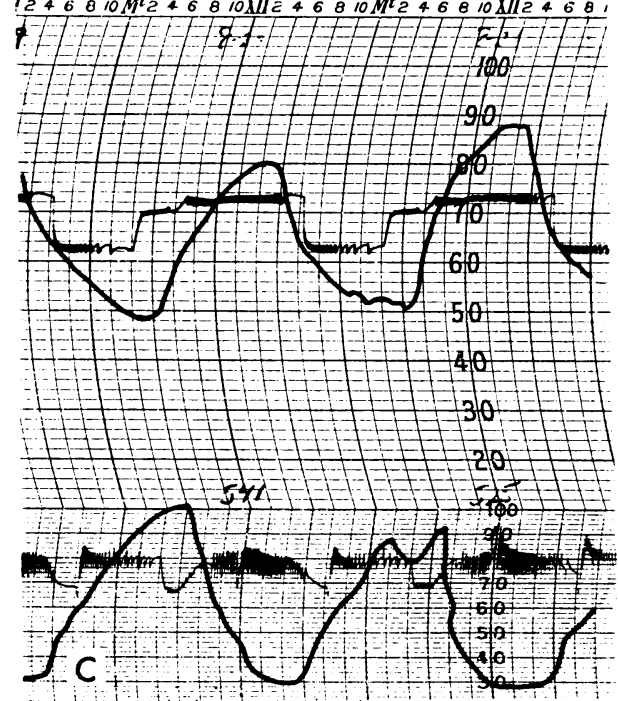

With a solar altitude of $37^{\circ}, 10,400 \mathrm{ft}-\mathrm{c}$ per (cal per sq. cm. min.) were obtained for both the horizontal and direct measurements. For a $65^{\circ}$ solar altitude, a direct reading of $10,700 \mathrm{ft}$-c per (cal per sq. cm. min.) was obtained. A practical factor for general use would be 10,000 ft-c per (cal per sq. cm. min.).

Use of the factor from the straightline slope of figure $11 \mathrm{~A}$ permits the comparisons of table $7 \mathrm{~A}$ between our energy values calculated from ft-c observations and total radiation observations made with an Eppley pyrheliometer at the United States Weather Bureau's Davis station. This agreement is considered highly satisfactory.

Fig. 8A. Records of temperature and relative humidity under several operating conditions. Heavy, solid lines represent outdoor conditions. Upper scale in each chart is for temperature $\left({ }^{\circ} \mathrm{F}\right)$; lower scale for relative humidity. Both were recorded on a BendixFriez hygrothermograph. A : September 1416,1960 . Sunlight values outdoors were 543 , 538 , and 472 cal. per sq. cm. day, respectively. Fan speed, $419 \mathrm{rpm}$. One compressor on. Glass block orientation $2 / 3 \mathrm{E} \longleftrightarrow \mathrm{W}, 1 / 3 \mathrm{~N} \rightarrow \mathrm{S}$. No regulation of humidity. The cycles of refrigeration are reflected in relative humidity cycles. Experiments with light saver and vents, in progress here, account for erratic temperature curve. A microswitch $\left( \pm 2^{\circ} \mathrm{F}\right)$ was regulating temperature, and no heating was involved. After 4:00 p.m. on September 14, only the fan operated, with no temperature regulation. B: October 24-25, 1962. Sunlight values outdoors were 100 and 74 cal. per sq. cm. day, respectively. Weather foggy. Fan speed, 505 rpm. One compressor on. Humidifier set for about 80 per cent. A microswitch $\left( \pm 1.5^{\circ} \mathrm{F}\right)$ regulated the temperature. No lights were involved. At $70^{\circ} \mathrm{F}$, heating was required; at $63^{\circ} \mathrm{F}$, only refrigeration was needed. This room had been remodeled with plastic roof and wide windows. C: September 20-21, 1962. Sunlight values outdoors were 541 and 525 cal. per sq. em. day, respectively. Other conditions same as for B. Because of higher light values, refrigeration was required from about 9:00 a.m. to $6: 00$ p.m. The controls of heating and refrigeration cycles could not agree perfectly at this time without opposing each other; hence, they are about $2^{\circ} \mathrm{F}$ apart. Humidity control was set for 80 per cent. The effects of rapid change of temperature are seen twice each day. 


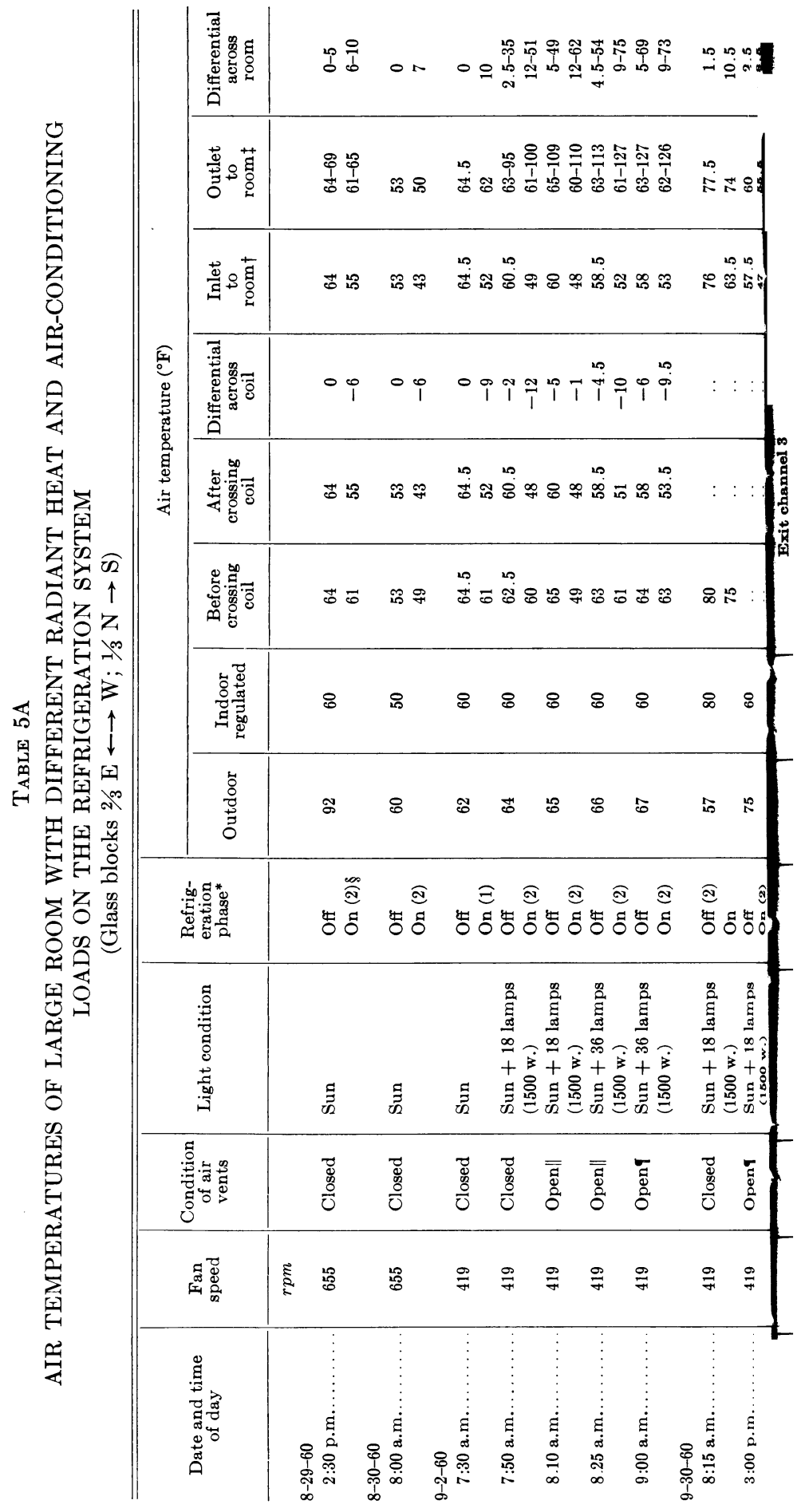




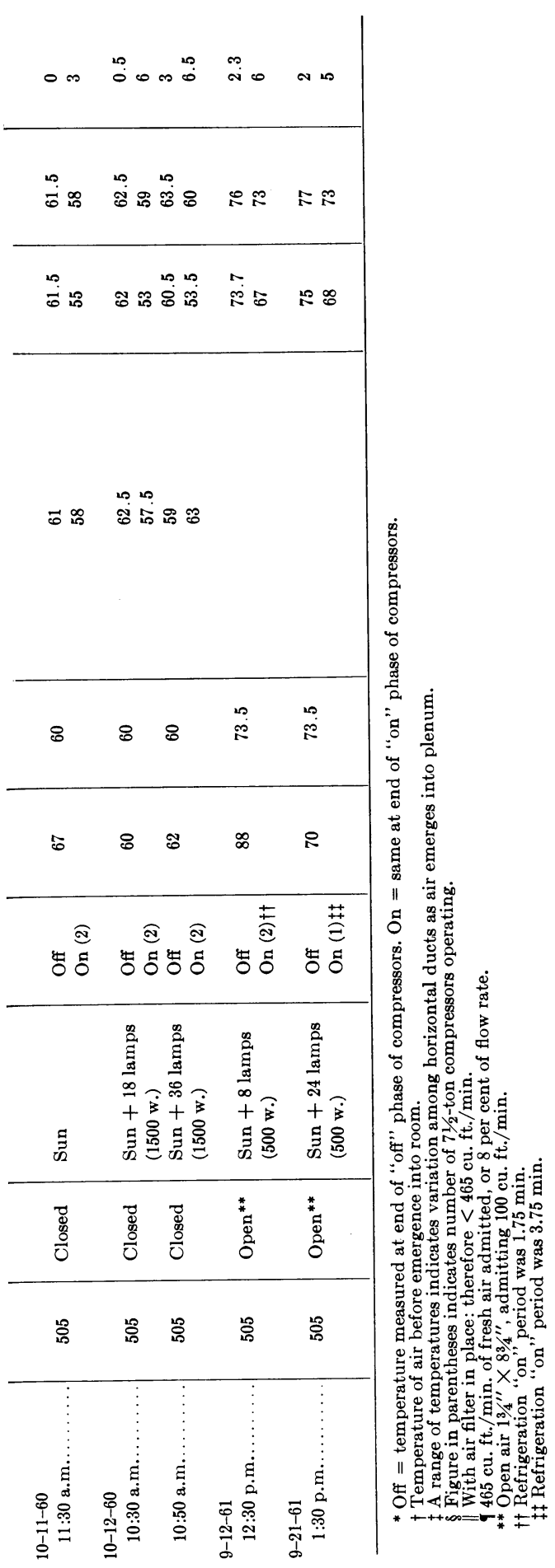


TABLE 6A

EFFECT OF AIR VENTS ON REFRIGERATION POWER CONSUMPTION IN LARGE ROOM

\begin{tabular}{|c|c|c|c|c|c|c|c|}
\hline \multirow{2}{*}{$\begin{array}{c}\text { Run } \\
\text { no. }\end{array}$} & \multirow{2}{*}{$\underset{\text { speed* }}{\text { Fan }}$} & \multirow{2}{*}{$\begin{array}{c}\text { Average } \\
\text { temperature } \\
\text { differential }\end{array}$} & \multirow{2}{*}{$\begin{array}{l}\text { Condition } \\
\text { of vents }\end{array}$} & \multicolumn{2}{|c|}{ No. of hours } & \multicolumn{2}{|c|}{ Average kw-hr./hr. for: } \\
\hline & & & & Night & Day & Lights & Refrigeration \\
\hline & $r p m$ & ${ }^{\circ} \mathrm{F}$ & & & & & \\
\hline $1 \ldots \ldots$ & 419 & +17 & Closed & 15 & $\cdots$ & 20.9 & 6.14 \\
\hline $2 \ldots \ldots$ & 419 & +22 & Open & 15 & . & 41.9 & 5.97 \\
\hline $3 \ldots \ldots$ & 419 & +17 & Closed & 15 & . & 41.5 & 11.2 \\
\hline $4 \ldots \ldots$ & 419 & +6 & Open & 12.5 & .. & 41.9 & 9.6 \\
\hline $\mathbf{5} \ldots \ldots$ & 419 & -30 & Open & . & 7.3 & 36.1 & 13.9 \\
\hline 6 . & 655 & -8 & Closed & 22 & 27 & 0 & 2.62 \\
\hline 7. & 655 & -22 & Open & . & 12 & 0 & 6.41 \\
\hline $8 \ldots \ldots$ & 655 & -8 & Closed & 11 & 13 & 12.3 & 6.21 \\
\hline $9 \ldots \ldots$ & 655 & -6 & Closed & 11 & 13 & 6.23 & 4.75 \\
\hline $10 \ldots \ldots$ & 655 & -10 & Open & 22 & 26 & 5.52 & 4.41 \\
\hline $11 \ldots$ & 655 & -12 & Open & 11 & 13 & 11.0 & 6.42 \\
\hline 12. & 655 & -18 & Closed & 11 & 13 & 13.0 & 6.75 \\
\hline $13 .$. & 655 & 0 & Open & 12 & .. & 20.4 & 6.42 \\
\hline $14 \ldots$ & 655 & -1 & Open & 12 & .. & 40.2 & 9.76 \\
\hline
\end{tabular}

* The runs at $419 \mathrm{rpm}$ occurred in September; those at $655 \mathrm{rpm}$ in August.

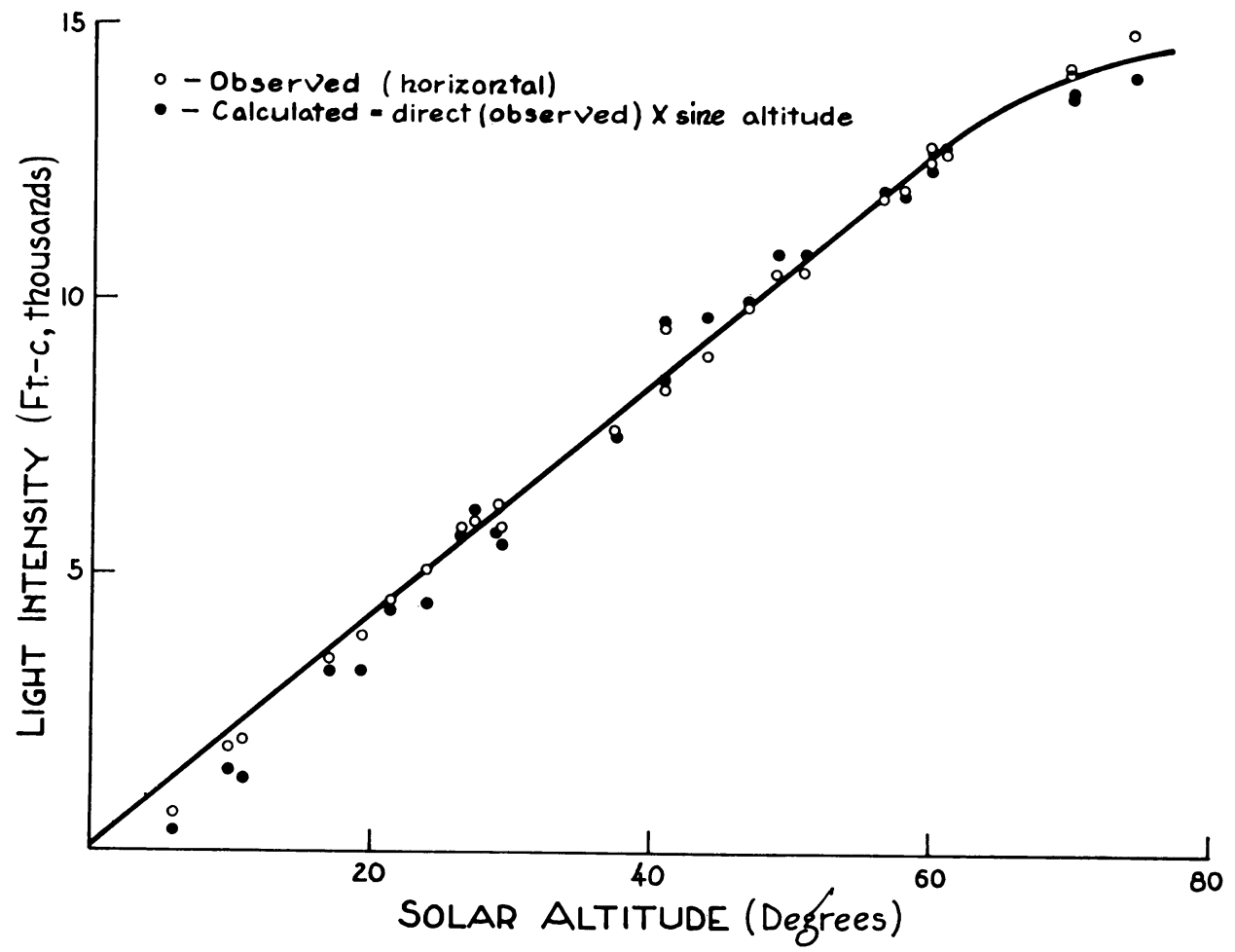

Fig. 9A. Conversion of direct (+ diffuse) observed solar light intensities to horizontal (+ diffuse) light intensities; correlation of calculated values with simultaneous observed horizontal (+ diffuse) intensities. For clear days at Davis, California. 


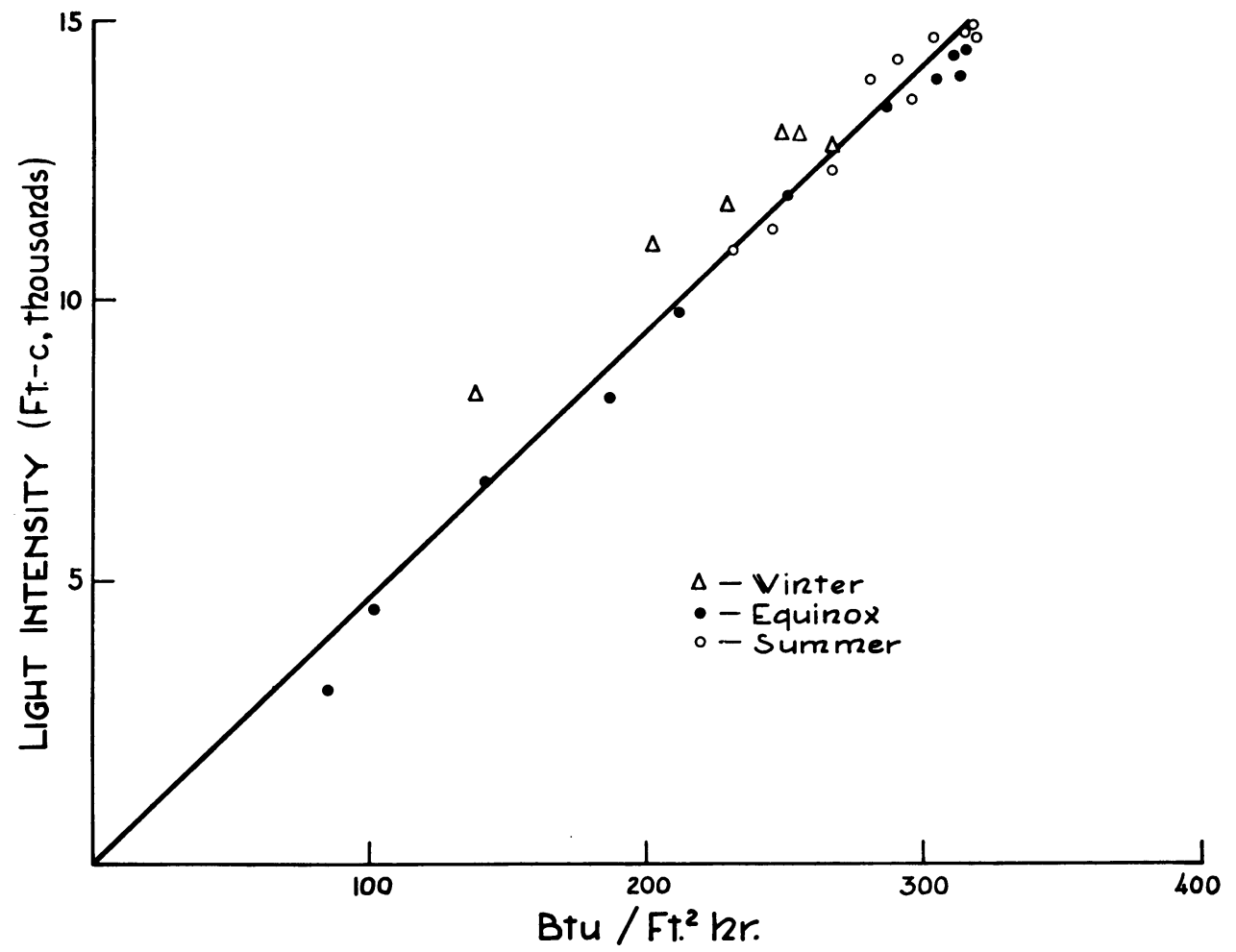

Fig. 10A. Conversion of observed solar light intensity at Davis (1960) to total radiant energy units (direct + diffuse). Energy values were presented by the American Society of Heating and Air-Conditioning Engineers (1960), and were corrected for solar distance variation with season and estimated diffuse values. Slope $=47 \mathrm{ft}-\mathrm{c} / \mathrm{Btu} \mathrm{ft}^{-2} \mathrm{hr}^{-1}$ or $10,400 \mathrm{ft}-\mathrm{c} / \mathrm{cal} \mathrm{cm}^{-2} \mathrm{~min}^{-1}$. For clear days at Davis, California. 


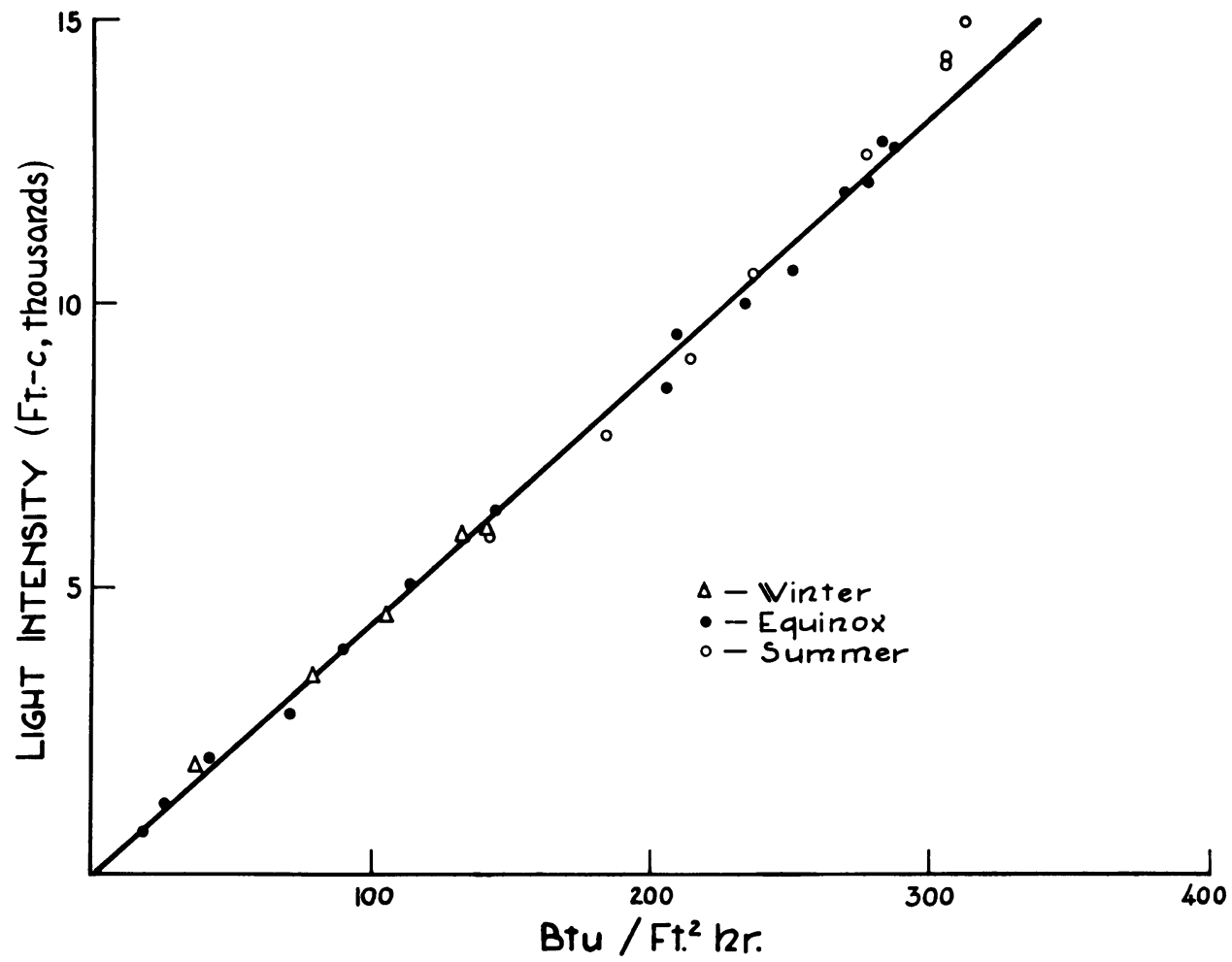

Fig. 11A. Conversion of observed solar light intensity at Davis to total radiant energy units (horizontal + diffuse). Energy values were presented by the American Society of Heating and Air-Conditioning Engineers (1960), and were corrected for solar distance variation with season. Slope $=44 \mathrm{ft}-\mathrm{c} / \mathrm{Btu}_{\mathrm{ft}}^{-2} \mathrm{hr}^{-1}$ or $9,700 \mathrm{ft}-\mathrm{c} / \mathrm{cal} \mathrm{cm}^{-2} \mathrm{~min}^{-1}$. For clear days at Davis, California.

Agreement is poor in winter when noon solar altitudes are as low as $28^{\circ}$. Figure $9 \mathrm{~A}$ shows that for altitudes below $30^{\circ}$, ft-c values tend to be low.

Table 8A compares our values of

TABLE 7A

CALCULATED AND MEASURED

SEASONAL SOLAR INTENSITIES ON

A HORIZONTAL SURFACE

(Davis, California, at noon on clear days)

\begin{tabular}{|c|c|c|}
\hline \multirow{2}{*}{ Season } & \multicolumn{2}{|c|}{ Solar intensity } \\
\hline & Calculated* & Measured $\dagger$ \\
\hline & $\left(\mathrm{cal} / \mathrm{cm} .{ }^{2} \mathrm{~min}.\right)$ & $\left(\mathrm{cal} / \mathrm{cm} .^{2} \mathrm{~min}.\right)$ \\
\hline Maximum (June).. & 1.47 & 1.48 (1 reading) \\
\hline Average (June) ... & 1.41 & 1.41 (mean) \\
\hline Equinox $($ March 21$) \ldots$ & 1.20 & 1.21 \\
\hline Minimum (December). & 0.60 & 0.75 (mean) \\
\hline
\end{tabular}

* Calculated from ft-c meter observations and conversion factor of $9,700 \mathrm{ft}-\mathrm{c} / \mathrm{cal} \mathrm{cm} .^{-2} \mathrm{~min} \cdot{ }^{-1}$.

t Measured with Eppley pyrheliometer, by the United States Weather Bureau Station at Davis. noontime solar intensities (in Btu) at different seasons (1) calculated with the above factors of figures $10 \mathrm{~A}$ and $11 \mathrm{~A}$ from measurements with the ft-c meter at Davis; (2) measured with an Eppley pyrheliometer at Davis; and (3) taken from the literature (data for Massachusetts, latitude $42^{\circ}$, only slightly different from that of Davis). Considering the difference in time, location, and measurement, the agreement of the measured values with the data of Hand (1950) is remarkably good. Calculated values agree well except at the extremes of solar altitude, where values become slightly low, as explained by figure $9 \mathrm{~A}$.

It seemed desirable to determine total radiant energies received from sunlight on bright clear days as a function of time of year. Representative days were 
TABLE 8A

CALCULATED AND MEASURED MAXIMUM HORIZONTAL AND DIRECT SOLAR INTENSITIES AT NOON ON CLEAR DAYS AT DAVIS, CALIFORNIA, COMPARED WITH CALCULATIONS BY HAND (1950)

\begin{tabular}{|c|c|c|c|}
\hline \multirow[b]{2}{*}{ Season } & \multicolumn{3}{|c|}{ Solar intensity } \\
\hline & Calculated & Measured & $\begin{array}{c}\text { Hand's } \\
\text { calculations }\end{array}$ \\
\hline & $B t u / f t^{2} h r$. & $B t u / f t^{2} h r$. & $B t u / f t^{2} h r$. \\
\hline \multicolumn{4}{|l|}{ Horizontal (includes diffuse): } \\
\hline Summer (maximum) ........ & 326 & 327 & 314 \\
\hline More nearly average....... & 312 & 312 (mean) & \\
\hline Equinox ................. & 265 & 267 (mean) & 275 \\
\hline Winter* $\ldots \ldots \ldots \ldots \ldots$ & 131 & 159 (mean) & 148 \\
\hline \multicolumn{4}{|l|}{ Direct (normal + diffuse): } \\
\hline Summer (maximum, June 25,1962$) \ldots \ldots \ldots \ldots \ldots \ldots \ldots$ & 314 & $345 \dagger$ & $332 \ddagger$ \\
\hline More nearly average $\ldots \ldots \ldots \ldots \ldots \ldots \ldots \ldots \ldots \ldots \ldots$ & 304 & $337 \dagger$ & \\
\hline Equinox (April 16, 1962) $\ldots \ldots \ldots \ldots \ldots \ldots \ldots \ldots \ldots \ldots \ldots \ldots \ldots \ldots$ & 310 & $309 \dagger$ & $319 \ddagger$ \\
\hline Winter* ${ }^{*} \ldots \ldots \ldots \ldots \ldots \ldots$ & 265 & 300 & $296 \ddagger$ \\
\hline
\end{tabular}

* November 27,1961 , at 1:30 p.m., when solar altitude was $28^{\circ}$, as at $12 \mathrm{M}$ in midwinter.

† Calculated from horizontal measurements, at Davis, from sine values of the solar altitude.

$\ddagger$ Diffuse estimated from total measured values and angle of measuring device.

chosen from our recordings of outdoor horizontal ft-c and, for the same or similar days, from the Eppley pyrheliometer recordings of the United States Weather Bureau Station at Davis (1960-1961). These provided the data of figure $12 \mathrm{~A}$. A wide range of values for ft-c hr. per day applies over the season, and will be reflected in terms of plant growth or the cost of supplying supplementary lighting. The variation in terms of (ft-c hr. per day) per (cal per sq. cm. day) is not great, but reflects effects of solar elevation on instrument calibration and atmospheric effects. Factors of atmospheric clarity may vary with the locality, causing some asymmetry in this curve. The figures of table $9 \mathrm{~A}$ were adopted for calculation purposes. The table presents these values converted to true ft-c. and compares them with a recent value from the literature.

TABLE 9A

SOLAR RADIATION FACTORS TO CONVERT CAL./CM. ${ }^{2}$ DAY TO FT-C HR./DAY

(Measured with horizontal instruments)

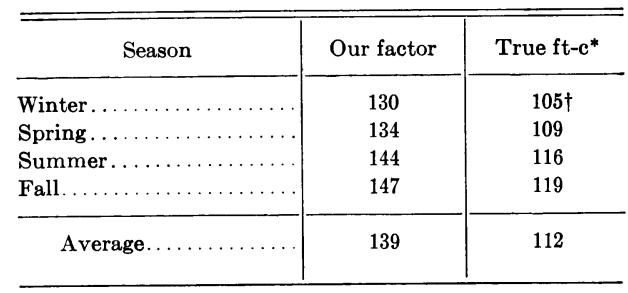

* The factor obtained with our ft-c meter was multiplied by 0.81 (correction for absence of green filter on the photocell) to obtain true ft-c.

$\dagger$ Black (1957) gives 115 true $\mathrm{ft}-\mathrm{c}$ for winter. 


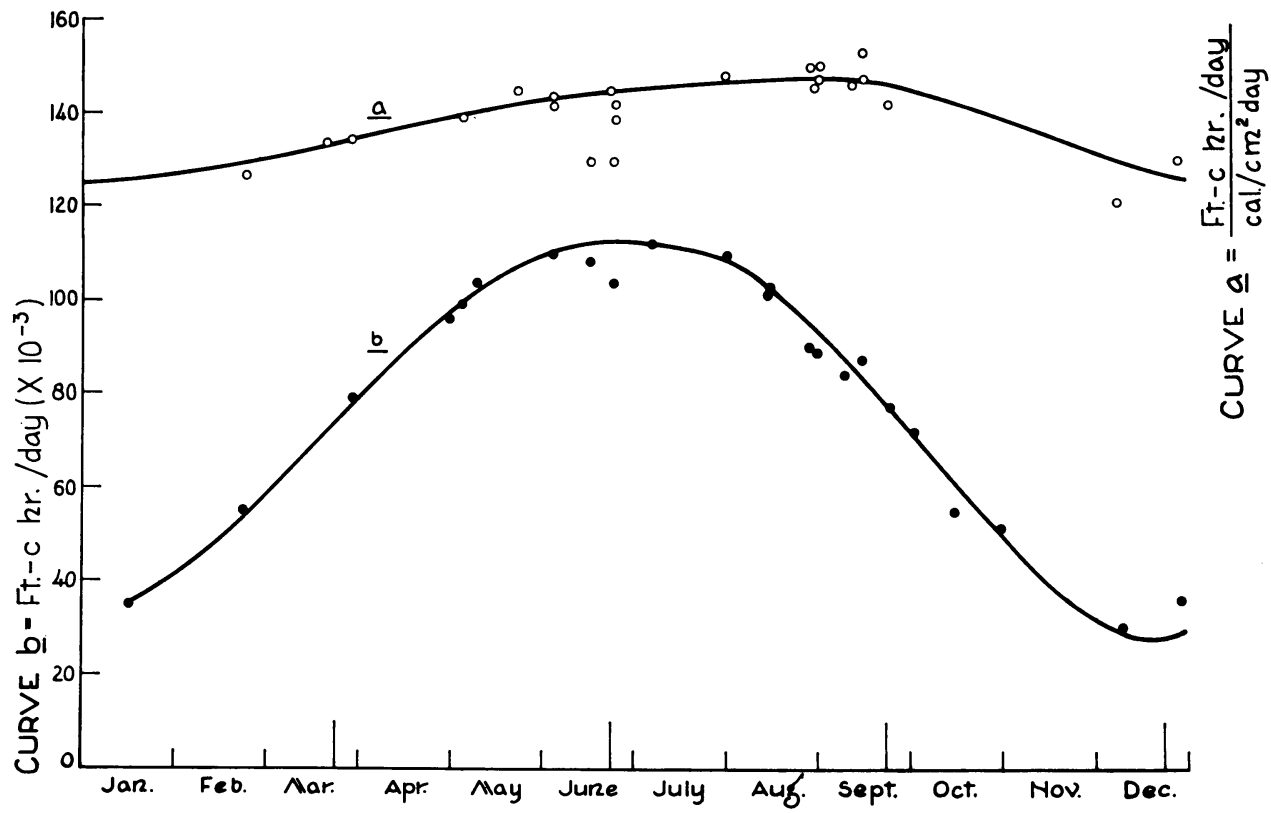

Fig. 12A. Observed factors for conversion of total light energy per day to total radiant energy per day on clear days at Davis, California $(a)$. Seasonal change of total light energy received on clear days at Davis $(b)$. 
TABLE 10A

TRANSMISSION OF LIGHT AND TOTAL RADIATION FROM INCANDESCENT AND SOLAR SOURCES BY VARIOUS TYPES OF MATERIAL

\begin{tabular}{|c|c|c|c|c|}
\hline \multirow{2}{*}{ Material* } & \multicolumn{2}{|c|}{ Incandescent lamp $\dagger$} & \multicolumn{2}{|c|}{ Sun $\dagger$} \\
\hline & $\underset{\text { light }}{\text { Amount of }}$ & $\begin{array}{l}\text { Total } \\
\text { radiation }\end{array}$ & $\underset{\text { light }}{\text { Amount of }}$ & $\begin{array}{l}\text { Total } \\
\text { radiation }\end{array}$ \\
\hline & per cent & per cent & per cent & per cent \\
\hline \multicolumn{5}{|l|}{ Glass: } \\
\hline Polished plate $\left(1 / 4^{\prime \prime}\right)$. & 89.6 & 77.1 & 89.0 & 84.2 \\
\hline Window glass $\left(1 / 8^{\prime \prime}\right) \ldots \ldots \ldots$ & 90.7 & 82.2 & 91.2 & 87.3 \\
\hline Rough plate $\left(21 / 64^{\prime \prime}\right) \ldots \ldots \ldots \ldots \ldots$ & 86.8 & 71.0 & 89.3 & 65.8 \\
\hline Rough plate, heat absorbing $\left(21 / 64^{\prime \prime}\right) \ldots$ & 70.0 & 35.5 & 75.0 & 41.7 \\
\hline Polished plate, heat absorbing $\left(7 / 32^{\prime \prime}\right) \ldots \ldots \ldots \ldots \ldots \ldots \ldots \ldots \ldots \ldots \ldots \ldots \ldots \ldots$ & 74.0 & 37.9 & 75.0 & 51.6 \\
\hline 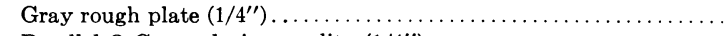 & 43.0 & 49.5 & 41.5 & 52.0 \\
\hline Parallel-O-Gray, glazing quality $\left(1 / 4^{\prime \prime}\right) \ldots \ldots \ldots \ldots \ldots \ldots \ldots \ldots$ & 45.6 & 51.0 & 41.5 & 52.0 \\
\hline 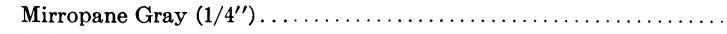 & 5.7 & 15.5 & $\ldots$ & $\ldots$ \\
\hline 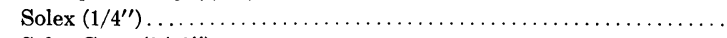 & 73.0 & 33.7 & 75.7 & 47.8 \\
\hline Solar Gray $\left(3 / 16^{\prime \prime}\right) \ldots \ldots \ldots \ldots \ldots \ldots \ldots$ & 62.0 & 83.5 & 62.5 & 75.6 \\
\hline Luxlite $\left(1 / 8^{\prime \prime}\right) \ldots \ldots \ldots \ldots \ldots \ldots \ldots$ & 93.0 & 88.0 & 91.5 & 89.0 \\
\hline Luxlite Coolite $\left(11 / 64^{\prime \prime}\right) \ldots \ldots \ldots \ldots \ldots$ & 55.0 & 23.4 & 62.3 & 37.4 \\
\hline Coolite Luxlite $\left(11 / 64^{\prime \prime}\right)$, glare reducing . . . . . . . . . & 37.4 & 19.0 & 40.2 & 12.3 \\
\hline 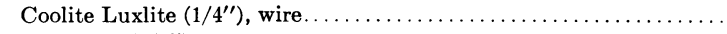 & 41.0 & 11.6 & 46.8 & 26.5 \\
\hline 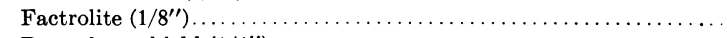 & 93.5 & 89.5 & 91.7 & 75.5 \\
\hline 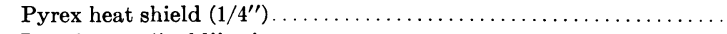 & 80.7 & 54.9 & 79.6 & 70.4 \\
\hline Interference "cold" mirror..$\ldots \ldots \ldots \ldots \ldots \ldots \ldots \ldots \ldots \ldots \ldots \ldots \ldots \ldots \ldots$ & 5.4 & 53.0 & 7.1 & 40.0 \\
\hline 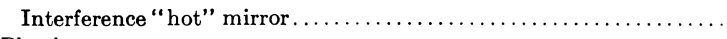 & 87.6 & 56.2 & 86.2 & 65.6 \\
\hline \multicolumn{5}{|l|}{ Plastics: } \\
\hline \multicolumn{5}{|l|}{ Plexiglas (clear) $\ddagger$} \\
\hline $\mathrm{G}\left(1 / 8^{\prime \prime}\right) \ldots \ldots$ & 95.0 & 76.5 & 94.0 & 85.1 \\
\hline $\mathrm{G}\left(1 / 4^{\prime \prime}\right) \ldots \ldots \ldots \ldots$ & 95.0 & 71.1 & 94.5 & 84.2 \\
\hline \multirow[t]{2}{*}{ P-4 $\left(1 / 4^{\prime \prime}\right) \uparrow$ smooth } & 87.1 & 61.9 & 87.5 & 82.0 \\
\hline & 91.8 & 65.2 & 92.5 & 88.6 \\
\hline \multirow[t]{4}{*}{ P-7 $\left(1 / 4^{\prime \prime}\right) \uparrow$ grooves $\|$ to light source } & 76.5 & 53.5 & & \\
\hline & 85.5 & 57.5 & 87.0 & 74.0 \\
\hline & 83.0 & 55.9 & & \\
\hline & 90.5 & 64.2 & 94.0 & 89.5 \\
\hline Controlens No. 6250 grooves smooth side $\uparrow \ldots \ldots \ldots \ldots \ldots \ldots \ldots$ & 82.7 & 56.0 & 83.5 & 80.6 \\
\hline grooves smooth side $\downarrow \ldots \ldots \ldots \ldots \ldots \ldots \ldots$ & 89.4 & 61.5 & 87.5 & 82.0 \\
\hline Controlens No. 6014 grooves smooth side $\uparrow \ldots \ldots$ & 77.5 & 52.8 & 81.5 & 79.5 \\
\hline grooves smooth side $\downarrow \ldots \ldots$ & 82.0 & 57.3 & 87.3 & 85.5 \\
\hline 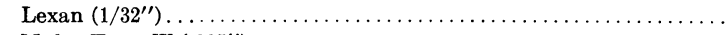 & 90.2 & 64.6 & 88.0 & 90.0 \\
\hline 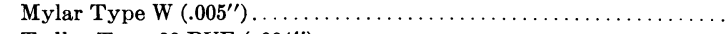 & 88.0 & 85.7 & 81.5 & 91.4 \\
\hline 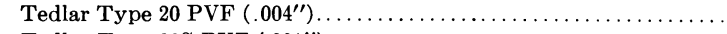 & 93.5 & 92.3 & 94.0 & 91.5 \\
\hline 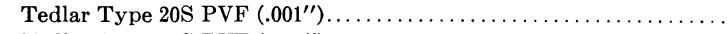 & 94.0 & 93.0 & 94.5 & 94.5 \\
\hline 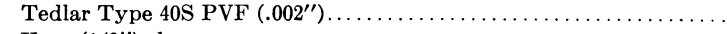 & 90.4 & 89.0 & 89.7 & 91.6 \\
\hline 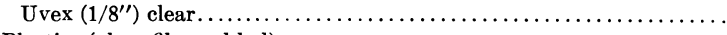 & 88.8 & 74.7 & 86.5 & 84.5 \\
\hline \multicolumn{5}{|l|}{ Plastics (glass fiber added): } \\
\hline Structoglas A 711 clear $\left(5 / 64^{\prime \prime}\right) \ldots \ldots \ldots$ & 85.5 & 68.2 & 84.3 & 69.3 \\
\hline 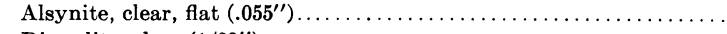 & 80.6 & 64.5 & 73.8 & 75.9 \\
\hline 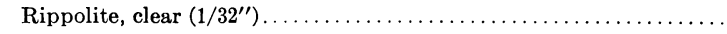 & 80.5 & 74.0 & 81.5 & 78.8 \\
\hline \multicolumn{5}{|l|}{ Liquid filters: } \\
\hline Ethyl alcohol, 1 inch in box with glass bottom $\ldots \ldots \ldots \ldots \ldots \ldots$ & 90.0 & 33.0 & $\cdots$ & $\cdots$ \\
\hline \multicolumn{5}{|l|}{ Water: } \\
\hline 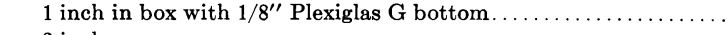 & 95.5 & 29.6 & 91.5 & 67.0 \\
\hline 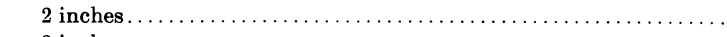 & 98.0 & 24.2 & 91.2 & 64.3 \\
\hline 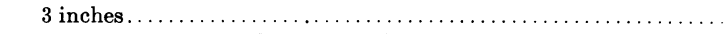 & 98.5 & 21.1 & 90.4 & 60.8 \\
\hline 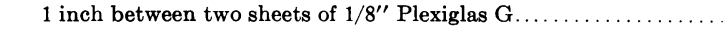 & 97.5 & 29.6 & 95.6 & 69.0 \\
\hline
\end{tabular}

* Materials are manufactured by various companies, as follows: Polished and rough plate (plain and heat-absorbing), Parallel-O-Gray, and Mirropane Gray-Libby-Owens-Ford, Toledo, Ohio; Solex and Solex Gray-Pittsburgh Plate Glass Co., Pittsburgh, Pa.; Luxlite, Luxlite Coolite, Coolite Luxlite (both types), and Factrolite-Mississippi Glass Co. St. Louis, Mo.; Pyrex Heat Shield-Corning Glass Works, Corning, N. Y.; interference "cold" and "hot" mirrors-Optical Coating Laboratory, Inc., Santa Rosa, Calif.; Plexiglas, G 1/8", G1/4", P-4, and P-7-Rohm and Haas Co., Philadelphia, Pa.; Controlens (all types)-Holophane Co., Inc., New York; Lexan-General Electric Co., Pittsfield, Mass.; Mylar, Tedlar (all types)-E. I. du Pont de Nemours \& Co., Inc., Wilmington, Del.; Uvex-Eastman Kodak Co., Rochester, N. Y.; Structoglas-Structoglas, Inc., Cleveland, Ohio; Alsynite-Alsynite Co. of America, San Diego, Calif.; Rippolite-Rippolite Plastics Products, Inc., Burbank, Calif.

$\dagger$ Samples were held above receiver, which was $2 \mathrm{ft}$. from a 500-watt Quartzline lamp with aluminum reflector, in the case of the foot-candle meter, and 14 inches where the Eppley pyrheliometer was used.

$\ddagger$ P-4 (1/4") and P-7 (1/4") vary in thickness from 13/64" at bottom of pyramids on prismatic ridges to $15 / 64^{\prime \prime}$ at top. Controlens No. 6014 varies in thickness from $8 / 64^{\prime \prime}$ at bottom of conical prisms to $15 / 64^{\prime \prime}$ at top; No. 6250 varies from $8 / 64^{\prime \prime}$ at bottom to $12 / 64^{\prime \prime}$ at top. 
To simplify the information, it is sometimes necessary to use trade names of products or equipment. No endorsement of named products is intended nor is criticism implied of similar products not mentioned. 
Positive film strips, for use in a microfilm reader, are on deposit in the Agricultural Reference Service, University of California Library, Berkeley, the University of California Library, Davis, and in the Library of the U. S. Department of Agriculture, in Washington, D.C. These are identified in the card catalog as follows:

Zscheile, F. P., S. M. Henderson, A. S. Leonard, L. W. Neu-

bauer, S. J. Sluka, A sunlight phytotron unit as a practical research tool, microfilm supplement.

Copies of the entire microfilm supplement may be purchased from Library Photographic Service, University of California, Berkeley. The price for the entire strip is $\$ 3.00$ plus postage. Please do not remit in advance. You will be billed. Specify Misc. Microfilm No. 58.

The microfilm contains the following material:

Single-panel studies

Construction details of walls and roof

Admission of sunlight to large stationary room

Effects of room size on light distribution

Table showing wall and roof contributions to sunlight distribution in large room

Use of a reflector

Table of relative solar intensities in reflector cubicle

Table of calculated maximum sunlight intensities with outside reflector

Heliostat rotating mirror system

Admission of sunlight to small rotating room

Table of observed light intensities in small rotating room with $45^{\circ}$ roof

Table showing light intensities in rotating room
Comparisions of light intensities at various levels in small rolating room

Table showing distribution of observed light intensities in small stationary room with inclined roof of glass blocks

Design for porcelain-on-steel reflectors for Quartzline lamps

Table of air-duct temperatures as affected by outside vents

Table of radiant energy relationships for filtered incandescent and solar sources

Table showing reflection of light and infrared by various materials

Plant-growth studies

Detailed plans of control circuits for fan, cooling and heating, lights, rotating room, vent motor, and dark curtain 
The journal HILGARDIA is published at irregular intervals, in volumes of about 650 to 700 pages. The number of issues per volume varies.

Single copies of any issue may be obtained free, as long as the supply lasts; please request by volume and issue number from:

\author{
Agricultural Publications \\ University Hall \\ University of California \\ Berkeley, California 94720
}

The limit to nonresidents of California is 10 separate titles. The limit to California residents is 20 separate titles.

The journal will be sent regularly to libraries, schools, or institutions in one of the following ways:

1. In exchange for similar published material on research.

2. As a gift to qualified repository libraries only.

3. On a subscription basis_ $\$ 7.50$ a year paid in advance. All subscriptions will be started with the first number issued during a calendar year. Subscribers starting during any given year will be sent back numbers to the first of that year and will he billed for the ensuing year the following January. Make checks or money orders payable to The Regents of The University of California; send payment with order to Agricultural Publications at above arldress. 